Florida International University FIU Digital Commons

\title{
A Developmental Intervention Science Outreach Research Approach to Promoting Positive Youth Development
}

Roberto L. Rinaldi

Florida International University, rinaldi.robertol@gmail.com

DOI: $10.25148 /$ etd.FI1 1041503

Follow this and additional works at: https://digitalcommons.fiu.edu/etd

Part of the Developmental Psychology Commons

\section{Recommended Citation}

Rinaldi, Roberto L., "A Developmental Intervention Science Outreach Research Approach to Promoting Positive Youth Development" (2011). FIU Electronic Theses and Dissertations. 342.

https://digitalcommons.fiu.edu/etd/342 


\section{FLORIDA INTERNATIONAL UNIVERSITY}

Miami, Florida

\section{A DEVELOPMENTAL INTERVENTION SCIENCE OUTREACH RESEARCH APPROACH TO PROMOTING POSITIVE YOUTH DEVELOPMENT}

A dissertation submitted in partial fulfillment of the requirements for the degree of DOCTOR OF PHILOSOPHY

in

PSYCHOLOGY

by

Roberto L. Rinaldi

2011 


\section{To: Dean Kenneth Furton}

College of Arts and Sciences

This dissertation, written by Roberto L. Rinaldi, and entitled A Developmental Intervention Science Outreach Research Approach to Promoting Positive Youth Development, having been approved in respect to style and intellectual content, is referred to you for judgment.

We have read this dissertation and recommend that it be approved.

$\begin{array}{r}\text { Mary Levitt } \\ \hline \text { Robert Lickliter } \\ \hline \text { Thomas Reio } \\ \hline \text { William Kurtines, Major Professor }\end{array}$

Date of Defense: March 21, 2011

The dissertation of Roberto L. Rinaldi is approved.

\begin{tabular}{r}
$\begin{array}{r}\text { Dean Kenneth Furton } \\
\text { College of Arts and Sciences }\end{array}$ \\
\hline Interim Dean Kevin O'Shea \\
University Graduate School
\end{tabular}

Florida International University, 2011 


\section{DEDICATION}

I dedicate this to my two sons, who are an inspiration of life. This is to show them that if you put your mind to it, anything in this world can be accomplished. 


\section{ACKNOWLEDGMENTS}

I owe many thanks to many people who have helped me throughout this process. I would like to thank the entire YDP lab for their assistance, guidance, and motivation in completing this project, especially to Dr. Kurtines for seeing something in me that I never knew I had. And finally to my wife, Gina, I thank you for being there for me when I needed support, for always letting me know that I could do it, and for standing by me through thick and thin. 
ABSTRACT OF THE DISSERTATION

A DEVELOPMENTAL INTERVENTION SCIENCE OUTREACH RESEARCH APPROACH TO PROMOTING POSITIVE YOUTH DEVELOPMENT

\author{
by \\ Roberto L. Rinaldi \\ Florida International University, 2011 \\ Miami, Florida

\section{Professor William Kurtines, Major Professor}

Recent intervention efforts in promoting positive identity in troubled adolescents have begun to draw on the potential for an integration of the self-construction and selfdiscovery perspectives in conceptualizing identity processes, as well as the integration of quantitative and qualitative data analytic strategies. This study reports an investigation of the Changing Lives Program (CLP), using an Outcome Mediation (OM) evaluation model, an integrated model for evaluating targets of intervention, while theoretically including a Self-Transformative Model of Identity Development (STM), a proposed integration of self-discovery and self-construction identity processes. This study also used a Relational Data Analysis (RDA) integration of quantitative and qualitative analysis strategies and a structural equation modeling approach (SEM), to construct and evaluate the hypothesized OM/STM model. The CLP is a community supported positive youth development intervention, targeting multi-problem youth in alternative high schools in the Miami Dade County Public Schools (M-DCPS).

The 259 participants for this study were drawn from the CLP's archival data file. The model evaluated in this study utilized three indices of core identity processes (1) 
personal expressiveness, (2) identity conflict resolution, and (3) informational identity style that were conceptualized as mediators of the effects of participation in the CLP on change in two qualitative outcome indices of participants' sense of self and identity.

Findings indicated the model fit the data $\chi^{2}(10)=3.638, p=.96$; $\operatorname{RMSEA}=.00$; $\mathrm{CFI}=1.00 ; \mathrm{WRMR}=.299)$. The pattern of findings supported the utilization of the STM in conceptualizing identity processes and provided support for the OM design. The findings also suggested the need for methods capable of detecting and rendering unique sample specific free response data to increase the likelihood of identifying emergent core developmental research concepts and constructs in studies of intervention/developmental change over time in ways not possible using fixed response methods alone. 


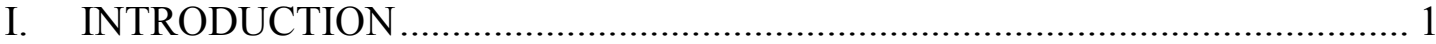

Positive Youth Development ........................................................................... 1

Applied Developmental Science …………………………………………..... 2

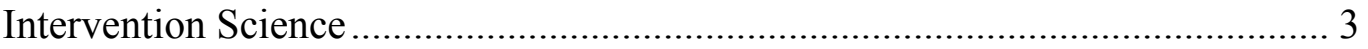

Developmental Intervention Science.................................................................. 4

Developmental Intervention Science: Outreach Research ..................................... 4

Promoting Positive Development: The Changing Lives Program ......................... 7

A Psychosocial Developmental Life Course Approach ......................................... 8

A Self-Transformative Model of Identity Development ........................................ 8

A Participatory Transformative Approach to Promoting Idenity Development ... 9

The Changing Lives Program: Outreach Research ............................................... 11

Evaluating the Changing Lives Program: An Outcome Mediation Model......... 12

Evaluating the Changing Lives Program:Relational Data Analysis ................... 14

Conceptual Analyses ……………………………………........................... 17

Theoretical Analyses ………………………………….......................... 18

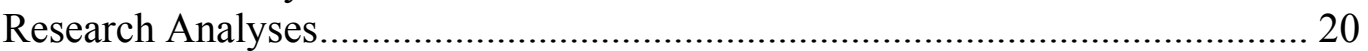

The Need for Relational Methods in Outreach Developmental Intervention

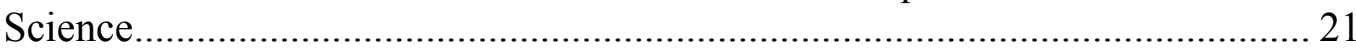

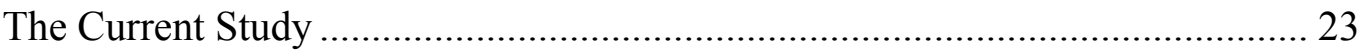

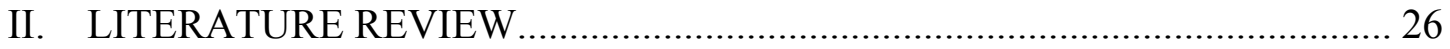

PYD Interventions: Targeting Identity ........................................................... 26

Self-Construction and Self-Discovery in Adolescence ........................................ 27

Self-Construction: The Identity Style Model .................................................... 30

Self-Discovery: Feelings of Personal Expressiveness......................................... 32

Developmental Challenge: Resolving Psychosocial Conflict.............................. 34

Relational Data Analysis of Life Goals............................................................ 36

Conceptual and Theoretical Analyses: Identification of Properties ....................... 37

Hierarchical Structural Organization of Properties: Flat and Nested

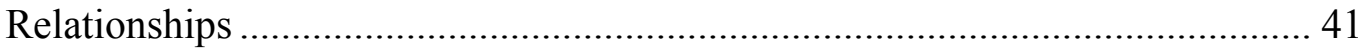

Relational Data Analysis of Future Possible Selves ........................................... 45

Reversible and Cyclical Movement through RDA............................................... 46

Hierarchical Structural Organization of Properties: Flat and Nested

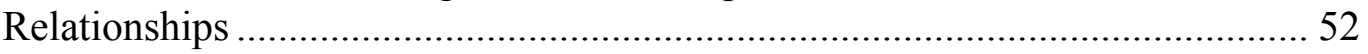

Personal Expressiveness and Self Development …………………………….... 54

Future Possible Selves Content Categories: Feelings of Personal

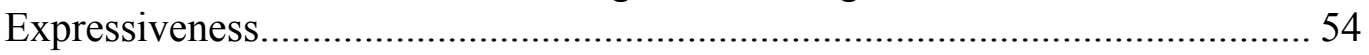

Research Analyses of Pathways of Intervention Change .................................... 56

Hypothesized Pathways of Intervention Change .............................................. 58

The Conceptual Evaluation Model................................................................... 59

Specificity of Effects: Intervention Effects on Identity Processes ........................ 59

Direct Effects: Qualitative Intervention Outcomes ............................................... 60 
Mediator Effects: Psychosocial Developmental Mediators of Intervention

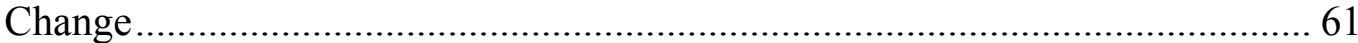

Mediation of Outcomes: Treatment Specificity ............................................. 61

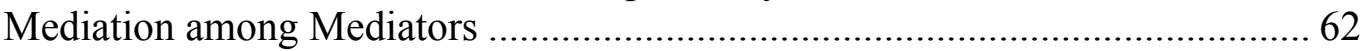

Change Relations Among Positive Outcomes................................................. 63

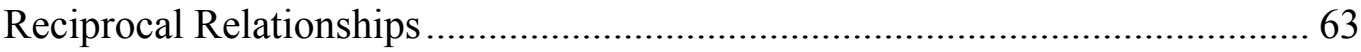

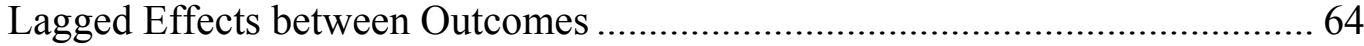

Moderator Effects: Boundaries of Treatment.................................................. 64

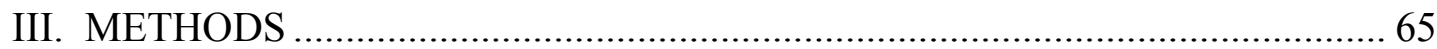

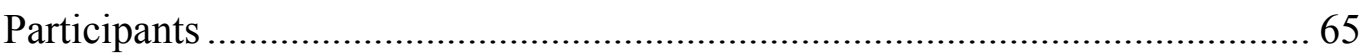

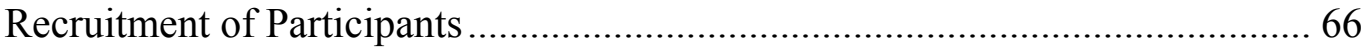

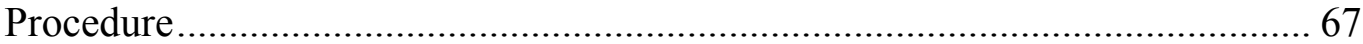

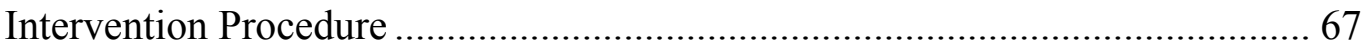

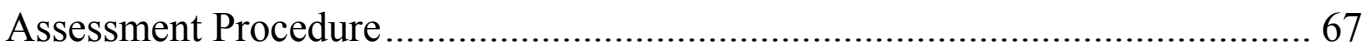

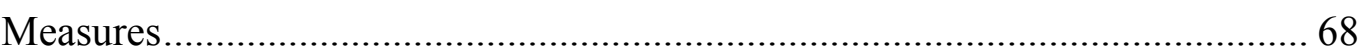

Psychosocial Mediator: Identity Conflict Resolution ..................................... 68

Self Discovery: Feelings of Personal Expressiveness........................................6 68

Self Construction: Identity Styles ................................................................... 69

Positive Outcome: Personally Expressive Life Goals ..................................... 70

Positive Outcome: Future Possible Self ......................................................... 72

Moderators of Outcome (Gender and Ethnicity)......................................... 73

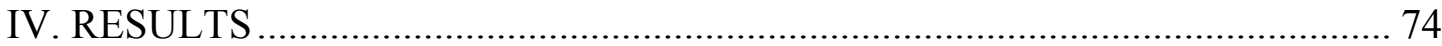

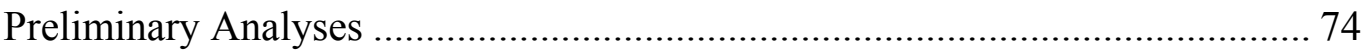

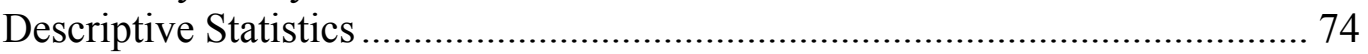

Outliers, Missing Data, and Non-Normality ................................................ 78

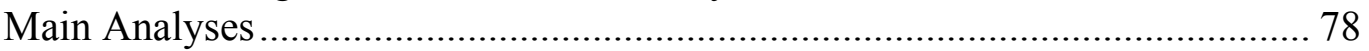

Hypothesized Direct and Moderated Intervention Effects ............................. 81

Hypothesized Moderated Mediation of Positive Outcomes............................... 83

Hypothesized Mediation Among Mediators ..................................................... 86

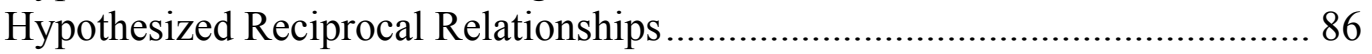

Hypothesized Lag Effects ............................................................................ 87

Qualitative Change in Life Goal and Future Possible Self: Fine-grained

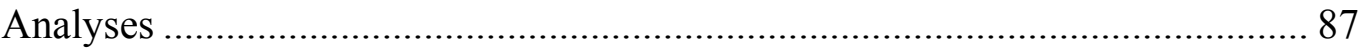

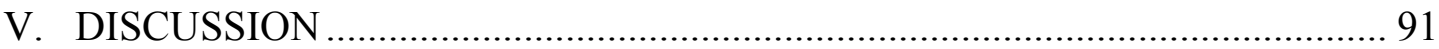

Research Aim 1: Promoting Emotion-Focused and Cognitively-Focused Identity

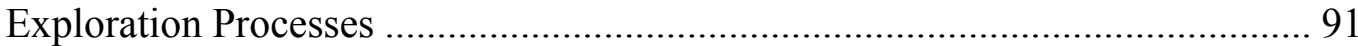

Research Aim 2: Mediation of Positive Outcomes ............................................ 95

Research Aim 3: The Utility of RDA............................................................... 96

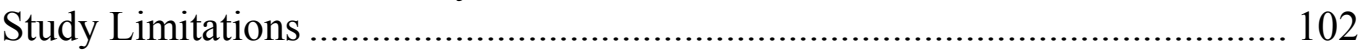

Future Research Directions ........................................................................ 103

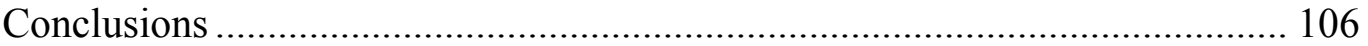




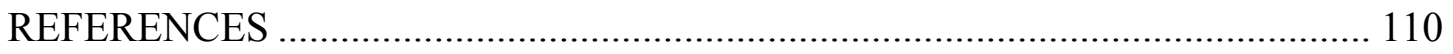

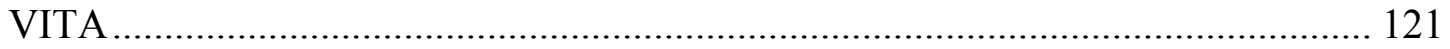




\section{LIST OF TABLES}

TABLE

PAGE

1. Descriptive Statistics for Continuous Evaluation Variables .....................................74

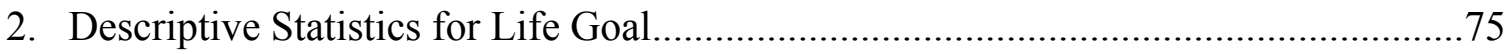

3. Descriptive Statistics for Future Possible Self.................................................. 76

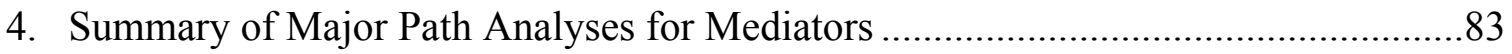

5. Summary of Major Path Analyses Positive Outcomes ….......................................85

6. Frequencies of Change in Self Satisfying Life Goals .........................................8

7. Frequencies of Change in Self Satisfying Future Possible Selves.............................90 


\section{LIST OF FIGURES}

FIGURE

PAGE

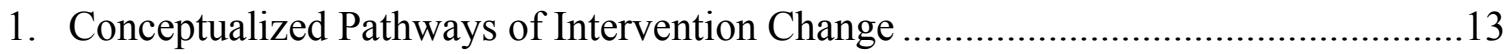

2. Hierarchical Structural Organization of Life Goals ................................................43

3. Hierarchical Structural Organization of Future Possible Selves................................52

4. Conceptualized Pathways of Intervention Change .................................................57

5. Hypothesized Outcome Mediation Evaluation Model............................................58

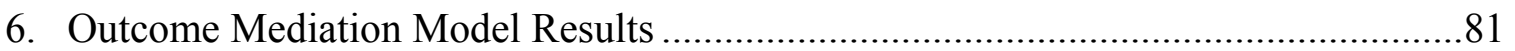




\section{INTRODUCTION}

\section{Positive Youth Development}

Consistent with the view that youth from even the most disadvantaged backgrounds and the most troubled histories are potential resources to be developed rather than "problems to be managed" (Arnett, 2000; Damon, 2004; Roth, Brooks-Gunn, Murray, \& Foster, 1998), a positive youth development (PYD) approach to the development, implementation, and evaluation of interventions arose from the need for intervention strategies that complement and extend treatment (Benson, Scales, Hamilton, \& Sesma, 2006; Csikszentmihalyi, 1998; Damon, 2004; Damon, Menon, \& Bronk, 2003; Kurtines, Ferrer-Wreder, Berman, Cass Lorente, Briones, et al., 2008; Lerner, Fisher, \& Weinberg, 2000). Drawing on Applied Developmental Science (ADS), PYD emphasizes the development of strengths and potentials in order to foster long-term positive development (Schwartz, 2002; Schwartz, Kurtines, \& Montgomery, 2005; Seligman, Steen, Park, \& Peterson, 2005). The PYD approach thus represents a shift away from the view of adolescence as a period of "storm and stress" and while recognizing the developmental challenges faced by adolescents, it sees youths as children "eager to explore the world, gain competence, and acquire the capacity to contribute importantly to the world" (Damon, 2004).

There is mounting awareness of the importance, and growing interest in creating positive development programs designed to encourage and empower young people, particularly troubled youth (Brandtstadter \& Lerner, 1999; Catalano, Berglund, Ryan, Lonczak, \& Hawkins, 1999; Larson, 2000; Peterson \& Reid, 2003; Pittman, 2000). Adolescence is a time of transition and profound change (LeCroy, 2004). Adolescence 
has become the life transition during which the individual chooses and makes a commitment to the values, goals, and beliefs that guide the process of intra-individual and inter-individual functioning (Erikson, 1963). It is the developmental period in which the formation of a sense of identity (i.e., "who one is" and "what one means to others") takes on considerable developmental salience (Erikson, 1959; 1968).

\section{Applied Developmental Science}

Applied Developmental Science (ADS) is scholarship that seeks to advance the integration of developmental research with actions, policies and programs that promote positive development and/or enhance the life chances of vulnerable children and families (Lerner et al., 2000). From this perspective, the term Applied Developmental Science (ADS) is used to refer to scientific investigation that focuses on the use of research and application to promote positive development across the lifespan (Damon, 2004; Lerner et al., 2000). Applied developmental scientists adopt the view that positive individual development and family functioning is an interactive product of biology and the physical and social environments that continuously evolve and change over time (Kurtines, FerrerWreder, Berman, Lorente, Silverman, \& Montgomery, 2008). The ADS perspective stresses the importance of understanding normative and atypical processes as they emerge within different developmental periods that occur across the lifespan and across diverse physical and cultural settings. The ADS orientation is committed to the use of descriptive and explanatory knowledge about changes within human systems that not only addresses a full spectrum of applied concerns (ranging from specific intervention strategies to broadband social policy), but is also influenced by the outcome of these community activities (Lerner et al., 2000). ADS thus helps shift the model of 
amelioration, prevention, or optimization research from one demonstrating efficacy to one promoting outreach (Lerner et al., 2000).

\section{Intervention Science}

During the same period of change in developmental science, the conceptual foundations of intervention science were also undergoing transformation (Kurtines et al., 2008). With respect to intervention science, these changes included the emergence of prevention science as a logical extension of treatment science and its emphasis on positive adjustment and optimal functioning (Eichas, Albrecht, Garcia, Ritchie, Varela, et al., 2010). As noted by Eichas et al. (2010), within prevention science literature, efforts have been made to broaden the criteria by which prevention intervention outcomes are evaluated (beyond reducing risk factors). These efforts have resulted in the inclusion of more general indices of positive adjustment and optimal functioning to include emerging views of psychological health and resilience (including a sense of one's meaning and purpose) as components of well being (e.g., Masten \& Coatsworth, 1998). However, the interventions developed under the prevention science model continue to maintain a core focus on "preventing" negative developmental outcomes rather than promoting positive ones (Catalano et al., 1999). The beginning of a convergence of concepts and constructs broadly related to promoting positive development in both developmental and intervention science has resulted in a recognition that intervention science needs to do more than "treat" problem behaviors or "prevent" negative developmental outcomes (Damon, 2004; Lerner, 2005; Lerner et al., 2000). 


\section{Developmental Intervention Science}

As noted above, the beginning convergence of concepts and constructs broadly related to promoting positive development in both developmental and intervention science has resulted in a recognition (1) that intervention science needs to do more than “treat" problem behaviors or "prevent" negative developmental outcomes (Damon, 2004; Lerner, 2005; Lerner et al., 2000), and (2) that developmental science needs to do more than generate complex "descriptive" models of developmental systems (Kurtines et al., 2008). In this context, there has been a growing interest in bringing together evolving developmental science models, what Overton (1998) refers to as models of what changes and how it changes (Lerner, 2005), and evolving intervention science models of what to change and how to change it (Holmbeck, 2002; Weisz \& Hawley, 2002).

Drawing on the conceptual base provided by ADS and informed by social policy research (Lerner et al., 2000), a Developmental Intervention Science (DIS) perspective is thus specifically committed to the use of both descriptive and explanatory knowledge about changes within human systems that occur across the lifespan in the development, implementation, and evaluation of evidence-based multidisciplinary lifespan intervention strategies (Kurtines et al., 2008). To date, however, there has been a lack of examples of this type of research in the intervention literature in general and on positive youth development interventions in particular (Kurtines et al., 2008).

Developmental Intervention Science: Outreach Research

In an effort to translate descriptive models into programs that can be implemented in "usual care" practice in community settings, the Miami Youth Development Project's (YDP) Changing Lives Program (CLP), a PYD intervention program, has adopted an 
outreach research model. The PYD perspective has arisen because of interest among developmental scientists in using developmental systems, or dynamic, models of human behavior and development for understanding the plasticity of human development and, as well, the importance of relations between individuals and their real-world ecological settings as the basis of variation in the course of human development (Lerner, 2005).

In the area of intervention science, for example, Jensen et al. (1999) described two distinctly different models of intervention research, one that has been prominent and highly funded, and a second model that has become of growing interest in the recent literature. The first and most traditional model is "efficacy research" or university lab/clinic based research. Efficacy research is defined by its use of well-controlled university clinic or lab based settings for conducting intervention research. The efficacy model has been historically well funded and has resulted in positive support for a wide range of treatment and prevention interventions (Kurtines et al., 2008). The emphasis on well controlled "efficacy research" has resulted in a gap between university based research and its research in "real world" settings (Kurtines et al., 2008). The use of rigorous experimental controls for unwanted sources of variations in research designs proved difficult to transport into usual care practice. The result has been that the utility and validity of the resulting interventions and their "effectiveness" when applied to "real world" settings is unclear, hence, the gap between the lab-based efficacy of interventions and their effectiveness in the "real world".

A second and less prominent type of intervention research described by Jensen et al. (1999) is referred to as "outreach research". In contrast to "efficacy research," outreach research takes a different perspective and starting point with respect to the 
evaluation of intervention research. Outreach research emerges out of and remains rooted in the "real world" setting. . In outreach research, when intervention strategies and intervention research are employed in the settings for which they are designed, the effectiveness of the intervention is already built in (Kurtines et al., 2008). Therefore, there is no real need to "transport" an intervention from a lab-based setting to a "real world" setting and there are no issues of implementation, because the research or practice of the intervention has never been in a lab or clinic to begin with. Another advantage of outreach research is its ability to address the difficulty associated with data collection and cost of running an externally funded research project. The need for outreach research to create community commitment and support generates enduring access to resources that provide the foundation for the type of short-term efficacy and long-term effectiveness research designs needed to evaluate both internal and external validity (Kurtines et al., 2008).

Efforts have been made to integrate the two models of intervention research described by Jensen et al., 1999; Kurtines et al., 2008). "Outreach research" and "efficacy research" can be viewed as complementary approaches to intervention research, but their use as separate or "mixed" approaches should be contingent upon factors relevant to the issue in question. Specifically, the type of intervention proposed, type of outcome expected, population being used, area of implementation, etc. The idea is to advance the utilization of the "outreach research" and "efficacy research" approaches for addressing both "narrow-band/short-term problems" and "broadband/long-term problems." As Kurtines et al. (2008) noted, a researcher may choose to initially develop and refine an intervention approach under controlled conditions in a university lab or clinic setting and 
then extend that approach to usual care practices in the community to address a "narrowband/short-term" problem. On the other hand, in addressing a "broad-band/long-term" problem, the researcher may choose to develop, refine, and implement an intervention in a "real world" setting, then establish its basic utility and validity under these conditions and conduct long-term evaluations of the program itself.

It has been proposed (Lerner et al., 2000) that through the conduct of research consistent with the "outreach" frame described by Jensen, Hoagwood, \& Trickett (1999) the blurring of the distinctions between science and practice in developmental science will be facilitated. Moreover, such scholarship will provide needed vitality for future progress in the field of human development and, according to Lerner et al. (2000), for the very viability of the academy.

Promoting Positive Development: The Changing Lives Program

The Changing Lives Program (CLP) is an ongoing community supported gender and ethnic inclusive PYD intervention targeting multi-problem youth. The CLP is an important outcome of efforts to create positive youth development interventions that draw on the strengths of developmental intervention science outreach research in the development of community-based positive development programs. It is an approach that focuses on meeting community needs by generating innovative knowledge of evidencebased change intervention strategies that are feasible, affordable, and sustainable in "real world" settings (Kurtines et al., 2008). The CLP has been implemented as a selected/indicated group counseling intervention in a practice setting, the alternative high schools of the Miami-Dade County Public Schools (M-DCPS), for nearly two decades. M-DCPS is the fourth largest school system in the United States. Students come to 
alternative schools on a negative life course pathway and at risk for multiple negative developmental outcomes and/or engaged in multiple problem behaviors.

A Psychosocial Developmental Life Course Approach

For its work with troubled adolescents, the CLP draws its developmental framework from Erikson's (1968) psychosocial developmental theory and Elder's (1998) life course theory. Erikson (1968) conceptualized identity as an internal and selfconstructed dynamic organization of drives, abilities, beliefs, and individual history, while Elder (1998) described the life course as the pathway of the individual's life as it moves through the sequence of socially defined, age-graded events and roles over time. Life course theory holds that life transitions are comprised of social and psychological qualitative state changes that are elements of a larger life course pathway. The CLP's psychosocial developmental life course framework integrates Erikson's psychosocial view of identity formation with Elder's description of the life course to depict identity as the "steering mechanism" that guides the individual's life course, and adolescence as a transitional period of increased likelihood of a radical break or departure from a previous life course pathway, referred to as a life course turning point (Montgomery, Hernandez, \& Ferrer-Wreder, 2008). That is, the self-constructed dynamic organization of drives, abilities, beliefs, and individual history that a person begins to form during adolescence is thought to guide the life course within the constraints of history and social circumstances. A Self-Transformative Model of Identity Development

The CLP intervention and evaluation efforts with adolescents adopt the SelfTransformative Model of Identity Development (STM; Albrecht, 2007). For this model, the adolescent's sense of self is hypothesized to be the direct result of both affective 
exploration for insight (self-discovery) and cognitive exploration of alternatives (selfconstruction), as well as contextual factors such as age, gender, ethnicity, etc. that may moderate identity processes (Eichas, 2008). Consistent with the CLP's psychosocial developmental life course framework, this model proposes that historical, social, and/or personal contextual opportunities and constraints have a direct association with the adolescent's sense of self (Eichas, 2008). The relationship between contextual opportunities and constraints and the adolescent's sense of self is hypothesized to be partially or fully mediated by self-construction and/or self-discovery identity processes. Both self-construction and self-discovery are considered to have positive effects on the development of the "steering mechanism" guiding the life course, while contextual factors may have variable associations (Eichas, 2008). Participation in weekly counseling sessions conducted according to the CLP's intervention framework is conceptualized as a particularly important personal contextual opportunity for positive identity development (Eichas, 2008).

A Participatory Transformative Approach to Promoting Identity Development

The CLP uses a participatory and transformative approach to create contexts in which troubled (multi-problem) young people can change their lives for the better by taking responsibility for their lives and their communities (Kurtines et al., 2008). The CLP intervention efforts take a person-centered participatory transformative approach, informed by Freire's (1970/1983) transformative pedagogy and recent work on multicultural counseling theory (Sue \& Sue, 2003), in employing both emotion-focused and cognitively-focused intervention strategies in a manner consistent with Albrecht's (2007), Self-Transformative Model of Identity Development, described above (Eichas, 
2008). Freire (1970/1983), developed and practiced his transformational pedagogy with impoverished Brazilian peasants, and the CLP extends this approach to culturally diverse multi-problem youths whose lives often take place outside mainstream social institutions. As described by Montgomery et al. (2008), the primary intervention goal is to empower troubled adolescents to change their lives in positive directions. Rather than directing the activities of the group, counselors seek to empower students by facilitating the development of a group context in which adolescents have the opportunity to transform their sense of control and responsibility by taking an active role in the counseling process (Eichas, 2010). Special attention is paid to opportunities for the group to collaborate on cognitively-focused identification of problems and solutions (Montgomery et al., 2008) and on the emotion-focused development of awareness of personal strengths, potentials, and qualities (Albrecht, 2007).

The CLP uses youth-directed transformative activities as its key behavioral intervention strategy for facilitating empowerment (Kurtines et al., 2008). The positive developmental intervention strategy implemented in the CLP, specifically draws on the behavioral concept of mastery experiences. The CLP intervention uses youth selected change producing activities generated by the adolescent in response to youth selected life course change goals as its key behavioral intervention strategy for facilitating adolescent empowerment as means for promoting a positive identity (see Kurtines, Montgomery, et al., 2008). Successful engagement in self-selected and self-directed goal oriented activities have been hypothesized to empower youth by strengthening intrinsic motivation to achieve life goals, control and responsibility with respect to life activities, and selfefficacy (Bandura, 1997; Seligman \& Csikszentmihalyi, 2000). 
Through attempts that adolescents make to solve problems and change their lives for the better, called mastery experiences, they become the "experts" and in the process become empowered (Eichas, 2010). Mastery experiences generated by cognitivelyfocused and emotion-focused transformative activities are thought to have the potential to transform the way youth understand and/or feel about their current life course (Eichas, 2010).

The Changing Lives Program: Outreach Research

The CLP's basic implementation strategy is "bottom-up versus top-down." Consistent with the collaborative model, the implementation of CLP is integrated into the ongoing flow of each school's regular activities (e.g., as part of the school's ongoing counseling program, outreach social services, etc.). In the alternative high schools, students participate in program services either through self or counselor referral. The types of counseling services include psychoeducational services, individual counseling, and counseling groups (the groups include abuse, anger management, alternative lifestyles, relationships, self-esteem, substance use/abuse, teen parenting, troubled families, etc.). In implementing the CLP, the most immediate and direct goal is to address the presenting problems that youth bring into counseling (i.e., relationship issues, life choices, anger management, substance use, etc.) (Kurtines et al., 2008). The immediate focus is thus on addressing identified presenting problems, while the long-term focus is on promoting positive development. The CLP thus adopts a "bottom-up" implementation strategy that focuses on targeting developmental gains that assist youth in proactively guiding the systems/contexts that have an impact on their lives (Kurtines \& Silverman, 1999). In many cases, this "bottom-up" approach provides a useful complement to "top- 
down" prevention models designed to intervene at a contextual/ecosystemic level (e.g., with parents, peers, school, etc.).

Evaluating the Changing Lives Program: An Outcome Mediation Model

Silverman, Kurtines, Jaccard, \& Pina (2009), have highlighted the need within the treatment literature of moving beyond the standard comparative randomized clinical trial outcome studies (Eichas, 2010). A core constraint of such evaluation models is that they are limited to addressing questions of what works and for whom does it work differently and unable to address the issue of how interventions work (outcome and mediation) (Eichas, 2010). As Silverman et al. (2009) noted, during the early stages of developing and evaluating interventions, the focus is necessarily on evaluating whether interventions work (or do not work). As evidence accumulates that interventions work, however, the issue of how they work moves to the foreground because of its implications for enhancing and maximizing intervention efficiency, efficacy, and effectiveness (Eichas, 2010).

Drawing on the recommendations of Silverman et al. (2009), Eichas et al. (2010), reported an investigation of the CLP using an integrative quantitative evaluation model that utilized a Structural Equation Modeling (SEM) framework approach for measurable quantitative constructs hypothesized to make up core component processes of self and identity (e.g., exploration, commitment) and measurable qualitative narratives of participant's sense of self and identity. That is, the study utilized an evaluation model integrating treatment, prevention, and developmental perspectives in studying the mechanisms that underlie both intervention change and developmental change in the core components of self and identity. Using a model that drew on treatment outcome 
mediation models and prevention longitudinal mediation models, the study's findings highlighted the need for developmental intervention scientists to draw on the work of treatment and prevention science in developing evidence based theory-driven PYD intervention strategies for facilitating advances in both efficacy and effectiveness of developmental intervention PYD programs (Eichas, 2010).

Figure 1 depicts the conceptualized pathways of intervention change, across two follow up points, modeled by Eichas et al., (2010). The model includes (1) direct effects on outcomes in both the positive and problem domains, (2) indirect effects on both domains mediated by identity processes, and (3) indirect effects on outcomes in the problem domain mediated by change in the positive domain, that is, cascading positive change that spills over across positive and problem domains (Eichas et al., 2010).

Figure 1: Conceptualized Pathways of Intervention Change

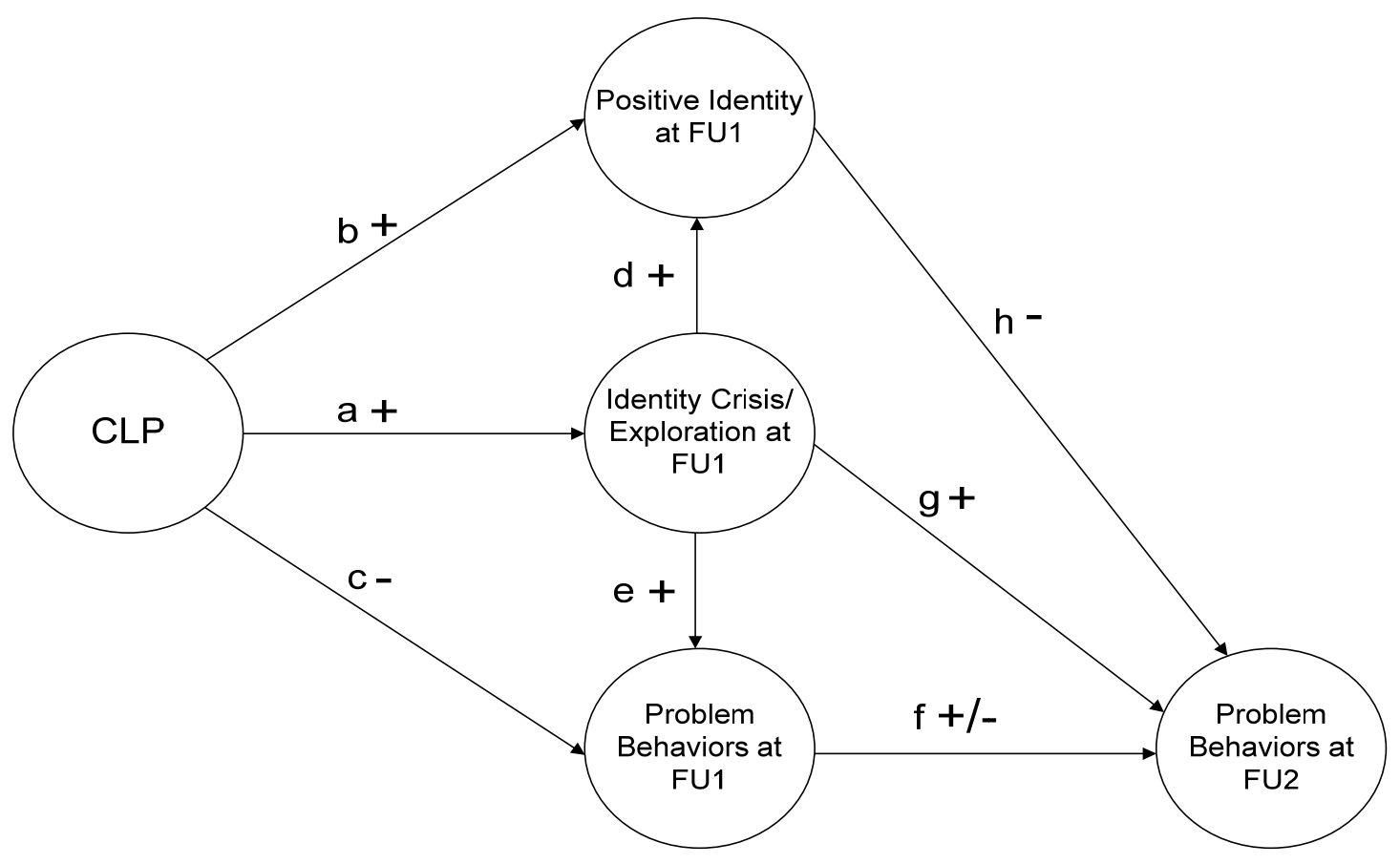


Evaluating the Changing Lives Program: Relational Data Analysis

In addition to an integrative outcome mediation model, the CLP uses a Relational Data Analysis framework (RDA; Kurtines, Montgomery, Arango, et al., 2008). RDA is a framework for evaluating research hypotheses regarding change in the content, structure, and organization of self and identity and its meaning and significance. Relational Data Analysis is a multidimensional, multiphasic framework for unifying data analytic strategies across dimensions (quantitative/qualitative, causal/structural, observation/interpretation, etc.) and phases of analyses (conceptual, theoretical, and research analyses). Relational Data Analysis was developed within a relational meta-theoretical methodological framework (Overton, 1998; 2006) for overcoming the splits that have historically characterized methodological meta-theory. The aim was to formulate a practical; ready-at-hand framework that the developmental scientist could use to unify the analysis of developmental change in real life "applied" settings as well as clinic and laboratory settings (Kurtines et al., 2008).

As mentioned above, an "efficacy research" model has been traditionally employed to evaluate intervention programs. The growing efficacy outcome research literature that utilizes quantitative measures and variable-oriented data analytic strategies has provided evidence for a relation between participation in youth development interventions and positive change (Catalano et al., 1999; Lerner, 2005). Although accumulating efficacy research in support of such interventions has advanced the field, a primarily reliance on the use of efficacy outcome research places limits on the types of questions that can be asked and the types of answers that can be obtained (Eichas, 2010). In this context, a call has been made to move in new research directions that expand our 
capacity to generate useful knowledge (Jensen et al., 1999; Kurtines et al., 2008; Lerner et al., 2000).

The response to move in new research directions has involved exploring new directions in developmental theory, resulting in the evolution of the developmental and intervention theories that are implemented in the CLP (i.e., theories of what changes and how it changes and what to change and how to change it) (Kurtines et al., 2008). It was also in this arena that the CLP found it most useful to draw on (and extend) emerging relational methodological meta-theory (Overton, 1998; 2006). Moreover, because of the nature of the CLP's population and their problems, the CLP sought to articulate a practical, ready-at-hand framework that the developmental scientist could use to address complex issues of documenting life course change (Kurtines et al., 2008).

Consistent with the intervention aims of the CLP, the research aims of adopting an RDA framework include (1) identifying patterns of differential positive qualitative (structural organizational) change in the subjective meaning and significance of participant life course experiences in general, and of their experiences of self and identity in particular, and (2) identifying the positive and problematic quantitative (dimensional) changes that predict, underlie, or accompany structural organizational change (Eichas, 2010). Within RDA, quantitative (causal) variational change and qualitative (structural organizational) transformational change are viewed as two sides of a unified explanation, a conceptualization that more closely approximates the "relational" meta-theoretical ideal of overcoming the splits that have historically characterized methodological meta-theory (Overton, 1998; Kurtines et al., 2008). 
Within the RDA framework, objective reports of observable responses, rather than being considered the definitive foundational data, are viewed as "raw" behavioral observations to be extended, refined, enriched, and verified by data collected. The objective reports of observable responses are collected with measures and methods designed to capture and facilitate the interpretation of the human meaning and significance of the linguistic and culture-laden intentions of the person or persons engaged in the behavior being observed. Open-ended measures elicit narrative/linguistic expressions of the meaning and significance of life course experiences (including experiences of self and identity) (Eichas, 2010). Although the subjective meaning and significance of these experiences is not directly observable and thus not directly available for analysis, narrative/linguistic expressions of subjective meaning and significance, including the meaning and significance of experiences of self and identity, are available for inter-subjective examination and analysis (Montgomery et al., 2008).

In $\mathrm{RDA}$, the collection of open response data and the intentional manipulation of the level of theoretical saturation of the coders (theory-neutral versus theory-laden) across phases of analysis are specifically designed to facilitate the detection of sample specific unique content properties in cross sectional research or newly emergent properties in longitudinal research (Eichas, et al., 2010). Grounded theory data analytic strategies (Strauss \& Corbin, 1998) are used to code the open-ended narrative response data during each of RDA's three analytic phases: Conceptual, Theoretical, and Research Analyses. As reported in Kurtines et al., (2008), the use of an experimental manipulation of three sets of coders (theory neutral, theory laden, theory neutral), each using a distinctly different variant of the method of constant comparison, provides multiple 
independent perspectives on the participants' response data and has proved particularly useful when fused with a systematic application of the grounded theory method of constant comparison. From an RDA perspective, the movement through the Conceptual, Theoretical, and Research Analyses is cyclical and, in the process of completing each cycle, open to diverse types of modification (i.e., conceptual, theoretical, or empirical). On the basis of empirical findings (or lack of findings), any (or all) of these modifications are capable of transforming the movement of the next new cycle into a directional spiral. Conceptual Analyses

During the Conceptual Analysis phase of RDA a set of theoretically neutral conceptual coders (coders systematically selected to represent no particular theoretical perspective) are assembled to use the grounded theory concept of "open" coding and the method of constant comparison. The method of constant comparison (Strauss \& Corbin, 1998), is the process of comparing content properties of participant response data for similarities and differences. Drawing on an ordinary language perspective (Wittgenstein, 1953), the process is operationalized as the comparison of the properties of participant response data for the purpose of creating and eliminating "ordinary language" content groups of responses, with each group of responses defined by a single unique ordinary language content property. The ordinary language content properties identified in the raw response data are used to identify all qualitatively different (non-overlapping) groups of responses in the data set, and to formulate and document an explicit description of the unique content property that the response data of each content group share in common (similarity) and that they do not share with any other content response groups (difference) (Kurtines et al., 2008). In essence, the theory neutral coders identify all of the unique 
content properties in a particular data set and in doing so break the data down into the largest possible set of basic elements, with each element representing the most basic conceptually meaningful units of content from an ordinary language perspective (Eichas, 2010).

Theoretical Analyses

During the Theoretical Analysis phase of RDA, a set of theoretically committed coders (coders systematically selected to be representative of a particular theoretical perspective) are assembled to work collaboratively on four tasks, each of which generates a particular type of outcome. Specifically, during this phase, the theoretical coders are asked to use the method of constant comparison to review and discuss the content categories identified in the previous conceptual phase, from the perspective of the guiding theory.

Theoretical Analysis Task 1: Identifying Theoretical Categories

During Task 1, the theoretically committed coder's task is to identify the root category and the smallest number of theoretically meaningful associated subcategories, using a defined theoretical perspective, from the initial pool of conceptual categories identified in the raw data during the conceptual analysis. The theoretically committed coder's also generate a set of property descriptions of the unique properties that define each subcategory. As part of generating this outcome, theoretical coders are asked to formulate and document an explicit description of the unique property that the response data of each theoretical subcategory share in common (similarity) and that they do not share in common with any other subcategories (difference) (see Lewis-Arango, Kurtines, Montgomery, \& Ritchie, 2008, Kurtines et al., 2008). 
Theoretical Analysis Task 2: Identifying Relations

During Task 2, the theoretically committed coder's task is to identify a theoretically hypothesized structural organization between the identified theoretical subcategories (flat, nested, hierarchical, etc.), from whicha Structural Tree Chart (STC) is constructed. An STC is a means for visually representing the structural organization among the root category, subcategories, and properties identified (see Kurtines et al., 2008).

Theoretical Analysis Task 3: Identifying Mechanisms of Change

During Task 3 , the theoretically committed coder's task is to identify and specify hypothesized plausible mechanisms that provide a theoretically meaningful (and plausible) explanation of change over time (causal/functional, structural/transformational, etc.) in the theoretical subcategories. This third outcome is only generated when the theoretical analysis involves a temporal analysis of change (e.g., a developmental analysis, an historical analysis, etc.) (see Kurtines et al., 2008)

Theoretical Analysis Task 4: Constructing a Decision Tree Chart (DTC)

During Task 4 , the unique properties that define each subcategory are now translated into decision rule formats and formulated rules are utilized to construct a Decision Tree Chart/Decision Tree Matrix (DTC/DTM). For this task, the theoretical coders construct a DCT (and associated DTM) to be used for classification coding of uncoded free response data into the subcategories that emerged out of the open coding process during the theoretical analysis phase. 


\section{Research Analyses}

In the Research Analysis phase, the hypothesized developmental hierarchical structural organization model (STC) serves as an analytic framework for conceptually linking the analysis of quantitative (variational/dimensional) and qualitative (structural organizational) progressive short term intervention change (Eichas, 2010). Quantitative progressive developmental change is represented by the identification of differential intervention effects hypothesized to result in the theoretically meaningful adaptive variational change in the dimensional property or properties of one or more of element(s) in the developmental system, but that do not result in hierarchical structural organizational change in any of the developmental system's subsystems (Eichas, 2010). Similarly, Eichas, (2010) noted that the identification of differential intervention effects that result in theoretically meaningful adaptive structural or organizational change in the "hierarchical" developmental system that does result in structural organizational change in the subsystems represents qualitative progressive developmental change.

In essence, the RDA structural organizational framework models both quantitative and qualitative progressive developmental change; done by (1) modeling the effects of intervention change on quantitative progressive developmental change in the dimensional properties of elements in the developmental system and the effects of intervention change on qualitative progressive developmental change in structural organizational properties of elements within subsystems and, (2) in the structural organization of the subsystems within the developmental system (Eichas, 2010). As noted by Eichas, (2010), within this framework, structural organizational change occurs within the three levels of the developmental system. At the first most basic level, the primary marker of qualitative 
change is the emergence or disappearance of a property or properties of one or more of element(s) and/or the relocation of a property or properties within the hierarchical system. At the second level, the primary marker of qualitative change is the emergence or disappearance of a subsystem or subsystems and/or a reorganization of the structure within the ordered hierarchy of the subsystems either vertically through hierarchical levels of the developmental system or horizontally across subsystems. Finally, at the developmental system level, that of the adolescent or emerging adult, the structural transformation is marked by the emergence of an evolving sense of identity (i.e., an extension of the self into the future, the emergence of a sense of direction, meaning, and purpose, and the construction of life goals) that transforms a childhood sense of self into a mature and more fully intentional sense of self.

The Need for Relational Methods in Outreach Developmental Intervention Science The use of complementary qualitative free-response measures and quantitative fixed response measures in DIS outreach research effectively expands the scope of intervention outcome investigation beyond the examination of properties identified as theoretically meaningful prior to conducting the research, i.e., as is usually done under cross-sectional and longitudinal quantitative research and "efficacy" research designs using fixed response measures (Eichas, 2010). Although there are many advantages to the use of such methods of data collection, an important limitation of their use is that fixed response measures rule out in advance, the possibility of detecting response properties that are uniquely meaningful (ordinary language meaning, theoretical meaning, or both) within a specific population not previously studied or newly emergent properties in a previously studied population (Eichas, 2010). RDA, in contrast, provides a method for 
detecting, isolating, identifying, and rendering explicit and intelligible previously undetected or newly emergent "real world" properties in ways that are not possible using traditional cross-sectional and longitudinal research designs using fixed response quantitative measures.

The RDA process of detecting, isolating, identifying, and rendering explicit newly emergent properties across the conceptual and theoretical phases is relatively straightforward. In the conceptual analysis phase of RDA, the use of theory neutral coders ensures that any longitudinally newly emergent content properties are identified utilizing their ordinary language meaning (Kurtines et al., 2008). Specifically, the lack of a formal theoretical orientation among the theory-neutral ordinary language coders (who are also blind to time and condition), the exploratory (rather than confirmatory) nature of their task, and the use of a longitudinal design to evaluate the effects of an intervention process explicitly designed to generate longitudinally newly emergent content properties, facilitates the process of detecting, isolating, identifying, and rendering explicit response content properties, as least in terms of ordinary language meaning sense (Eichas, 2010). Moreover, RDA's explicit requirement for consensual agreement among the independent coders greatly limits the incorporation of the coder's own personal meaning as well as ensuring that particular content properties that lack consensual ordinary language meaning are not included in the analysis (Eichas, 2010).

In the theoretical analysis phase of RDA, the use of a panel of theoretically committed coders (who are also blind to time and condition), the confirmatory and convergent (rather than exploratory) nature of their task, and the use of a longitudinal design, make the detection of longitudinally newly emergent content properties, that are 
theoretically meaningful from a specific theoretical framework, also relatively straightforward and uncomplicated (Eichas, 2010). The use of theory-laden coders in the theoretical analysis phase is useful not just in describing the previously identified content categories theoretically identifiable but, in the process, also in generating a theoretically meaningful developmental hierarchical structural organizational model of the properties of the narrative expressions of the meaning and significance of participants' life course experiences.

\section{The Current Study}

Consistent with recommendations for the development and evaluation of interventions by Rounsaville, Carroll, \& Onken (2001), the on-going evaluation of intervention outcomes within the CLP has taken place as part of Stage II of the CLP MLC program evaluation (Montgomery et al., 2008). Stage II evaluation consists of the extension and refinement of previous Stage I pilot/feasibility testing, manual/protocol writing, infrastructure development, and measure development. CLP Stage II evaluation focuses primarily on psychometric evaluation of measures and short-term controlled outcome studies in the preliminary evaluation of the CLP intervention that precede Stage III evaluations of long-term program effectiveness and possible transportability through long-term controlled effectiveness outcome studies over the life span of the participants and the program.

The short-term outcome study reported here was conducted as part of the Stage II evaluation of the CLP participatory transformative intervention approach in promoting positive change in sense of self and identity among troubled adolescent youth. Recent intervention efforts in promoting positive identity development in troubled adolescents 
have begun to draw upon the potential for an integration of the self-construction and selfdiscovery perspectives in conceptualizing basic positive identity processes and identifying practical targets for intervention utilizing traditional empirical methods of analysis as well as the integration of quantitative and qualitative data analytic strategies. Previous studies have evaluated the effect of the CLP intervention on change in identity processes (e.g., Albrecht, 2007; Eichas et al., 2010) or change in subjective sense of self and identity through the examination of narrative expressions of meaning and significance (e.g., Lewis-Arango et al., 2008; Kortsch, Kurtines, \& Montgomery, 2008), and intervention change in identity processes as mediators of intervention change in sense of self and identity (Eichas et al., 2010). However, no studies, to date, have incorporated both quantitative measures of identity processes and multiple qualitative assessments of subjective sense of self and identity. The current study sought to contribute to the evaluation of Albrecht's (2007) STM, a proposed integration of emotion-focused and cognitively-focused identity exploration processes and Eichas et al., (2010) outcome mediation model $(\mathrm{OM})$ and, toward that end, had three main research aims. The first aim of this study was to further investigate the CLP intervention effectiveness in promoting positive change in cognitive identity exploration, identity commitment, and emotion focused identity evaluation. The second aim was to investigate examined intervention change in identity processes as mediators of intervention change in subjective sense of self and identity. The third aim was to further evaluate the utility of the RDA framework for investigating differential intervention change in sense of self and identity through examination of narrative expressions of subjective meaning and significance of participants' sense of self and identity as an outreach research methodology. 
At a methodological level, this study extends previous use of an RDA/SEM framework in the contextual and complementary use of qualitative and quantitative methods for evaluating causal processes underlying intervention change in sense of self and identity. At the theoretical level, this study furthered the evaluation of the STM/OM model by identifying which core identity processes (i.e., cognitive identity exploration, identity conflict resolution, and emotion focused identity evaluation) serve as mediators of effects of participation in the CLP on change in sense of self and identity.

The next section reviews the literature on cognitive identity exploration (selfconstruction) and emotion focused identity evaluation (self-discovery); summarizes previous RDA conceptual and theoretical analyses of narrative/linguistic expressions of the subjective meaning and significance of CLP participants' most important life goals, and participants' most important future possible self, both a future-oriented sense of self and identity; and describes the specific model evaluated in this study. 


\section{LITERATURE REVIEW}

PYD Interventions: Targeting Identity

Initial evidence of the effectiveness of PYD programs in promoting positive change in concepts and constructs related to positive identity has led to an interest in developing, implementing, and evaluating interventions that specifically target core components of identity formation in adolescents as a strategy for promoting positive outcomes (Eichas et al., 2010). The potential utility of interventions that target identity formation has also been discussed extensively within the identity literature (Archer, 1994; Erikson \& Erikson, 1957; Hernandez, Montgomery, \& Kurtines, 2006; Kurtines et al., 2008; Montgomery et al., 2008).

As Ferrer-Wreder, Montgomery, \& Lorente (2003) point out, the literature on identity formation has a potential contribution to make to efforts to promote positive development, in part because it offers guidance for the effort to identify and investigate the component processes of identity formation. Montgomery et al. (2008) suggest that the inclusion of variables tapping key identity processes and outcomes such as identity cohesion, style, distress, and turning points in intervention research would make treatment and prevention interventions for youth more effective and potent, in part because this type of research would add to knowledge about for whom interventions work and why they work. Within the identity literature, two core identity processes have been discussed extensively: identity exploration and identity commitment (Marcia, 1966, $1980,1988)$. 
Elaborating upon Erikson's writing, Marcia (1966) described behavioral markers of the processes by which an adolescent consolidates a coherent sense of identity. Adolescents face the challenge of first exploring multiple possible identity alternatives in order to make decisions about life choices and then choosing one or more of the multiple possible identity alternatives and following through with them (Grotevant, 1987; Marcia, 1980, 1988; Schwartz, 2001). According to this formulation, identity exploration is the search for a revised and updated sense of self, and identity commitment is the adherence to a particular course of action characterized by a self-selected specific set of goals, values, and beliefs (Marcia, 1988; Schwartz, 2001).

Marcia (1966) further derived four identity statuses based of the juxtaposition of in the level of exploration and commitment. The first, Identity Achieved, is associated with someone who has committed to a set of goals, beliefs, and ideas after a period of intense identity exploration. An individual who has yet to make any commitments to a sense of self, but is still exploring through alternatives is said to be in Moratorium. An individual who has committed to a sense of self but without engaging in exploration of identity alternatives is in the Foreclosure status. Finally, the Identity Diffused status is associated with individuals who not only have not made any identity commitments, but also are not engaged in any form of exploration.

Self-Construction and Self-Discovery in Adolescence

Building upon empirical evidence for the convergence of self-construction and self-discovery (Schwartz, Mullis, Dunham, \& Waterman, 2000), identity exploration has been shown to consist of both affective exploration for insight and cognitive exploration 
of alternatives (Schwartz, 2002; Schwartz et al., 2005; Soenens, Berzonsky, Vansteenkiste, Beyers, \& Goosens, 2005).

Empirical attention toward investigating and promoting identity exploration and development has most often focused on cognitive processes and skills development in areas such as problem-solving and cognitive decision-making (Enright, Ganiere, Buss, Lapsley, \& Olson, 1983; Ferrer-Wreder, Cass-Lorente, Kurtines, Briones, Bussel, \& Berman, 2002; Markstrom-Adams, Ascione, Braegger, \& Adams,1993; Schwartz, 2002; Schwartz et al., 2005). The self-construction approach postulates that individuals actively construct the self through identity-related choices made rationally from among alternatives offered by the individual's context (Schwartz, 2002). Within intervention change strategies, this approach has focused primarily on training individuals to consider potential choices, weigh potential consequences of those choices, and finally, generate any conceivable alternative courses of action. Thus, from a self-construction perspective, identity exploration involves rational, dispassionate consideration of externally presented alternatives (Berman, Schwartz, Kurtines, \& Berman, 2001; Berzonsky, 1990; Grotevant, 1987; Schwartz et al., 2005). A large and growing literature has emerged linking selfconstruction identity exploration processes (e.g., information processing style and problem-solving approach) to a diversity of identity-related outcomes such as orientation toward education and goal-directedness, as well as one's level of identity commitment (Berzonsky, 1990; Berzonsky \& Kuk, 2000).

More recently, a literature has begun to emerge focusing on an alternative to the self-construction perspective on identity development. Known as a self-discovery perspective, this approach adopts an emotion-focused orientation to identity exploration 
(Schwartz, 2002; Schwartz et al., 2005; Waterman, 1984, 1993, 1995, 2004) and is rooted in eudaimonism, which holds that there is a pre-existing true or optimal self to be discovered, referred to as the daimon, defined by the set of unique potentials, talents, skills, and capabilities that exist within an individual. (Schwartz et al., 2005). Emotionfocused identity exploration is characterized as being "discovery-based," where individuals identify and explore their feelings with respect to specific life activities. Emotion-focused decision-making is therefore largely intuitive, resulting in an affective examination of identity alternatives in terms of how well they resonate with one's "true self" (Schwartz, 2002; Schwartz et al, 2005; Waterman, 1984; 1993; 1995). In this way, identity-relevant information and situations are evaluated by the degree to which they "fit" with the individual, and unlike the dispassionate reasoning, problem solving competence, and alternatives generation of the self-construction approach (Berman et al., 2001; Grotevant, 1987), the self-discovery approach is rooted in Maslow's (1968) theory of self-actualization and in Csikszentmihalyi's (1990a) theory of flow, where particular emphasis is placed on intra-individual subjective experience (Schwartz et al., 2005).

For comparison, Waterman (1984) developed two metaphors, discovery "finding something that was present but previously not known" and creation "bringing into being something that did not previously exist" (Schwartz et. al., 2000). The latter corresponds to the eudemonic approach (Waterman, 1990), the former to the constructivist approach (Berzonsky, 1990). As pointed out by Schwartz (2002), the fundamental distinction between the self-construction and self-discovery perspectives is one of process versus content. Schwartz (2002) conceptualized the self-construction perspective as pertaining to the process that an individual uses to form a coherent identity, whereas the content of the 
identity that is formed is associated with the self-discovery perspective. Thus, according to this model, self-construction processing is thought to precede self-discovery processing such that choices made rationally from among alternatives offered by the individual's context provide opportunities for the discovery of the unique potentials, talents, skills, and capabilities that already exist in the individual.

\section{Self-Construction: The Identity Style Model}

Within the identity exploration literature, a significant body of work has drawn upon the constructivist tradition, as expressed by Kelly (1955), in asserting that the individual is an intentional agent who participates in the construction of his or her world (Berman et al., 2001). The individual is depicted as a scientist, proactively making identity-related choices by forming and testing hypotheses in a cognitive, rational, and dispassionate manner (Grotevant, 1987; Berzonsky, 1989; Berman et al., 2001). Identity theories in this vein have emphasized abilities and orientations (Grotevant, 1987), cognitive problem-solving competence (Berman et al., 2001), and cognitive processing styles (Berzonsky, 1989). Berzonsky's (1989) constructivist approach to identity formation emphasizes the cognitive processing orientations with which a person forms and maintains an identity rather than the identity status model's focus on the outcome of identity formation (Vleioras \& Bosma, 2005). Drawing on the work of Kelly (1955), Berzonsky (1993) proposed that people are self-theorists who create a conceptual structure in order to make sense of their experience. There are three types of selftheorists, (1) the scientific information-oriented, (2) the dogmatic normative-oriented, and (3) the ad hoc diffuse/avoidant oriented. When applied to the psychosocial task of identity formation, these orientations toward self-construction are termed identity styles. 
The informational style is characterized by seeking out and utilizing of selfrelevant information when making decisions related to identity (Berzonsky \& Sullivan, 1992). It incorporates information seeking and problem-focused coping (Berzonsky \& Sullivan, 1992), active exploration (Schwartz et al., 2000), flexible commitment (Berzonsky \& Neimeyer, 1994), need for cognition (Berzonsky, 1993), and high levels of self-esteem (Nurmi, Berzonsky, Tammi, \& Kinney, 1997).

The normative orientation is characterized by conformation to the expectations of others or of reference groups and thus involves imitation and conformity; it is described as a closed-minded approach (Berzonsky, 1993), adherence to rigid and dogmatic commitments (Berzonsky \& Neimeyer, 1994), stable self-conceptions (Nurmi et al., 1997), and the suppression of exploration (Schwartz et al., 2000). Individuals with a normative style avoid dealing with information that may conflict with self-conceptions by turning to authority figures and significant others to make important life decisions.

Lastly, the diffuse avoidant identity style, often distinguished by avoidance of identity-related choices, is best characterized as a situation-by-situation approach to life and involves an emotion-focused coping strategy (Berzonsky, 1993). Diffuse-avoidant people do engage in some form of exploration, but this exploration is disorganized and haphazard (Berman et al., 2001).

Most individuals have the ability to use all three identity orientations by late adolescence (Berzonsky, 1990). Evidence suggests that while both normative and informational styles are generally more adaptive than the diffuse avoidant style, the informational style is more adaptive than the normative style in situations in which youths must assume personal responsibility for academic priorities and monitor their own 
activities and progress (Berzonsky \& Kuk, 2000). As noted by Schwartz (2009), "the informational identity would most likely be manifested as the moratorium and achieved statuses, the normative identity as the foreclosed status, and the diffuse-avoidant identity as the diffused status". The process perspective, however, is more indicative and reflective of continuing decision-making strategies than the status approach (Berzonsky, 1990).

\section{Self-Discovery: Feelings of Personal Expressiveness}

Within the identity literature, a body of work is emerging in the humanist tradition, resonant with the rapidly growing interest in positive psychology (Seligman \& Csikszentmihalyi, 2000), to emphasize the consideration of personal strengths and creative potentials. The individual is depicted as becoming or growing toward the fulfillment of his or her potential. Theories in this vein have asserted the importance of self-actualization (Maslow, 1968), flow (Csikszentmihalyi, 1990a), and feelings of personal expressiveness (Waterman, 1990). Flow is an affective state characterized by a balance between the challenge at hand and the skills one brings to it (Csikszentmihalyi, 1990a), while self actualization refers to fulfilling one's potentials and living up to one's ideals on a consistent basis (Maslow, 1968). Personal expressiveness emphasizes the subjective experience associated with engaging in identity-related activities (Waterman, 2005) and the self-discovery process (Waterman, 1984).

Personal expressiveness is considered the second of these successively more integrated levels of affective processing, more integrated than the experience of flow and less integrated than self-actualization (Schwartz, 2002, 2006; Schwartz et al, 2005; Waterman, 1990). Feelings of personal expressiveness are defined as the positive, 
subjective state characterized by the deep satisfaction that accompanies engagement in activities or goals that utilize one's unique potentials and that are hypothesized to represent one's basic purpose in living (Waterman, 1993). While performing activities that evoke feelings of personal expressiveness, individuals experience (a) an unusually intense involvement, (b) a special fit or meshing with the activities, (c) a feeling of intensely being alive, (d) a feeling of completeness or fulfillment, (e) an impression that this is what one was meant to do, and (f) a feeling that this is who one really is (Waterman, 2005).

Existing research suggests that feelings of personal expressiveness are associated with many positive life outcomes (Csikszentmihalyi, 1975, 1990b; Waterman, 1993, 2004). Participation in personally expressive activities is related to higher levels of intrinsic motivation to accomplish life tasks (Waterman, 2005), as well as higher scores on measures of perceived competence and self realization values and importance. Evidence suggests a strong association between personal expressiveness and self determination (Waterman, 2005). Recent studies conducted with high school students have also found evidence of the association between personal expressiveness and several indices of positive psychosocial adjustment in adolescence. Feelings of personal expressiveness, in combination with flow and goal-directed behavior, have been found to be significantly associated with higher levels of adolescent-reported psychological wellbeing and lower levels of adolescent reported problem behavior (Palen \& Coatsworth, 2007). While there appears to be gender differences in the types of activities that males and females find personally expressive (socializing, instrumental, and literary activities for females and sports/physical activities for males), reported levels of personal 
expressiveness within those activities have been found to be similar across gender (Sharp, Coatsworth, Darling, Cumsille, \& Ranieri, 2007). Research also suggests that there are more similarities in feelings of personal expressiveness across countries and cultures than differences (Coatsworth, Sharp, Palen, Darling, Cumsille, \& Marta, 2005; Sharp et al., 2007).

\section{Developmental Challenge: Resolving Psychosocial Conflict}

According to a psychosocial perspective, the task of resolving identity conflict is an important developmental challenge for adolescents (Albrecht, 2007). As such, current levels of identity conflict resolution may influence the degree of cognitive exploration of alternatives and affective exploration for insight that an adolescent is willing or able to undertake at any given time. However, the meaning of current resolution of identity conflict may not be clear (Albrecht, 2007). Though the resolution of adolescent identity conflict has been conceptualized as an indicator of positive identity development in the context of positive youth development efforts (Lerner et al., 2005), resolutions of the identity crisis during adolescence may theoretically be positive, as in the achieved identity status (Marcia, 1967), while others may be less successful or even negative.

Erikson (1985) emphasized the role of the social environment and ideological institutions in the emergence of either the ego strength of fidelity, the product of successful identity resolution, or role repudiation (Albrecht, 2007). Contemporary adolescents, especially those living in disempowering low-income, urban community contexts, have become increasingly alienated from and less invested in such institutions (Cote, 1994; Freer-Wreder, Cass-Lorente, Kurtines, Briones, Bussell, \& Berman, 2002) and often experience psychosocial difficulties related to the community, peer groups, 
family, and work (Duchnowski, Kutash, \& Friedman, 2002). For these adolescents, the conflict associated with the identity crisis may be more challenging when also exposed to the dangers associated with these contexts, such as daily violence, crime, and substance abuse (Berman, Kurtines, Silverman, \& Serafini, 1996). Previous research suggests that approximately one third of CLP participants, experience moderate, severe, or very severe upset, distress, and/or worry associated with long-term goals, career choices, friendships, sexual orientation and behavior, religion, values and beliefs, and group loyalties (Hernandez et al., 2006).

Intervention programs that seek to promote positive development with troubled adolescent populations, such as the CLP, may confront the task of facilitating the awareness of identity deficits and identity conflicts in the face of contextual factors that make these challenges more difficult to manage (Albrecht, 2007). Existing research findings regarding indices conceptually linked to identity resolution are mixed (Albrecht, 2007). On the one hand, evidence suggests that psychosocial interventions can be effective in increasing identity exploration (crisis) and decreasing or loosening commitments with adolescents and with CLP participants in particular (Albrecht, 2005, 2007; Ferrer-Wreder et al., 2002) and that increases in self-discovery processing associated with participation in the CLP may be accompanied by an increase in identity distress (Albrecht, 2007). On the other hand, evidence also suggests that increases in perceived positive group support for the CLP counseling group members are associated with increasing resolution of identity conflict (Garcia, 2005). It is thought that increases in self-reported identity distress that co-occur with increased self-discovery processing may indicate engagement in positive identity development through exposure to new and 
stressful but ultimately beneficial identity options (Albrecht, 2007), and further, that the context of a counseling group may offer support during a period of exploration. However, while it may be hypothesized that participation in positive youth development interventions would increase the resolution of identity conflict, the relationship between participation in the CLP intervention and identity conflict may be complex and influenced by contextual factors, and therefore open to examination (Albrecht, 2007).

\section{Relational Data Analysis of Life Goals}

During adolescence, youth are confronted with the difficult challenge and responsibility of choosing the goals, roles, and beliefs about the world that give life direction and purpose as well as coherence and integration (Montgomery et al., 2008). The life goals chosen during the transition to adulthood are an expression of the futureoriented component of the adolescent's sense of self and identity and represent the means by which youth begin to give direction to their lives as active producers of their own development (Brandtstadter \& Lerner, 1999; Eichas, 2010). The narrative/linguistic description of life goals during adolescence thus represent an important marker of the formation of a positive sense of self and identity, the formation of an increasingly integrated and therefore an increasingly complex self-constructed self-structure that is experienced subjectively by the individual (Eichas et al., 2010).

It is important to note that the construction of this self-structure has many measureable dimensions (e.g., identity exploration and commitment, identity style), any of which may potentially be measured and evaluated with quantitative strategies. However, a strictly quantitative approach cannot capture changes in the meaning and significance of critical experiential components of an individual's sense of self and 
identity because these changes are subjective in nature and characterized by an increasing complex (i.e., integrated) structural organization with new emergent properties (Eichas, 2010). As noted, a quantitative approach is not capable of the detection of qualitative change that involves the emergence of new content domains or new structural organizations outside empirically or theoretically pre-selected content domains because fixed response quantitative measures are by design not capable of collecting and capturing data outside of their pre-specified content domains (Eichas, 2010). On the other hand free-response qualitative measures are capable of capturing the emergence of new content domains or new structural organizations (Eichas et al., 2010). Conceptual and Theoretical Analyses: Identification of Properties

This section describes a study (Rinaldi, Eichas, Ritchie, Meca, \& Kurtines, under review) that used Relational Data Analysis (RDA) to construct a sample-specific model of the developmental hierarchical structural organization of subjective meaning and significance of participants' most important life goals elicited using a free response qualitative measure. The current study drew on this structural organization in conceptualizing and evaluating positive developmental change in participants' futureoriented sense of self and identity. Consistent with the RDA framework, the Rinaldi et al. study investigated the subjective experience associated with life goals through the examination of narrative/linguistic expressions of the subjective meaning and significance of the most important life goal identified by the participants. RDA theoryladen coders drew on a psychosocial developmental life course framework (Kurtines et al., 2008) and Waterman's (2005) conceptualization of feelings of personal expressiveness. 
During the conceptual analysis of the participant-generated most important life goals, RDA ordinary language (theory-neutral) coders identified seven unique theory-neutral content categories (i.e., categories with ordinary language meaning): Career, Relationships, SelfImprovement, Personal Satisfaction, Education, and Financial Gain (Rinaldi et al., under review). During the Theoretical Analysis phase, RDA theory-laden coders re-organized the ordinary language categories to construct a theoretical root category and associated subcategories that were meaningful from the perspective of a psychosocial developmental life course framework. Responses were found to fit into two general types: Non-personally Expressive or Personally Expressive. That is, the theory-laden coders identified a subcategory of participants whose narrative expressions included at least one explicit verbal reference to one of the properties reported by Waterman's (1993) characterization of feelings of personal expressiveness and a subcategory of participants whose narrative expressions did not include an explicit verbal reference to any of the properties in the characterization of feelings of personal expressiveness (Eichas et al., 2010).

The theory-laden coders further identified within the Personally Expressive subcategory, two nested subcategories: Personally Expressive through Others and Personally Expressive through Self (Rinaldi et al., under review). For individuals in these subcategories, the most important life goal was found to express personally expressive qualities through engagement with others (Personally Expressive through Others) or through a focus purely on one's self (Personally Expressive through Self).

The theory-laden coders also identified within the Non-personally Expressive subcategory three nested subcategories: Self Satisfying, Prove to Others, and Benefit of Others. For individuals in these subcategories, the most important life goal was found to express qualities that indicated a focus on proving to others that the goal can be 
accomplished (Prove to Others), a focus on self-satisfaction or gain (Self Satisfying), or a focus on helping or assisting others without mention of the self (Benefit of Others) (see Figure 2). In addition, a mixed subcategory was identified; for individuals in this subcategory, the most important life goal was found to express qualities that indicated a focus on more than one property (e.g., mixed Prove to Others and Self Satisfying, mixed Self Satisfying and Benefit of Others). Rinaldi et al., (under review) generated property descriptions for the five main nested subcategories. These are described below:

Prove to Others

The unique property of the Prove to Others Level 2 subcategory was that the description of the life goal's meaning and significance included reference to proving to others that the goal can be accomplished and did not include reference to properties of personal expressiveness. The description of meaning and significance included reference to others but solely in the context of proving that the goal can be done. The respondent's goal did not have to be a personal choice, rather it could have been a response to or reaction to an outside influence (parents, teachers, society, etc.). The meaning and significance may have been either negative or positive. For example, in response to the question of what does your most important life goal mean to you and how is it significant, for the Prove to Others level 2 subcategory a participant responded: "Become an architect. I could spit in my father's face that I made it."

\section{Self Satisfying}

The unique property of the Self Satisfying Level 2 subcategory was that the description of the life goal's meaning and significance included reference to selfsatisfaction or gain and did not include reference to any property of personal 
expressiveness. The description did not include reference to the meaning and significance to others or any focus other than the satisfaction of the self. The meaning and significance may have been either negative or positive. For example, in response to the question of what does your most important life goal mean to you and how is it significant, for the Self Satisfying level 2 subcategory a participant responded: "Travel a lot. Explore the world. Having freedom. Free my mind and be like an eagle."

Benefit of Others

The unique property of the Benefit of Others Level 2 subcategory was that the description of the life goal's meaning and significance included reference to helping or assisting others but did not include reference to any property of personal expressiveness. The description of meaning and significance included reference to others but solely in the context of the benefit provided to them and without mention of the self. The meaning and significance may have been either negative or positive. For example, in response to the question of what does your most important life goal mean to you and how is it significant, for the Benefit of Others level 2 subcategory a participant responded: "I want to put my family first. It means leaving a legacy and provides a future for my children."

Personally Expressive through Others

The unique property of the Personally Expressive through Others Level 2 subcategory was that the description of the life goal's meaning and significance included reference to others that did include explicit reference to any property of personal expressiveness. Any reference to the properties of personal expressiveness was exclusively based on the others-orientation of the life goal and reference to properties of personal expressiveness was not based on any selforientation of the life goal. The meaning and significance was positive. For example, in 
response to the question of what does your most important life goal mean to you and how is it significant, for the Personally Expressive through Others level 1 subcategory a participant responded: "Being a Nurse means a lot to me because I always have liked helping others. I have always known I would be good at taking care of others."

Personally Expressive through Self

The unique property of the Personally Expressive through Self Level 2 subcategory was that the description of the life goal's meaning and significance included reference to the self that did include explicit reference to any property of personal expressiveness. Any reference to the properties of personal expressiveness was strictly based on the self-orientation of the life goal and reference to properties of personal expressiveness was not based on any others-orientation of the life goal. The meaning and significance was positive. For example, in response to the question of what does your most important life goal mean to you and how is it significant a participant responded: " $I$ was born to play baseball and I feel that if I make it to MLB it would mean my life will be accomplished, it is what I am meant to do."

Hierarchical Structural Organization of Properties: Flat and Nested Relationships

In RDA, theory-laden coders identify a theoretically meaningful hierarchical structural organization of the RDA root category and associated subcategories and generate the type of structural tree chart used to visually represent the organizational structure of the root category and associated subcategories identified in the data set as theoretically meaningful (Eichas et al., 2010). In doing so, coders use standard naming conventions in generating the structural tree chart. Called a "tree" chart because it resembles an up-side-down tree (with the roots on top and the leaves on the bottom), 
every finite tree structure has an element on top called the "root" or root node (Kurtines et al., 2008). The lines connecting elements are called "branches;" the elements (categories/subcategories) themselves are called "nodes." Nodes on top are called parent nodes and the ones below are called child nodes. Nodes without children are called "endnodes" or "leaves."

Identifying theoretically meaningful hierarchal structural organizations for subcategories draws on dynamic developmental systems theory (Lerner, 2002) in general and on the application of constructs derived from hierarchy theory (Pumain, 2006) in particular. Pumain (2006) characterized "hierarchical" systems as those that have a number of elements that can be described at least three levels of observation, i.e., the system, subsystems, and elements. The structural organization may be depicted in terms of the number of subsystems that make up the system, the number of elements that make up the subsystems, and the number of properties of each element. The structural organization of the system may also be summarized by statistical distributions within each subsystem or across subsystems. Structural organization may also be characterized in term of their structural arrangement, e.g., flat, nested, balanced, etc. The RDA approach draws on the hierarchy theory (Pumain, 2006), specifically for characterizing the organizational structure of the theoretically meaningful subcategories identified by the theoretical coders as well as the dynamic developmental systems theory (Lerner, 2002), for conceptualizing structural and organizational change over time. This involves extending standard systems theory hierarchal structural organizational models to include a fourth non-hierarchal, non-structural, non-organizational component, viz., a temporal component, change over time (represented by $\mathrm{T}_{1} \rightarrow \mathrm{T}_{2} \ldots$ ). Moreover, the focus of the 
temporal component is on a specific pattern of change and successive change over time that may be characterized as developmental change. Figure 2 presents the hypothesized hierarchical structural organization of participants' life goals and the directional outcome of the interaction of normative and intervention developmental change.

Figure 2: Hierarchical Structural Organization of Life Goals

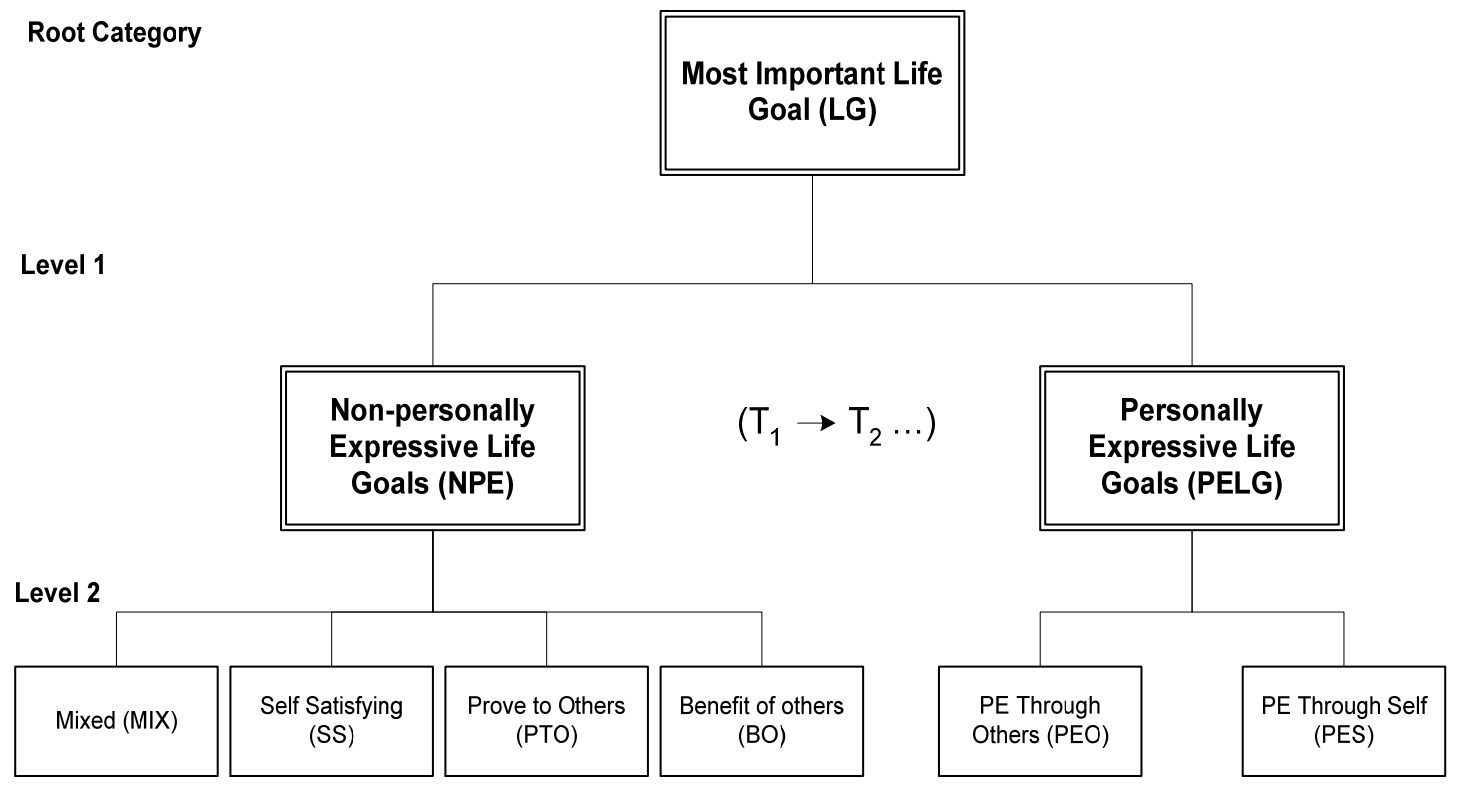

Figure 2 depicts the hierarchical structural organization reported by Rinaldi et al. (under review), with the addition of a hypothesized directional outcome of the interaction of normative and intervention developmental change process under investigation. This STC shows that the "Most Important Life Goal", as the "root" category, has two levels of subcategories. Level 1 (by convention, the root is level 0) has two subcategories, Nonpersonally Expressive and Personally Expressive. Level 2 has six subcategories, Mixed, Self Satisfying, Prove to Others, Benefit of Others, Personally Expressive Through Others, and Personally Expressive Through Self. 
Specifically, theory-laden coders were able to generate a consensually derived theoretically meaningful hypothesized direction of progressive developmental change for Level 1 of the hierarchical structural organization of participants' free response descriptions of their life goals as personally expressive of a true self, i.e., progressive developmental change from Non-personally Expressive $\rightarrow$ Personally Expressive $\left(\mathrm{Tt}_{1} \rightarrow\right.$ $\mathrm{Tt}_{2} \ldots$ ) (Rinaldi et al., under review). The coders drew on current conceptions of adolescent self and identity development in the psychosocial developmental literature (described above) that suggests that individuals who more frequently engage in personally expressive activities exhibit more positive life outcomes than those who engage in activities that provide mostly extrinsic reward or purely hedonic enjoyment (Csikszentmihalyi, 1975, 1990b; Waterman, 1993, 2004). Because adolescence is considered a developmental period characterized by the formation of a more integrated and complex "self-structure," the categorical structures described in Rinaldi et al. (under review), mirror theoretical developmental expectations. Thus, the theoretical coders reached a consensual agreement that the Personally Expressive property was more developmentally advanced than the Non-personally Expressive property and further hypothesized that the effect of the developmental intervention process, represented by $\left(\mathrm{Tt}_{1} \rightarrow \mathrm{Tt}_{2} \ldots\right)$, on the targeted normative positive developmental process would be positive and significant.

Equally significant, the theory-laden coders were unable to generate a consensually derived theoretically meaningful hypothesized direction of progressive developmental change for the properties of the four subcategories nested within the Nonpersonally Expressive subcategory (i.e., Prove to Others, Self Satisfying, Benefit of 
Others, and Mixed) or the two subcategories nested within the Personally Expressive subcategory (i.e., Personally Expressive through Others, Personally Expressive through Self). Thus, the theory-laden coders provisionally hypothesized a flat relationship for each. As such, to provide a more theoretically informed focus on the directionality of change, the Personally Expressive through Others and Personally Expressive through Self subcategories were both considered more integrated (i.e., developmentally advanced) than the Prove to Others, Self Satisfying, Benefit of Others, and Mixed subcategories, but not more integrated, relative to each other in any way theoretically meaningful from the psychosocial developmental life course approach used in the study (Eichas, 2010). From such a perspective, a change from the Non-personally Expressive subcategory (regardless of nested subcategory designation) to the Personally Expressive subcategory (regardless of nested subcategory designation) was considered an indicator of positive developmental change (Eichas, 2010).

\section{Relational Data Analysis of Future Possible Selves}

Kortsch (2003) found that the intervention strategies used by the CLP demonstrated preliminary efficacy with respect to promoting a more positive sense of future self (i.e. future possible self; Oyserman, 1987), one aspect of the development of an overall positive, increasingly consolidated sense of self. One's future possible self is the conceptualization of self an individual believes they could become, hopes to become, or hopes to avoid becoming, that has been found to be an important contributor to identity formation (Dunkel, 2000). Future possible selves represent one aspect of the ability to conceptualize the self in the future based on one's past and present, given historical, social, and personal opportunities and constraints (Dunkel \& Kerpelman, 2006; Markus 
\& Nurius, 1986). As such, one's conceptualization of "who one is" is believed to strongly influence one's expectations and beliefs about the directions one's life can take, as this conceptualization draws on one's past, one's present, and one's perceived potential futures. Indeed, research has demonstrated a link between possible selves and an individual's ability to orient towards the future in a personally meaningful way (Oyserman \& Markus, 1990a, 1990b; Oyserman \& Fryberg, 2006).

As part of the CLP Stage I evaluation, Kortsch et al., (2008), investigated intervention participants' qualitative expressions of their most important future possible self, including what achievement of that self would mean and how significant that achievement would be. Using the Possible Selves Questionnaire-Qualitative Extension (PSQ-QE) that builds on the Possible Selves Questionnaire (PSQ; Oyserman, 1987), responses to the PSQ-QE were used as an index of one component of the individual's overall future-oriented sense of identity, (i.e., the future self as one sees it). Participants' qualitative responses were coded using RDA methods of that time.

Reversible and Cyclical Movement Through RDA

The description of the RDA processes described above provided an overview of the basic forward movement through three analytic phases of the core cycle of RDA (Conceptual, Theoretical, and Research Analysis). The description provided an illustration of the general directional guidelines for applying the framework. Consistent with Overton's (1998) articulation of knowledge development as a directional spiral, it has been found that the movement through the core cycle of RDA is usually reversible as well as cyclical, with conceptual, theoretical, and empirical finding/results generating new iterations of analysis and/or re-cycling through previous analytic phases in a 
dialectical fashion (Overton, 1998). Thus, an RDA cycle that begins at the conceptual analysis phase may identify a set of categories that, during the subsequent theoretical analysis, may not provide enough theoretically meaningful and/or relevant information to identify plausible theoretical hypotheses about structural organizational patterns within or between identified categories or theoretically meaningful hypotheses about the causal relations among the identified variables. In this case, the result may be the need to collect additional data of the same type or additional data of an alternative type and to return the conceptual analysis phase to identify a new set of categories.

Alternatively, the open coding may identify a set of categories that during the subsequent theoretical analysis provides enough theoretically meaningful and/or relevant information to generate plausible theoretical and/or research hypotheses about the structural relations among the identified categories or theoretical and/or research hypotheses about the causal relations among the identified variables, resulting in movement to the next phase of the cycle, the research analysis phase. The hypothesis testing that takes place during the research analysis phases, in turn, may fail to support the research hypotheses, resulting in the need to return to a previous conceptual or theoretical analysis phase (or even data collection) to identify new categories and/or generate theoretical and/or research hypotheses.

This following section describes the current study's refinement and extension of Kortsch et al. (2008), that used RDA to extend the outward spiral of knowledge development goals of the CLP. Specifically, in this case, to draw on, refine, and advance early research on developing the PSQ-QE. The aim was to conduct a cohort and samplespecific investigation of the structural tree chart (STC) identified by Kortsch et al. (2008), 
using a next generation sample of adolescents drawn from the same public school system alternative high schools. The specific aim was to again use RDA to model the developmental hierarchical structural organization of subjective meaning and significance of participants' most important future possible self, elicited through the use of a free response qualitative measure. Consistent with Kortsch's et al. (2008), the current study's RDA theory-laden coders drew on Oyserman's (1987) conceptualization of an individual's future possible self and psychosocial developmental life course theory. The current study also integrated Overton's (1998) articulation of the knowledge development as a directional spiral in evaluating which of the features of the Kortsch's et al. (2008), structural model replicated in the current cohort and which needed to be modified and updated.

As a refinement to the Kortsch et al. (2008) study, an additional Theoretical Analysis was performed. During the Theoretical Analysis phase, RDA theory-laden coders re-organized the original ordinary language categories to construct theoretical categories that were meaningful from the perspective of a psychosocial developmental life course approach. The theoretical coding yielded findings with respect to participants' future possible selves orientations. Specifically, responses were found to fit into two general types: Non-Actualizing or Actualizing. That is, the theory-laden coders identified a subcategory of participants whose narrative expressions were described in terms that could not be characterized as striving for the realization of one's potential (NonActualizing) and a subcategory of participants whose narrative expressions were described in terms that could be characterized as striving for the realization of one's potential (Actualizing). 
The theory-laden coders further identified within the Actualizing subcategory two nested subcategories: Actualizing through Others and Actualizing through Self. For individuals in these subgroups, the most important future possible self was found to express actualizing qualities through engagement with others (Actualizing through Others) or through a focus, purely on one's self (Actualizing through Self). The theoryladen coders further identified within the Non-Actualizing subcategory three nested subcategories: Benefit of Others, Mixed, and Self Satisfying. For individuals in these subgroups, the most important future possible self was found to express qualities that focus on helping or assisting others without mention of the self (Benefit of Others), a focus on self-satisfaction or gain (Self Satisfying), or was found to express qualities that indicated a focus on more than one property (mixed Benefit of Others and Self Satisfying). The current study generated property descriptions for the five main nested subgroups. These are described below:

\section{Self Satisfying}

The unique properties of the Self Satisfying Level 2 subcategory was that it did not include any reference to the meaning and significance of the most important future possible self to others but that it did include explicit references to the meaning and significance of the most important future possible self to the self. Responses in this subcategory included references to striving for individual or personal pleasure or satisfaction (for the self) that tended to be present-oriented and described in terms that could be characterized as involving extrinsic rewards, hedonic enjoyment, materialistic satisfaction, or self-gratifying in orientation (or avoiding the loss of the same). For example, in response to the question, what would it mean to realize your most important 
future possible self, for the Self Satisfying level 2 subcategory a participant responded: "I want to be a successful lawyer. I want the freedom that money gives you. It's very important to me."

\section{Benefit of Others}

The unique property of the Benefit of Others Level 2 subcategory was that the description of the most important future possible self's meaning and significance included reference to helping or assisting others and did not include reference to the self. The description of meaning and significance included reference to others but solely in the context of the benefit provided to them and without mention of the self. For example, in response to the question, what would it mean to realize your most important future possible self, for the Benefit of Others level 2 subcategory a participant responded: "I want to be a lawyer because I want to be able to support my family."

Mixed

The unique property of the Mixed Level 2 subcategory was that it was a composite subcategory in which all the responses of participant's most important future possible self contained at least two distinct descriptions of the meaning and significance, and that these descriptions included at least one description characterized as Self Satisfying and at least one description characterized as Benefit of Others. . For example, in response to the question, what would it mean to realize your most important future possible self, for the Mixed level 2 subcategory a participant responded: "It is important to me to be a successful person. I also want to help others when I can, positive. I want other kids to look up to me." 


\section{Actualizing Through Others}

The unique property of the Actualizing through Others Level 2 subcategory was that the description of the most important future possible self's meaning and significance included reference to others that did include explicit reference to properties of NonActualizing. Reference to properties of actualizing was strictly based on the othersorientation of the future possible self; reference to properties of actualizing was not based on any self-orientation of the future possible self. For example, in response to the question, what would it mean to realize your most important future possible self, for the Actualizing Through Others level 2 subcategory a participant responded: "I want to be a lawyer because it is what I am meant to do. Many crimes against women are not recognized. I can make justice, help others, and make sure I help."

Actualizing through Self

The unique property of the Actualizing through Self Level 2 subcategory was that the description of the most important future possible self's meaning and significance included reference to the self that did include explicit reference to properties of NonActualizing. Reference to properties of actualizing was strictly based on the selforientation of the future possible self; reference to properties of actualizing was not based on any others-orientation of the future possible self. For example, in response to the question, what would it mean to realize your most important future possible self, for the Actualizing Through Self level 2 subcategory a participant responded: "I want to be a famous DJ or MC. It means everything to me. It's my life. Brings me happiness of joy. Without this, I wouldn't know who I am. It is important because it defines my character, who I am." 
Hierarchical Structural Organization of Properties: Flat and Nested Relationships As mentioned above, in RDA, theory-laden coders identify a theoretically meaningful hierarchical structural organization of RDA root categories and subcategories (i.e., RDA conceptual systems and subsystems) with the use of the type of structural tree chart routinely used to represent the organizational structure of root categories and subcategories identified in the data set as theoretically meaningful (Eichas et al., 2010).

Figure 3: Hierarchical Structural Organization of Future Possible Self

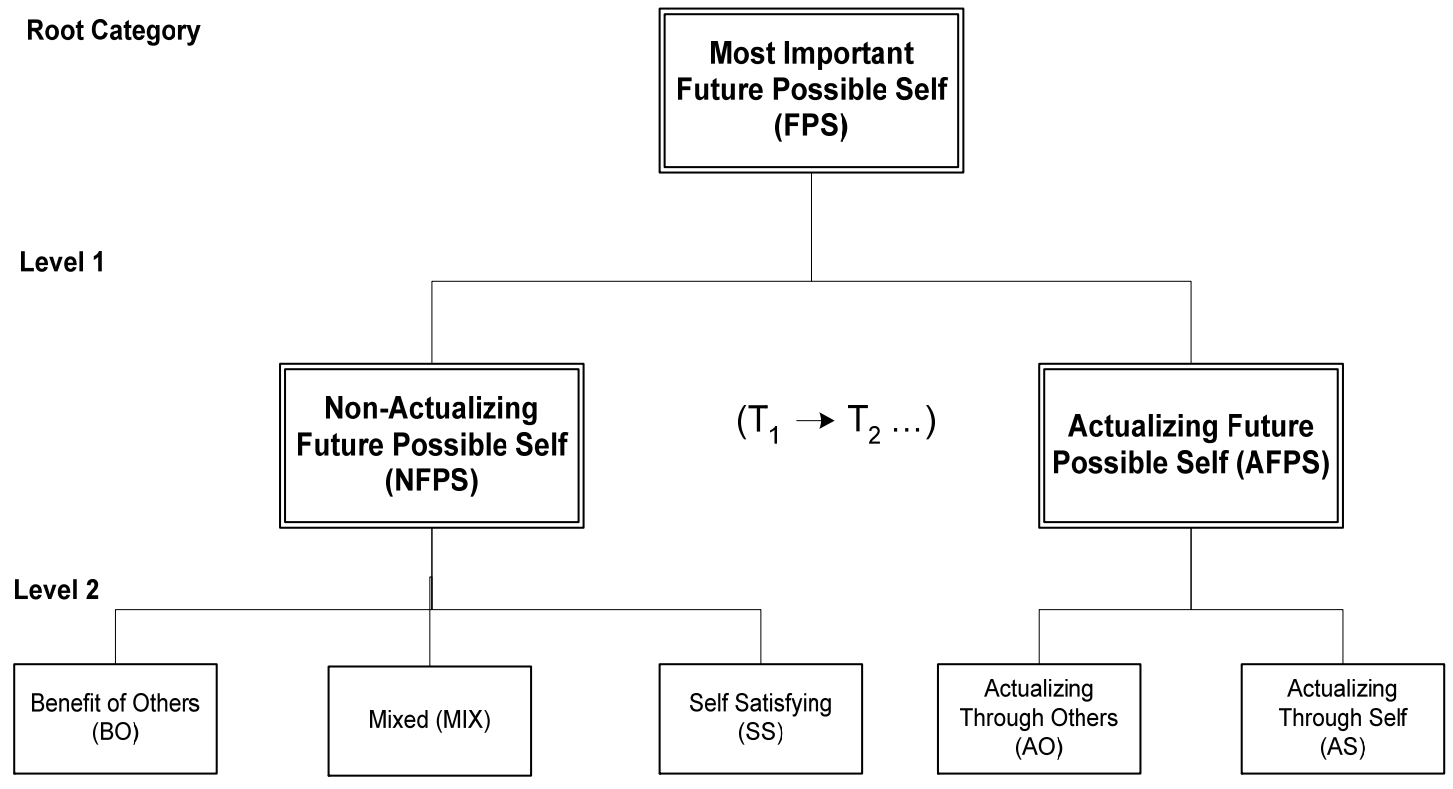

Figure 3 depicts the hierarchical structural organization refined under the current study, in which "Most Important Future Possible Self" as the "root" construct has two levels of subcategories. Level 1 (by convention, the root is level 0) has two subcategories, Non-Actualizing and Actualizing. Level 2 has five subcategories, Mixed, Self Satisfying, Benefit of Others, Actualizing Through Others, and Actualizing Through Self.

Specifically, theory-laden coders were able to generate a consensually derived theoretically meaningful hypothesized direction of progressive developmental change for 
Level 1 of the hierarchical structural organization of participants' free response descriptions of their future possible self as actualizing of a true self, i.e., progressive developmental change from Non-Actualizing $\rightarrow$ Actualizing. As described in detail in Kortsch and Kurtines (2005), the structural organization of the relationships between the two qualitatively different categories (Non-Actualizing and Actualizing) was tentatively identified as flat, or non-hierarchical. However, the structural organization of the properties within each of the two subcategories was identified in terms of the unique structural arrangement of the properties and/or associated subcategories within each subcategory, to have developmental directionality, or hierarchy, based on current conceptions of self development during adolescence.

As adolescence is considered a developmental period characterized by a shift from childhood egocentricism to the more socio-centric orientation of adulthood, as well as the formation and development of a more advanced "self-structure," (Kortsch et al., 2008). The theoretical coders reached a consensus that the Non-Actualizing group is the least developmentally advanced subcategory, as a primary characteristic of this group remains largely egocentric.

Equally significant, the theory-laden coders were unable to generate a consensually derived theoretically meaningful hypothesized direction of progressive developmental change for the properties of the three subcategories nested within the NonActualizing subcategory or the two subcategories nested within the Actualizing subcategory. Thus, the theory-laden coders provisionally hypothesized a flat relationship for each. As such, to provide a more theoretically informed focus on the directionality of change, the Actualizing through Others and Actualizing through Self subcategories were 
both considered more integrated (i.e., developmentally advanced) than the Self Satisfying, Benefit of Others, and Mixed subcategories, but not more integrated relative to each other in any way theoretically meaningful from the psychosocial developmental life course approach used in the study. From such a perspective, a change from the NonActualizing subcategory (regardless of nested subcategory designation) to the Actualizing subcategory (regardless of nested subcategory designation) was considered an indicator of positive developmental change.

\section{Personal Expressiveness and Self Development}

Adolescence is considered a time when an individuals' sense of identity develops into an increasingly self-directed, coherent, and dynamic organization of the individual's drives, abilities, beliefs, and personal history (Kortsch \& Kurtines, 2005). As such, qualitative distinctions between the future possible selves subcategories may indicate that one's conceptualization of a hoped for future possible self is at least partially defined by the degree to which it is personally expressive (Albrecht, 2007). In terms of developing a positive sense of identity, personally expressive individuals may conceptualize their future in terms of fulfillment of known interests, strengths, and potentials thus increasing the potential for continued positive development into the future. Whereas, less personally expressive individuals may conceptualize their future self in terms of hedonic pleasure or extrinsic reward, potentially limiting future growth (Albrecht, 2007).

Future Possible Selves Content Categories: Feelings of Personal Expressiveness In examination of qualitative differences between the most important future possible self subcategories, a Non-Actualizing possible self includes no reference to feeling a personal "fit" with their hoped for self. Because these possible selves (1) lack a 
specific reference to a striving beyond gratification or direct reinforcement and make no reference to a defined purpose in living, and (2) as their focus is non-actualization through self or others that does not go beyond immediate, hedonic reward, individuals with this hoped for future self might be presumed to be in a Non-Personally Expressive Life Goal Level 1 subcategory (Albrecht, 2007).

Actualizing possible selves, however, include references that tend to be futureoriented and described in terms that could be characterized as involving striving for the realization of one's potential. These responses often include descriptive words and phrases such as, "always wanted to be," "this is my dream," "what I am meant to be" "who I am," "it's part of my tradition," "my vision," "my life goal." etc. Such responses may potentially be considered more personally expressive, as the focus on the self is described in terms of respondents' personal connection to their hoped for self as an indicator of "being actualized" as a subjectively "better" self, one that is largely removed from considerations of immediate, extrinsic pleasure or reward (Kortsch \& Kurtines, 2005).

The current study built on the developmental hierarchical structural organization of participants' most important life goals by Rinaldi et al. (under review) and the current refinement of participant's most important future possible self as described above by investigating the role of qualitative change in the meaning and significance of participants' most important life goal and most important future possible self. Developmental outcome models have previously focused on the linear, additive aspects of development rather than the emergence of new properties that cannot be completely explained by previous elements within the developmental system (Eichas, 2010). In 
seeking to integrate the analysis of qualitative change in content, structure, and organization of self and identity and its meaning and significance with the analysis of quantitative/dimensional change in positive outcome domains identified as theoretically and empirically meaningful, this study specifically focused on the emergence of the personally expressive property in participants' narrative expressions of their most important life goals and the emergence of the self-actualizing property in participant's narrative expressions of their most important future possible self. The emergence or nonemergence of these properties are used as qualitative intervention outcomes and the evaluation of possible relationships between the identified subcategories of participant's narrative expressions of their most important life goals and future possible self.

Research Analyses of Pathways of Intervention Change

A main conceptual focus of the ongoing program of developmental intervention research on the Changing Lives Program (CLP) intervention has been on the theory informed selection of mediators and positive outcome variables (Eichas, 2010). The CLP uses a participatory transformative intervention process to target the formation of a positive sense of self and identity among multi-problem youth attending alternative high schools. Thus, the current study used quantitative and qualitative indices of positive identity development drawn from the literature on self and identity. 
Figure 4: Conceptualized Pathways of Intervention Change

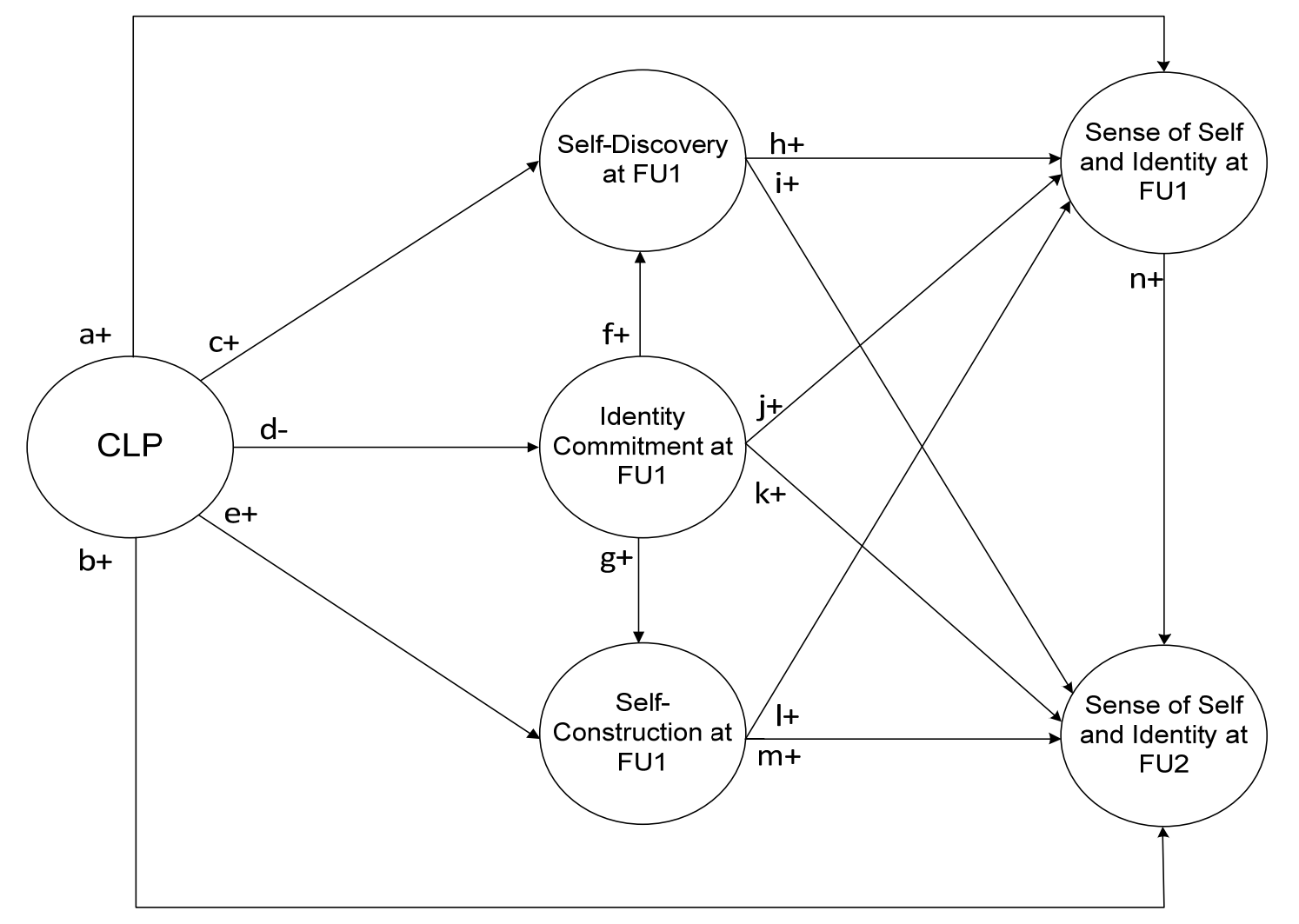

Figure 4 depicts the current study's basic conceptualized pathways of intervention change, including (1) direct effects on identity formation processes, (2) direct effects on positive identity outcomes, (3) indirect effects on positive identity outcomes mediated by hypothesized identity formation processes, (4) mediated effects of self-discovery and self-construction through the CLP's direct effect on participant's engagement in identity crisis, and (5) change relations between hypothesized intervention outcomes. As can be seen from Figure 4, the model predicts that the CLP's participatory transformative intervention process will be associated with increases and decreases in the identity formation processes (paths $\mathrm{c}, \mathrm{d}$, and e), increases in the probability of positive identity outcomes (path a and b), positive mediated effects on the probability of positive identity 
outcomes (paths h, I, j, k, l, and m), positive mediated effects on self-discovery and selfconstruction through identity crisis (paths $\mathrm{f}$ and $\mathrm{g}$ ), and a positive change relation between the two positive identity outcomes from follow-up 1 to follow-up 2 (path $n$ ).

Hypothesized Pathways of Intervention Change

Figure 5 presents the Outcome Mediation (OM) evaluation model used by the current study to investigate the CLP's intervention effects. Measured variables were selected to operationalize the conceptual model described above (see Measures section for a description of the measures)

Figure 5: Hypothesized Outcome Mediation Evaluation Model

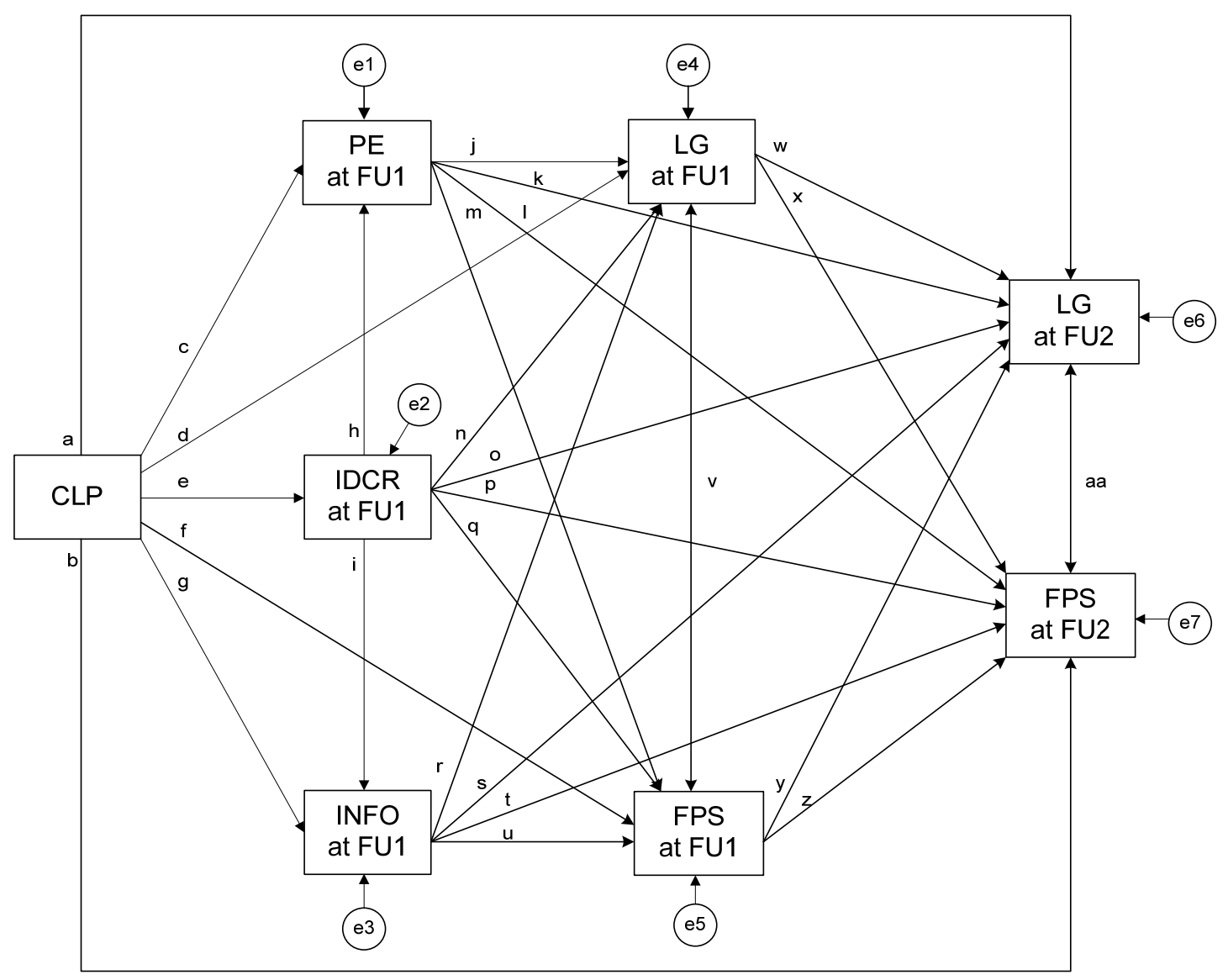




\section{The Conceptual Evaluation Model}

This section describes the theoretically hypothesized intervention effects for these variables and the specific causal paths hypothesized to underlie the putative change mechanisms. Because of the dearth of empirical mediation research in the positive development literature, the mediation construct for the model was derived from previous research on the CLP and the existing body of theoretical literature on positive identity development. Specificity of Effects: Intervention Effects on Identity Processes

Identity exploration and identity commitment are two core psychosocial processes for resolving the identity crisis and forming a positive sense of self and identity during adolescence that have been discussed extensively in the identity literature (Marcia, 1988). Further, identity exploration incorporates both cognitively focused and emotion focused processes (Schwartz, 2002; Schwartz et al., 2005; Soenens et al., 2005).

With regard to identity commitment, the conflict or mismatch between existing identity commitments and the individual's context has been described by Bosma and Kunnen (2001) as a starting point for increased identity processing. While existing adolescent identity commitments may have emerged through a process of identity exploration, identity commitments for many adolescents may be unexamined or unreflective (Forthun, Montgomery, \& Bell, 2006). Previous empirical findings (Eichas et al., 2010) have indicated that the effect of participation in CLP intervention on identity conflict resolution (IDCR) may be moderated by ethnicity, suggesting that the CLP may promote increases in identity conflict for some participants but decreases in conflict for others. 
With regard to cognitive and emotion focused identity exploration, the cognitive orientation toward proactively seeking out and utilizing self-relevant information when exploring identity choices has been described by Berzonsky (1992b), as an informational cognitive processing style (INFO). The positive affective experience (emotion focused) associated with engagement in identity-relevant activities that are consistent or resonant with the true self has been described by Waterman (1993) as feelings of personal expressiveness. Previous empirical findings (Eichas et al., 2010) have indicated evidence that participation in CLP intervention promotes increases in the use of an informational cognitive style (INFO), feelings of personal expressiveness (PE), and decreases in identity conflict resolution (IDCR). The model thus predicts the following specificity of effects: CLP $\rightarrow+$ INFO, -IDCR, + PE (paths g, e, and c).

Direct Effects: Qualitative Intervention Outcomes

The model specifically hypothesizes that participation in the CLP intervention promotes positive change in life goals (LG) and future possible selves (FPS) as measures of a future oriented sense of self and identity (paths a, b, d, and f). This study sought to further investigate positive identity development by evaluating both dimensional and structural/organizational change in indices of self and identity and its meaning and significance. As noted, a strictly quantitative approach cannot capture changes in the meaning and significance of critical experiential components of self and identity because not only are these changes non-linear, discontinuous, and not easily quantifiable, they are also subjective in nature (Eichas, 2010). Thus, qualitative indices of positive identity outcomes were used in the current study. 
The articulation of life goals and future possible selves represent an important marker of the development of a sense of self and identity as it emerges during adolescence (Eichas, 2010). As noted, RDA theoretical analyses (Rinaldi et al., under review) identified the emergence of a personally expressive life goal and the current study's refinement, identified the emergence of an actualizing future possible self as theoretically relevant structural organizational changes in participants' subjective sense of self and identity.

As can be seen in Figure 5, the evaluation model hypothesizes that participation in the CLP intervention promotes the qualitative progressive developmental change from a non-personally expressive life goal to a personally expressive life goal (LG) and a qualitative progressive developmental change from a Non-Actualizing future possible self to a n Actualizing future possible self (FPS). The model thus predicts the following direct intervention effects on positive identity outcomes: CLP $\rightarrow+L G,+$ FPS (paths a and b).

Mediator Effects: Psychosocial Developmental Mediators of Intervention Change Mediation of Outcomes: Treatment Specificity

Treatment specificity was evaluated by examining the effect of the CLP on change in the hypothesized mediators (INFO, IDCR, PE) and the effect of change in the hypothesized mediators on change in the outcome variables (LG, FPS) at follow-up 1 and 2. The model hypothesizes that increases in INFO, IDCR, and PE are associated with a higher probability of positive change in LG and FPS and the following psychosocially mediated intervention effects on LG and FPS: $\mathrm{CLP} \rightarrow+\mathrm{INFO},-\mathrm{IDCR},+\mathrm{PE} \rightarrow+\mathrm{LG},+\mathrm{FPS}$ (paths $\mathrm{r}, \mathrm{s}, \mathrm{e}, \mathrm{n}, \mathrm{j}$, and $\mathrm{k}$ for LG and paths $\mathrm{u}, \mathrm{t}, \mathrm{n}, \mathrm{o}, \mathrm{m}$, and $\mathrm{l}$ for FPS). 


\section{Mediation among Mediators}

Consistent with the literature on identity formation and previous research on the CLP, the model conceptualizes identity exploration as the "work" of the identity process (Grotevant, 1987). As noted, Marcia (1966) operationalized Erikson’s (1963) conceptualization of the identity confusion - identity synthesis crisis by describing identity exploration and identity commitment as the processes by which an individual forms a sense of identity that resolves the crisis. Identity commitment that follows a period of proactive exploration of identity alternatives, according to Marcia (1966) results in an achieved identity.

However, youth experiencing the complex biological, cognitive, and social changes characteristic of adolescence are at the earliest stages of the identity process, a process that emerges out of the these changes and that often extends into the late $20 \mathrm{~s}$ or the 30s (Arnett, 2000, 2004; Schwartz, Cote, \& Arnett, 2006). It is likely that many of these youth have not yet begun to engage in the challenge of choosing the goals, roles, and beliefs about the world that give life direction and purpose as well as coherence and integration (Eichas, 2010). Thus, it may be developmentally appropriate for an identity intervention with youth to target engagement in the challenge of choosing goals, roles, and beliefs about the world, i.e., engagement in the identity crisis, before seeking to increase exploration and commitment.

This conceptualization is consistent with the identity literature. Baumeister, Shapiro, and Tice (1985) suggest that identity crisis occurs when an adolescent encounters circumstances in which he or she lacks enough of a sense of identity to make important life decisions (i.e., an identity deficit) or circumstances that bring to light the 
incompatibility of two or more aspects of his or her identity (i.e., an identity conflict). As noted, other theorists (e.g., Adams \& Marshall, 1996; Breakwell, 1988; Grotevant, 1987; Kerpelman, Pittman, \& Lamke, 1997a; Kroger, 1997) have recognized the importance of the transaction between the individual and the individual's context as a potential "starting point" for the identity process (Bosma \& Kunnen, 2001).

Accordingly, the model (Figure 5) conceptualizes the CLP's participatory transformative intervention process as a prompt for engagement in the identity crisis (path e). Identity conflict or deficit may result from the adolescent's participation in the novel person $\leftrightarrow$ context interaction introduced by the intervention and/or from identityrelevant questions (e.g., questions regarding life goals, possible selves, turning points, etc.) generated by the transformative activities that the intervention targets (Eichas, 2010).

Thus, the model (Figure 5) hypothesizes that decreases in IDCR are associated with increases in PE and INFO (paths $h$ and $i$, respectively). The model predicts the following psychosocially mediated intervention effects among mediators, i.e., that increases in IDCR are associated with contemporaneous increases in PE and INFO, i.e., $\mathrm{CLP} \rightarrow-\mathrm{IDCR} \rightarrow+\mathrm{PE},+\mathrm{INFO}$.

\section{Change Relations Among Positive Outcomes}

\section{Reciprocal Relationships}

Because the field has little theory to guide research, little is known regarding the possible relationship between the categories identified from participant's narrative expressions of their most important life goal and future possible self, the evaluation model thus hypothesizes a reciprocal relationship between the two positive outcomes at 
follow-up 1 and at follow-up 2 (paths $\mathrm{v}$ and aa) as an exploratory methodology of possible relationships and to fully inform the model.

Lagged Effects between Outcomes

With respect to the evaluation of intervention lag effects across positive outcome domains, the evaluation model hypothesized that intervention change in positive identity outcomes at follow-up 1 will be associated with the change from a Non-Personally Expressive life goal to a Personally Expressive life goal at follow-up 2 and with change from a Non-Actualizing future possible self at follow-up1 to an Actualizing future possible self at follow-up 2. The model thus predicts the following indirect intervention effect: CLP $\rightarrow+$ LG1 $\rightarrow+$ LG2 (paths $\mathrm{d}$ and $\mathrm{w}$ ) and CLP $\rightarrow+$ FPS1 $\rightarrow+$ FPS2 (paths $\mathrm{f}$ and $\mathrm{z}$ ).

Moderator Effects: Boundaries of Treatment

The effects of gender, age, and ethnicity as potential exogenous moderators of the CLP on differential changes in the four outcome variables and three mediator variables was evaluated. As the literature is mixed with respect to gender, age, and ethnicity-related differences in identity development in general (Kroger, 1997; Spencer \& MarkstromAdams, 1990) and non-existent with respect to moderation of mediators of differential intervention outcome, the effects of the hypothesized exogenous moderator variables on both direct effects and/or mediated effects was included in evaluation of the structural model but hypotheses regarding directionality of moderated effects (i.e. which subgroup experienced greater differential intervention change) are unspecified (Eichas, et al., 2010). 


\section{METHODS}

\section{Participants}

The Changing Lives Program (CLP) is implemented by the Miami Youth Development Project (YDP) as a PYD program targeting multi-problem youth in alternative high schools in the Miami Dade County Public Schools (M-DCPS), the fourth largest school system in the United States. The CLP is a long-standing community supported, gender and ethnic inclusive PYD intervention aimed at promoting positive development in multi-problem youth in urban alternative high schools. The CLP specifically targets these youth because students who come to alternative schools are on a negative life course pathway and are at risk for multiple negative developmental outcomes and/or engaged in multiple problem behaviors.

The CLP provides on-site counseling services in all of the M-DCPS voluntary alternative high schools. As described in Kurtines, Ferrer-Wreder, Berman, Lorente, Briones, et al. (2008), the primary intervention goal is to create contexts that empower troubled adolescents in ways that promote the development of a positive identity and also result in positive change in problem outcomes, thereby changing their "negative" life pathways into positive ones. The YDP's primary long-term knowledge development strategy has been to draw on its ongoing and long-standing school-based data collection mechanism for developing and updating the empirically supported theory informed models of the causal mechanisms that are hypothesized to underlie PYD intervention change.

Participants for this study were drawn from the YDP's archival data file that, in addition to a core family of measures (group administered self-report, individually 
administered open ended and semi-structured interview measures, etc.), also includes specialty measures associated with specific evaluation projects. The sample for this study was comprised of 259 White/Non-Hispanic, African-American, and Hispanic adolescents. Because they were under-represented in my sample population, the 21 White/Non-Hispanic individuals were not included in the sample. The analysis was conducted with 238 African-American and Hispanic adolescents aged 14-18 who had completed the intervention, 98 of whom participated in a two-semester non-intervention (non-random) comparison control condition. The sample consisted of 137 females (87 African American, 50 Hispanic) and 101 males (52 African American, 49 Hispanic). With regard to the socio-economic characteristics of the sample, $38 \%$ of annual family incomes were below $\$ 21,000$, while $17 \%$ were over $\$ 41,000$. Seventy-four percent of the participants had at least one parent who completed high school, 50\% had two parents who completed high school, and $31 \%$ had at least one parent who completed a bachelor's degree.

\section{Recruitment of Participants}

Following the YDPs established procedures, participants were recruited to the CLP through self-referrals or through referrals from the school counselor/teachers. Participants completed parent consent and student assent forms approved by university and M-DCPS IRBs before being assigned to their condition. The CLP counseling groups were organized and implemented through the school administration as part of each school's ongoing counseling program. All of the students who participated in the comparison control condition were randomly selected from a pool of students identified by the school counselors or administrators as not having participated in counseling and 
guidance programs prior to or during the two semesters of their involvement with the YDP.

\section{Procedure}

Intervention Procedure

Following the Youth Development Project's established procedures for the CLP, each intervention group was led by an intervention team that consisted of one group facilitator, one co-facilitator, and one or two group assistants. All groups shared this structure and format. All group facilitators and co-facilitators were graduate level students enrolled in either a doctoral or a master's level program. Group assistants were undergraduate psychology students who had been trained in the administration of the measures and in participant tracking procedures.

The group facilitators and co-facilitators served as counselors and used the CLP's intervention strategy, a participatory transformative approach (Montgomery, Kurtines, et al., 2008). The intervention groups met for approximately 45 minutes to 1 hour every week for approximately 8 to 12 weeks in either the fall or spring semester.

\section{Assessment Procedure}

The participants were assessed by undergraduate psychology students serving as research trainees. Their training took place at the beginning of each semester and included instruction concerning confidentiality issues, assessment administration, dress code, high school regulations, interviewing strategies, and role-playing of interviews. Assessments were conducted at three times during the school year on school grounds and during school hours. Assessments took place the week preceding the commencement of the semester sessions and the week after the end of each semester's sessions. 


\section{Measures}

Psychosocial Mediator: Identity Conflict Resolution

The Erikson Psycho-Social Stage Index (EPSI; Rosenthal, Gurney, \& Moore, 1981 ) is a 72-item self-report measure that includes six subscales, each consisting of 12 items indicating how well respondents have resolved conflicts indicative of Erikson's stages of psychosocial development. This study used the identity conflict resolution subscale (IDCR). Items on this subscale utilize key words and statements from Erikson's characterizations of the identity synthesis versus identity confusion stage. Sample items included, "I know what kind of person I am." Items are rated on a 5-point Likert scale from 1 (almost never true) to 5 (almost always true) with half of the items representing resolution of the identity crisis, and half representing identity confusion. Items representing identity confusion were reverse-coded prior to analysis. Thus, mean scores for the IDCR subscale yield an index of degree of resolution, with high scores indicating higher levels of resolution. Rosenthal et al., (1981) reported a correlation coefficient of .56 between the identity conflict resolution subscale of the EPSI and the identity subscale of Greenberger and Sorensen's (1974) Psychosocial Maturity Inventory (PSM), Form D. Alpha coefficients of .74 have been reported in an adolescent sample (Ferrer-Wreder, Palchuk, Poyrazli, Small, \& Domitrovich, 2008) and in a large youth sample ranging across middle school through college (Montgomery, 2005). In this study, Cronbach's alpha coefficient was .77.

Self Discovery: Feelings of Personal Expressiveness

The Personally Expressive Activities Questionnaire (PEAQ; Waterman, 1995) is a 14-item self-report measure that includes three subscales indicating feelings of personal 
expressiveness, hedonic enjoyment, and flow challenge. This study used the feelings of personal expressiveness subscale $(\mathrm{PE})$ as a measure of differential intervention outcome in the positive domain. The PEAQ has been adapted for use in the evaluation of CLP such that questions refer to activities associated with the long-term life goals of the respondents. Thus, the PE subscale indicates the degree to which respondents feel that the pursuit of life goals is personally satisfying and expressive of their unique potentials. The PE subscale consists of six items, the scores of which are averaged to generate a subscale score. Sample items included, "When I do these activities, I feel like it's what I was meant to do." Items are rated on a 7-point Likert scale from 1 (strongly disagree) to 7 (strongly agree) (Waterman, 1995). Waterman (2004) found significant correlations between PE scores and identity status and identity style, providing evidence of concurrent validity. Waterman (2005) reported an alpha reliability coefficient of .77 for the PE subscale, .91 in this study.

Self Construction: Identity Styles

The Identity Style Inventory (ISI) (Berzonsky, 1992b) is a 39-item self-report measure that includes three subscales indicating the use of informational, normative, and diffuse avoidant styles in situations that require identity exploration and a fourth subscale indicating identity commitment. This study will use the informational style subscale (INFO) as a measure of self-construction identity process. Informational identity style is the cognitive orientation toward proactively seeking out and utilizing self-relevant information when exploring decisions related to identity (Berzonsky; 1992b). The INFO subscale consists of 10 items, the scores of which are averaged to generate a subscale score. Sample items included, "When making important decisions, I like to have as much 
information as possible." Items are rated on a 5-point Likert scale labeled: 1 = "almost never true", 2 = "usually not true", 3 = "undecided", 4 = "sometimes true", and $5=$ "almost always true" (Berzonsky, 1992b). Theoretically consistent relationships have been found between ISI subscales and measures of identity status, identity orientation, social-cognitive processes, and personality dimensions (Berzonsky, 1990, 1992;

Berzonsky \& Sullivan, 1992; Schwartz et al., 2000), indicating evidence of concurrent validity. Berzonsky (1992b) reported an alpha coefficient of .78 and test-retest reliability of .87 for the INFO subscale. Ferrer-Wreder et al. (2002) reported an alpha coefficient of .59 for INFO in a sample of ethnically diverse high school students. Analysis of a subsample of the present data set indicates an alpha coefficient of .70 for the INFO subscale.

Positive Outcome: Personally Expressive Life Goals

The Personally Expressive Activities Questionnaire - Qualitative Extension (PEAQ-QE) adds an open-ended response component to the PEAQ to provide a method for eliciting the narrative/linguistic expressions of meaning and significance of participants' most important life goals. Specifically, participants were asked to identify up to three life goals and then to identify their most important life goal. They were then asked to provide an open-ended description of its meaning and significance. More specifically, participants were asked, "What does this life goal mean to you?" and "Why is this significant or important to you? How significant or important is this to you?" The meaning and significance questions were then followed by three neutral probes (e.g., “Can you say more about that?"; "Is there anything else?”) to request secondary elaboration when necessary. 
This study used the conceptual and theoretical coding categories for PEAQ-QE responses developed by Rinaldi et al. (under review) using Relational Data Analysis (RDA; Kurtines et al., 2008). RDA draws on methods for analyzing free response data associated with grounded theory (e.g., open coding and constant comparison) and extends these methods by intentionally manipulating the theoretical saturation of coders across multiple phases of analysis. Rinaldi et al. (under review) used a psychosocial developmental life course theoretical framework to generate a theoretically meaningful developmental hierarchical structural organization of participants' most important life goals. Theory-laden coders consensually derived a hypothesized direction of progressive developmental change at Level 1 of the structural organization, from Non-personally Expressive $\rightarrow$ Personally Expressive. Analysis of inter-coder agreement for Level 1 subcategories indicated agreement of $96 \%$ and a Fleiss' Kappa of .84, suggesting almost perfect agreement (correcting for chance). The Personally Expressive subcategory had two nested subcategories: Personally Expressive through Others and Personally Expressive through Self. The Non-Personally Expressive subcategory had three nested subcategories: Prove to Others, Self Satisfying, Benefit of Others; and a mixed nested subcategory: Mixed Prove to Others/Self Satisfying and Mixed Self Satisfying/Benefit of Others. Analysis of inter-coder agreement for Level 2 subcategories indicated agreement of $86 \%$ and a Fleiss' Kappa of .69, suggesting substantial agreement (correcting for chance). Analyses of the full model used Level 1 subcategories, that is, Personally Expressive versus Non-Personally Expressive life goals (Life Goal). 
Positive Outcome: Future Possible Self

The Possible Selves Questionnaire-Qualitative Extension (PSQ-QE) adds an open-ended response component to the Possible Selves Questionnaire (PSQ; Oyserman, 1987). This is done to provide a method for eliciting the narrative/linguistic expressions of meaning and significance of participants' most important future possible self. Specifically, participants were asked to identify up to three future possible selves and then to identify their most important future possible self. Participants were then asked to provide an open-ended description of its meaning and significance. The meaning and significance questions are followed by three neutral probes to request secondary elaboration when necessary.

This study used the conceptual and theoretical coding categories for PSQ-QE responses developed by the current study using Relational Data Analysis (RDA; Kurtines et al., 2008). Theory-laden coders consensually derived a hypothesized direction of progressive developmental change at level 1 of the structural organization, from NonActualizing $\rightarrow$ Actualizing. Analysis of inter-coder agreement for Level 1 subcategories indicated agreement of $88 \%$ and a Fleiss' Kappa of .69, suggesting substantial agreement (correcting for chance). The Actualizing subcategory had two nested subcategories: Actualizing through Others and Actualizing through Self. The Non-Actualizing subcategory had three nested subcategories: Mixed, Self Satisfying, and Benefit of Others. Analysis of inter-coder agreement for Level 2 subcategories indicated agreement of $71 \%$ and a Fleiss' Kappa of .46, suggesting moderate/acceptable agreement (correcting for chance). Analyses of the full model used Level 1 subcategories, that is, Actualizing versus Non-Actualizing future possible self. 
Moderators of Outcome (Gender and Ethnicity)

The Background Information Form (BIF) is a record of demographic information completed by all participants in the YDP program. It provided the data used in analyses gender, age, and ethnicity (Hispanic/Latino, African American, Non-Hispanic White, Biethnic, and Other) as exogenous moderators. 


\section{RESULTS}

\section{Preliminary Analyses}

Descriptive Statistics

Table 1 presents the means, standard deviations, skewness and kurtosis for the continuous variables at Baseline (BL), and Follow-up 1 (FU1). These include the subscales of the Personally Expressive Activities Questionnaire (PEAQ): Personal Expressiveness (PE); the Identity Style Inventory (ISI); and the Erikson Psycho-Social Stage Index (EPSI) subscale of Identity Conflict Resolution (IDCR).

Table 1: Descriptive Statistics for Continuous Evaluation Variables

\begin{tabular}{lcccc}
\hline Outcomes & $\mathrm{M}$ & $\mathrm{SD}$ & Skewness & Kurtosis \\
IDCR at BL & 3.725 & .566 & -.306 & -.426 \\
IDCR at FU1 & 3.739 & .617 & -.456 & .091 \\
PE at BL & 5.531 & 1.295 & -1.055 & 1.014 \\
PE at FU1 & 5.305 & 1.469 & -.736 & -.182 \\
INFO at BL & 3.419 & .600 & -.292 & .004 \\
INFO at FU1 & 3.484 & .549 & -.023 & .268 \\
\hline
\end{tabular}

Table 2 and Table 3 present the number and proportion of responses assigned to Level 1 and Level 2 subcategories of the Life Goal (LG) and Future Possible Self (FPS) variable. Baseline evaluation indicated that $92 \%$ of descriptions of participants' most important life goals had the non-personally expressive property and, more specifically, that the majority of responses $(75 \%)$ had the self satisfying property. This proportion was similar for both males and females and for both Hispanic and African American 
participants (ranging from $75 \%$ to $76 \%$ within each subgroup), as well as among age subgroups (ranging from $71 \%$ to $83 \%$ ) The variation in proportions by age was not significant $\left(\chi^{2}=1.515, \mathrm{df}=4, p=.82\right)$. Baseline evaluation indicated that $71 \%$ of descriptions of participants' most important future possible self had the non-actualizing property and, more specifically, that the majority of responses (51\%) had the self satisfying property. This proportion was similar for both males and females and for both Hispanic and African American participants (ranging from 68\% to $72 \%$ within each subgroup), as well as among age subgroups (ranging from $62 \%$ to $65 \%$ ) The variation in proportions by age was not significant $\left(\chi^{2}=2.506, \mathrm{df}=4, p=.56\right)$.

Table 2: Descriptive Statistics for Life Goal

\begin{tabular}{lcc}
\hline Level 1 Subcategories & N & $\%$ \\
\hline Personally Expressive Life Goal at BL & 18 & $8 \%$ \\
Personally Expressive Life Goal at FU1 & 18 & $8 \%$ \\
Personally Expressive Life Goal at FU2 & 11 & $5 \%$ \\
Non-Personally Expressive Life Goal at BL & 206 & $92 \%$ \\
Non-Personally Expressive Life Goal at FU1 & 211 & $92 \%$ \\
Non-Personally Expressive Life Goal at FU2 & 121 & $51 \%$ \\
\hline Level 2 Subcategories & $\mathrm{N}$ & $\%$ \\
\hline Personally Expressive through Self at BL & 17 & $8 \%$ \\
Personally Expressive through Self at FU1 & 15 & $7 \%$ \\
Personally Expressive through Self at FU2 & 11 & $5 \%$ \\
Personally Expressive through Others at BL & 1 & $.4 \%$
\end{tabular}


Personally Expressive through Others at FU1

$31 \%$

$\begin{array}{lll}\text { Personally Expressive through Others at FU2 } & 0 & 0 \%\end{array}$

$\begin{array}{lll}\text { Benefit of Others at BL } & 12 & 5 \%\end{array}$

$\begin{array}{ll}\text { Benefit of Others at FU1 } & 6\end{array}$

Benefit of Others at FU2 $\quad 1 \quad .4 \%$

$\begin{array}{lll}\text { Self Satisfying at BL } & 168 & 75 \%\end{array}$

$\begin{array}{lll}\text { Self Satisfying at FU1 } & 174 & 76 \%\end{array}$

$\begin{array}{lll}\text { Self Satisfying at FU2 } & 109 & 46 \%\end{array}$

$\begin{array}{lll}\text { Prove to Others at BL } & 3 & 1 \%\end{array}$

$\begin{array}{lll}\text { Prove to Others at FU1 } & 2 & .9 \%\end{array}$

$\begin{array}{lll}\text { Prove to Others at FU2 } & 0 & 0 \%\end{array}$

$\begin{array}{ll}\text { Mixed Prove to Others/Self Satisfying at BL } & 13\end{array}$

Mixed Prove to Others/Self Satisfying at FU1 $\quad 9 \quad 4 \%$

Mixed Prove to Others/Self Satisfying at FU2 $4 \%$

$\begin{array}{ll}\text { Mixed Self Satisfying/Benefit of Others at BL } & 10\end{array}$

Mixed Self Satisfying/Benefit of Others at FU1 $\quad 20 \quad 9 \%$

$\begin{array}{lll}\text { Mixed Self Satisfying/Benefit of Others at FU2 } & 7 \%\end{array}$

Table 3: Descriptive Statistics for Future Possible Self

\begin{tabular}{lcc}
\hline Level 1 Subcategories & $\mathrm{N}$ & $\%$ \\
\hline Actualizing Future Possible Self at BL & 67 & $28 \%$ \\
Actualizing Future Possible Self at FU1 & 69 & $29 \%$
\end{tabular}


Actualizing Future Possible Self at FU2

Non- Actualizing Future Possible Self at BL

Non- Actualizing Future Possible Self at FU1

Non- Actualizing Future Possible Self at FU2

Level 2 Subcategories

Actualizing through Self at BL

Actualizing through Self at FU1

Actualizing through Self at FU2

Actualizing through Others at BL

Actualizing through Others at FU1

Actualizing through Others at FU2

Benefit of Others at BL

Benefit of Others at FU1

Benefit of Others at FU2

Self Satisfying at BL

Self Satisfying at FU1

Self Satisfying at FU2

Mixed at BL

Mixed at FU1

Mixed at FU2

$\mathrm{N}$

27

39

63

40

30

48

19

43

27

121

93

51

29

31

14
$49 \%$

$71 \%$

$70 \%$

$37 \%$

$\%$

$11 \%$

$16 \%$

$27 \%$

$17 \%$

$13 \%$

$20 \%$

$8 \%$

$18 \%$

$11 \%$

$51 \%$

$39 \%$

$21 \%$

$12 \%$

$13 \%$

$6 \%$ 
Outliers, Missing Data, and Non-Normality

Prior to the study's main analysis, data for the continuous variables were evaluated for outliers and normality. Outliers were evaluated by examining leverage statistics for each individual; an outlier was defined as an individual with a leverage score four times greater than the mean leverage. No outliers were found. Kurtosis and skewness were within acceptable ranges (see Table 1).

\section{Main Analyses}

The evaluation model (Figure 5), was evaluated using a Structural Equation Modeling (SEM) approach for modeling hypothesized causal pathways of intervention change. Figure 6 and Tables 4 and 5 present the results (outcome, moderation, and mediation) for the evaluation model, including relations between the hypothesized mediators (PE, IDCR, and INFO) and the two positive identity outcome variables (LG and FPS). Interaction effects for the moderated relationships were tested using product terms (Jaccard \& Turrisi, 2003). Two-valued dummy variables for two exogenous interpersonal contextual covariates, Gender (G) and Ethnicity (E), were included in the analysis of outcome as measured at pretest, as were all possible interaction terms (i.e., $\left.\mathrm{CLP}^{*} \mathrm{G}, \mathrm{CLP} * \mathrm{E}, \mathrm{G} * \mathrm{E}, \mathrm{CLP} * \mathrm{G} * \mathrm{E}\right)$, with CLP designated as the focal independent variable. Non-significant interactions were dropped from the final model, leaving one significant interaction term $(\mathrm{CLP} * \mathrm{E})$. To reduce clutter and improve visual clarity, the model in Figure 6 excludes the paths associated with $\mathrm{E}$ and CLP*E, however, the simple main effects are included in the model. Participants' age, gender, and scores of outcomes at $\mathrm{BL}$ were included as covariates. 
The fit of the model was evaluated with Mplus 5.0 (Muthen \& Muthen, 19982007) using the sample covariance matrix as input and a robust weighted least squares solution. The model is statistically overidentified. Data analysis used the robust WLSMV estimator available in Mplus in order to adjust the parameter estimates, standard errors, and fit indices for the categorical nature of the Life Goal and Future Possible Self variables. The WLSMV estimator provides weighted least square parameter estimates using a diagonal weight matrix with standard errors and a mean- and a variance-adjusted chi-square test statistic with a full weight matrix (Muthen \& Muthen, 1998-2007). Computation of standard errors and the chi-square test of model fit took into account nonindependence of observations due to cluster sampling, specifically to account for possible counseling group clustering effects.

The WLSMV estimator allows data to be missing completely at random (MCAR), and it allows data to be missing at random (MAR) if missingness is a function of covariates but not if it is a function of outcomes. Cases with incomplete covariate data were not included in the model analysis, resulting in a data set of 238 cases. This data set was assessed for missingness and appear to meet the specified criteria. Although a high percentage of data for the FU2 evaluation were missing ( $45 \%$ missing for LG and $14 \%$ FPS at FU2), only $4 \%$ or less missing data were identified for FU1 variables. In addition, dummy variables were created for missing data and correlated with gender, ethnicity, and age, as well as all other variables included in the model.

Following recommendations of Bollen and Long (1993), a variety of global fit indices were used, including indices of absolute fit, indices of relative fit and indices of fit with a penalty function for lack of parsimony. First, the chi-square and its probability 
value ( $p$-value) were examined. The higher the $p$-value is, the closer the fit between the hypothesized model and model fit (Byrne, 2001), with a target $p$-value of greater than .05. The comparative fit index (CFI) was used as an index of fit based on the comparison of the hypothesized model with the independence model. A CFI value of greater than .95 was used to indicate model fit. The root mean square error of approximation (RMSEA) accounts for the error of approximation in the population. An RMSEA of less than .08, and a $p$-value for the test of closeness of fit for the RMSEA of greater than .50 were used to indicate model fit. The weighted root mean square residual (WRMR) measures the weighted average differences between the sample and estimated population variances and covariances and is suited for categorical data (Yu \& Muthen, 2002; Finney \& Distefano, 2006). A WRMR of less than .90 was used to indicate model fit, with smaller values indicating better fit.

The overall chi square test of model fit of the evaluation model was statistically non-significant, $\chi^{2}(10)=3.638, p=.96$. The RMSEA was .00 . WRMR was .299 . The CFI was 1.00. Thus, fit indices were consistent with good model fit. The model in Figure 6 presents only statistically significant paths for visual clarity, while Tables 4 and 5 present the parameter estimates for the major analyses. 
Figure 6: OM Model Results

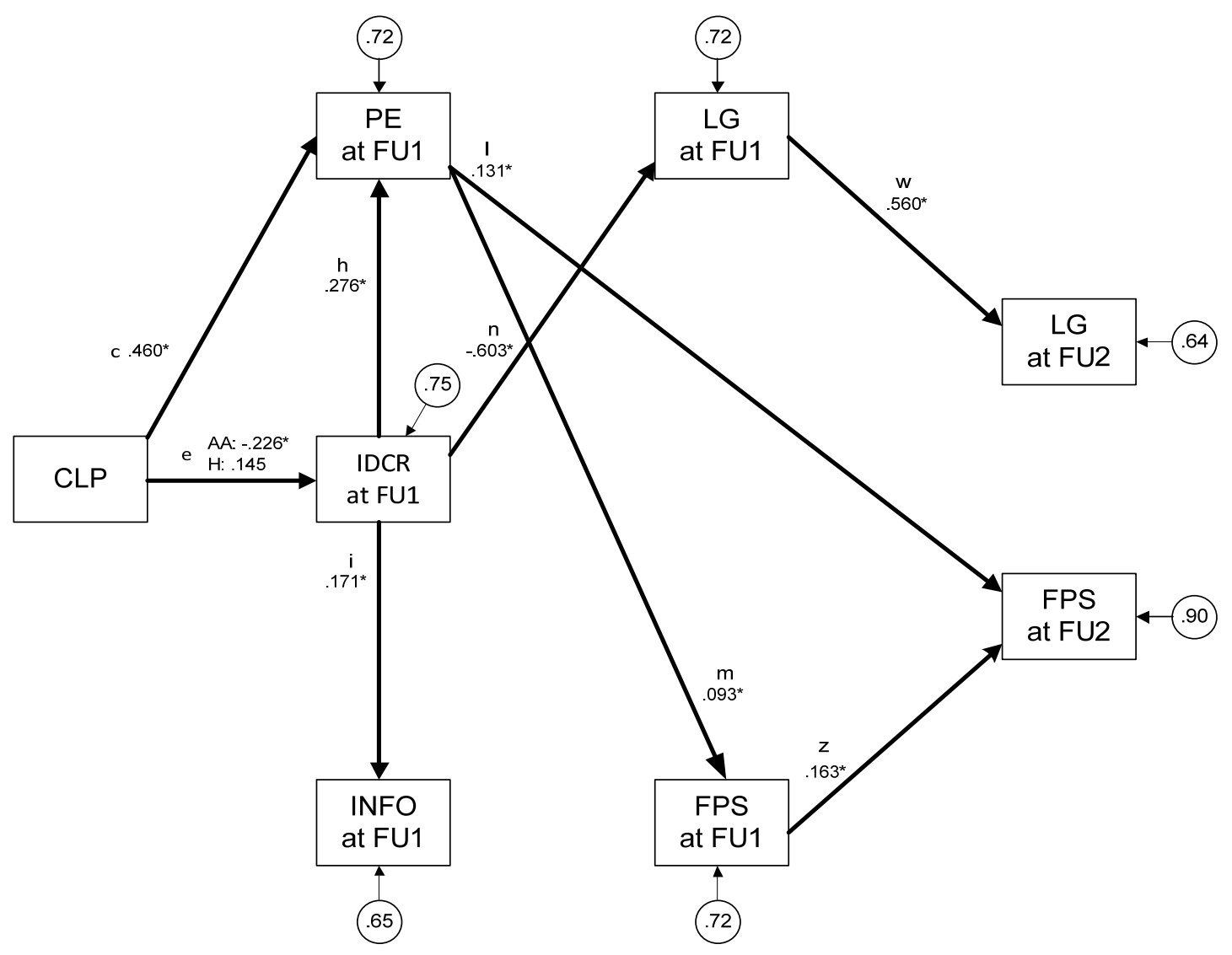

Hypothesized Direct and Moderated Intervention Effects

Following the logic of Rausch, Maxwell, and Kelly (2003), the scores of the baseline measures $\left(\mathrm{PE}_{1}, \mathrm{IDCR}_{1}, \mathrm{INFO}_{1}, \mathrm{LG}_{1}, \mathrm{FPS}_{1}\right)$ were used for the analysis of covariance of a quasi-experimental outcome design with two waves of assessments for the mediators (BL, FU1) and three waves of assessments for the outcome variables to evaluate whether participation in the CLP was associated with change in IDCR, PE, INFO, LG, and FPS relative to the comparison control condition. Specifically, CLP was defined as a two-valued dummy variable (scored 1 or 0 ) for the two intervention conditions (CLP vs. comparison control). By design, difference in this variable was hypothesized to be related to differential outcome (change in $\mathrm{IDCR}_{1}, \mathrm{PE}_{1}, \mathrm{INFO}_{1}, \mathrm{LG}_{1}$, 
$\left.\mathrm{FPS}_{1}\right)$ at FU1 (IDCR $\left.2, \mathrm{PE}_{2}, \mathrm{INFO}_{2}, \mathrm{LG}_{2}, \mathrm{FPS}_{2}\right)$ and related to differential outcome (change in LG and FPS) at FU2 ( $\mathrm{LG}_{3}$ and $\left.\mathrm{FPS}_{3}\right)$ controlling for BL $\left(\mathrm{IDCR}_{1}, \mathrm{PE}_{1}, \mathrm{INFO}_{1}\right.$, $\left.\mathrm{LG}_{1}, \mathrm{FPS}_{1}\right)$. The hypothesized differences were evaluated using covariate-adjusted change in which the measure of the outcome at BL and the outcome at the FU1 and FU2 are strategically used as covariates to define different features of change (Rausch et al., 2003).

As can be seen from Figure 6 and Table 4, the pattern of findings provided evidence of a significant relationship between CLP and change in PE (path $\mathrm{c} ; \beta=.460, p$ $<.01,95 \% \mathrm{CI}=.115$ to .840$)$. Results also indicated that the direct relationship between CLP and change in IDCR (path e) was significant. Specifically, the path coefficient for the relationship between CLP and change in IDCR was statistically significant, but the relationship was moderated by ethnicity, indicating a moderated specificity of effect. The 2-way CLP x Ethnicity (CLP*E) interaction term had a statistically significant coefficient when predicting change in IDCR (path $\mathrm{e} ; \beta=.344, p=.037,95 \% \mathrm{CI}=.021$ to .666 ), indicating that intervention change in IDCR differed between ethnic groups. Among Hispanic participants, the path coefficient for the relationship between CLP and change in IDCR was not significant (path $\mathrm{e} ; \beta=.145, p=.15,95 \% \mathrm{CI}=-.060$ to .394 ). Among African American participants, the path coefficient was significant (path e; $\beta=-.226, p=$ $.02,95 \% \mathrm{CI}=-.422$ to -.031 ), indicating that the intervention group decreased in IDCR relative to the comparison control group. As can be seen from Figure 6, the pattern of findings also did not provide evidence of significant relationships between CLP and changes in informational identity processing style and the positive outcome variables (LG and FPS). 
Table 4: Summary of Major Path Analyses for Mediators

\begin{tabular}{|c|c|c|c|c|}
\hline Outcomes & Predictors & Path coefficient & P-value & $95 \% \mathrm{CI}$ \\
\hline \multirow[t]{5}{*}{$\mathrm{IDCR}_{2}$} & CLP*E & $.344(.563)$ & .037 & .021 to .666 \\
\hline & CLP - Hispanic (path e) & $.145(.284)$ & .150 & -.060 to .394 \\
\hline & CLP - African American & $-.266(-.377)$ & .020 & -.422 to -.031 \\
\hline & (path e) & & & \\
\hline & Age & $-.035(-.064)$ & .397 & -.115 to .046 \\
\hline \multirow[t]{4}{*}{$\mathrm{PE}_{2}$} & CLP (path c) & $.460(.316)$ & .009 & .115 to .840 \\
\hline & $\mathrm{IDCR}_{2}$ (path h) & $.276(.114)$ & .020 & .043 to .509 \\
\hline & $\mathrm{INFO}_{2}$ & $.720(.260)$ & .451 & .261 to 1.178 \\
\hline & Age & $.062(.047)$ & .405 & -.084 to .209 \\
\hline \multirow[t]{4}{*}{$\mathrm{INFO}_{2}$} & CLP & $.077(.072)$ & .344 & -.082 to .235 \\
\hline & $\mathrm{IDCR}_{2}$ (path i) & $.171(-.304)$ & .003 & -.119 to .059 \\
\hline & $\mathrm{PE}_{2}$ & $-.018(.160)$ & .789 & -.153 to .116 \\
\hline & Age & $-.017(-.036)$ & .551 & -.074 to .040 \\
\hline
\end{tabular}

Note. Standardized coefficients shown in parentheses.

Hypothesized Moderated Mediation of Positive Outcomes

The relationship between $\mathrm{IDCR}_{2}, \mathrm{PE}_{2}, \mathrm{INFO}_{2}$ on $\mathrm{LG}_{2}$ and $\mathrm{LG}_{3}$ and on $\mathrm{FPS}_{2}$ and $\mathrm{FPS}_{3}$ was modeled using the latent response formulation for categorical outcomes as implemented in Mplus 5.0 with the WLSMV estimator (Muthen \& Muthen, 1998-2007). This approach models the observed categorical response variable as the realization of a latent continuous response variable. Specifically, the observed ordinal value changes when a probit threshold is exceeded on the latent continuous variable (Muthen, 1998- 
2007). In the case of the dichotomous LG variable, there is a single probit threshold for the latent continuous variable such that $\mathrm{LG}=1$ (Personally Expressive) when this threshold is exceeded and LG $=0$ (Non-personally Expressive) when the threshold is not exceeded. The probit regression coefficients generated by the analysis were interpreted in terms of probability units (i.e., probits) and reflect the relationship between a one unit change in a mediator and the probability that $\mathrm{LG}=1$ (see Agresti, 2007). Findings indicated that change in $\mathrm{IDCR}_{2}$ as a moderated mediator of the relationship between CLP and changes in $L G$ was significantly associated with the probit of change in $\mathrm{LG}_{2}$ (path $\mathrm{n}$; $\beta=-.603, p<.01,95 \% \mathrm{CI}=-1.057$ to -.148$)$ and that $\mathrm{IDCR}_{2}$ was not significantly associated with the probit of change in $\mathrm{LG}_{3}(\beta=-.304, p=.154,95 \% \mathrm{CI}=-.722$ to .114$)$. The relationship between $\mathrm{PE}_{2}$ on $\mathrm{LG}_{2}$ and $\mathrm{LG}_{3}$ was modeled in the same manner; change in $\mathrm{PE}_{2}$ was not significantly associated with the probit of change in $\mathrm{LG}_{2}(\beta=.144, p=$ $.119,95 \% \mathrm{CI}=-.037$ to .325$)$ and $\mathrm{LG}_{3}(\beta=-.099, p=.479,95 \% \mathrm{CI}=-.372$ to .175$)$. The relationship between $\mathrm{INFO}_{2}$ on $\mathrm{LG}_{2}$ and $\mathrm{LG}_{3}$ was modeled in the same manner; change in $\mathrm{INFO}_{2}$ was not significantly associated with the probit of change in $\mathrm{LG}_{2}(\beta=.055, p=$ $.828,95 \% \mathrm{CI}=-.439$ to .549$)$ and $\mathrm{LG}_{3}(\beta=.042, p=.930,95 \% \mathrm{CI}=-.902$ to .987$)$.

In the case of the dichotomous FPS variable, there is a single probit threshold for the latent continuous variable such that FPS $=1$ (Actualizing) when this threshold is exceeded and FPS $=0$ (Non-Actualizing) when the threshold is not exceeded. The probit regression coefficients generated by the analysis were interpreted in terms of probability units (i.e., probits) and reflect the relationship between a one unit change in a mediator and the probability that FPS $=1$ (see Agresti, 2007). Findings indicated that change in 
$\mathrm{IDCR}_{2}$ was not significantly associated with the probit of change in $\mathrm{FPS}_{2}(\beta=.238, p=$ $.228,95 \% \mathrm{CI}=-.149$ to .625$)$ and $\mathrm{FPS}_{3}(\beta=-.053, p=.811,95 \% \mathrm{CI}=-.482$ to .377$)$.

The relationship between $\mathrm{PE}_{2}$ on $\mathrm{FPS}_{2}$ and $\mathrm{FPS}_{3}$ was modeled in the same manner; change in $\mathrm{PE}_{2}$ was significantly associated with the probit of change in $\mathrm{FPS}_{2}$ (path $\mathrm{m} ; \beta=$ $.093, p=.020,95 \% \mathrm{CI}=-.050$ to .236 ) and $\mathrm{FPS}_{3}$ (path $1 ; \beta=.131, p=.026,95 \% \mathrm{CI}=-$ .285 to .023 ). The relationship between $\mathrm{INFO}_{2}$ on $\mathrm{FPS}_{2}$ and $\mathrm{FPS}_{3}$ was modeled in the same manner; change in $\mathrm{INFO}_{2}$ was not significantly associated with the probit of change in $\mathrm{FPS}_{2}(\beta=-.090, p=.618,95 \% \mathrm{CI}=-.443$ to .263$)$ and $\mathrm{FPS}_{3}(\beta=.121, p=.655,95 \%$ $\mathrm{CI}=-.409$ to .651$)$.

Table 5: Major Analysis of Positive Outcomes

\begin{tabular}{|c|c|c|c|c|}
\hline Outcomes & Predictors & Path coefficient & P-value & $95 \% \mathrm{CI}$ \\
\hline \multirow[t]{5}{*}{$\mathrm{LG}_{2}$} & CLP & $-.187(-.160)$ & .772 & -1.458 to 1.083 \\
\hline & $\mathrm{IDCR}_{2}$ (path n) & $-.603(-.310)$ & .009 & -1.057 to -.148 \\
\hline & $\mathrm{INFO}_{2}$ & $.055(.025)$ & .828 & -.439 to .549 \\
\hline & $\mathrm{PE}_{2}$ & $.144(.180)$ & .119 & -.037 to .325 \\
\hline & Age & $.302(.285)$ & .086 & -.043 to .648 \\
\hline \multirow[t]{6}{*}{$\mathrm{LG}_{3}$} & CLP & $.201(.162)$ & .875 & -2.301 to 2.704 \\
\hline & $\mathrm{IDCR}_{2}$ & $-.304(-.147)$ & .154 & -.722 to .114 \\
\hline & $\mathrm{INFO}_{2}$ & $.042(.018)$ & .930 & -.902 to .987 \\
\hline & $\mathrm{PE}_{2}$ & $-.099(-.116)$ & .479 & -.372 to .175 \\
\hline & $\mathrm{LG}_{2}$ (path w) & $.560(.529)$ & .035 & .168 to .952 \\
\hline & Age & $.027(.024)$ & .941 & -.693 to .747 \\
\hline
\end{tabular}




\begin{tabular}{|c|c|c|c|c|}
\hline \multirow[t]{5}{*}{$\mathrm{FPS}_{2}$} & CLP & $-.010(-.200)$ & .975 & -.673 to .652 \\
\hline & $\mathrm{IDCR}_{2}$ & $.238(.122)$ & .228 & -. 149 to .625 \\
\hline & $\mathrm{INFO}_{2}$ & $-.090(-.040)$ & .618 & -.443 to .263 \\
\hline & $\mathrm{PE}_{2}$ (path m) & $.093(.115)$ & .020 & .050 to .236 \\
\hline & Age & $.000(.000)$ & .999 & -.211 to .211 \\
\hline \multirow[t]{6}{*}{$\mathrm{FPS}_{3}$} & CLP & $-.129(-.124)$ & .699 & -.781 to .523 \\
\hline & $\mathrm{IDCR}_{2}$ & $-.053(-, 030)$ & .811 & -.482 to .377 \\
\hline & $\mathrm{INFO}_{2}$ & $.121(.061)$ & .655 & -.409 to .651 \\
\hline & $\mathrm{PE}_{2}$ (path 1) & $.131(-.182)$ & .026 & -. 285 to .023 \\
\hline & $\mathrm{FPS}_{2}$ (path z) & $.163(.182)$ & .043 & -.046 to .372 \\
\hline & Age & $-.024(-.025)$ & .825 & -.237 to .189 \\
\hline
\end{tabular}

Note. Standardized coefficients shown in parentheses.

Hypothesized Mediation Among Mediators

Findings provided support for IDCR as a plausible moderated mediator of the relationship between CLP and change in PE and between CLP and change in INFO. Findings indicated that BL to FU1 change in IDCR was associated with contemporaneous change in PE (path $\mathrm{h} ; \beta=.276, p=.02,95 \% \mathrm{CI}=.043$ to .509 ) and contemporaneous change in INFO (path $\mathrm{i} ; \beta=.171, p<.01,95 \% \mathrm{CI}=-.119$ to .059 ).

Hypothesized Reciprocal Relationships

As mentioned above, little is known regarding the possible relationship between the categories identified from participant's narrative expressions of their most important life goal and future possible self; the evaluation model thus hypothesized a reciprocal relationship between the two positive outcomes at follow-up 1 and at follow-up 2 . The 
model was drawn and as such no significant relationship was detected. The analysis also investigated directional effects between the categories identified from participant's narrative expressions of their most important life goal and future possible self and again no results were detected. Any directional effect was omitted from the evaluation model. Hypothesized Lag Effects

With respect to the evaluation of intervention lag effects across positive outcome domains, the evaluation model hypothesized that intervention change in positive identity outcomes at follow-up 1 will be associated with the change from a non-personally expressive life goal to a personally expressive life goal at follow-up 2 and with change from a Non-Actualizing future possible self at follow-up1 to an actualizing future possible self at follow-up 2. As can be seen by Figure 6 and Table 5, findings indicated that change in $\mathrm{LG}_{2}$ was significantly associated with the probit of change in $\mathrm{LG}_{3}$ (path w; $\beta=.560, p=.035,95 \% \mathrm{CI}=.168$ to .952$)$ and that $\mathrm{FPS}_{2}$ was significantly associated with the probit of change in $\mathrm{FPS}_{3}$ (path $\mathrm{z} ; \beta=.163, p=.043,95 \% \mathrm{CI}=-.046$ to .372 ). Qualitative Change in Life Goal and Future Possible Self: Fine-grained Analyses Because of the large proportion (75\%) of participants with a self satisfying life goal at baseline, Eichas, 2010, performed finer-grained analyses of the relationship between CLP and LG at FU1 (see Figure 1). Eichas, 2010 utilized limited information tests of conditional independence for CLP and LG at FU1 and found that this relationship was not significant for participants with a non-personally expressive life goal at BL $\left(\chi^{2}(1)\right.$ $=.487, p=.49 ; p=.56$, Fisher's exact test, $95 \% \mathrm{CI}=.397$ to 7.253 ), or for those with a personally expressive life goal at BL ( $p=1.00$, Fisher's exact test, $95 \% \mathrm{CI}=.092$ to $10.881)$. 
However, Eichas, 2010, did find that the CLP was significantly associated with LG at FU1 among participants with a self satisfying life goal at BL $\left(\chi^{2}(1)=4.925, p=\right.$ $.03 ; p=.04$, Fisher's exact test, $95 \% \mathrm{CI}=1.001$ to $\infty$ ). Eichas 2010 , concluded that this reflects primarily that, among participants with a self satisfying life goal at BL, CLP participants' responses at FU1 were more likely to have the personally expressive property than expected and that comparison control participants' responses at FU1 were less likely to have the personally expressive property than expected. Of the 66 comparison control group participants with a self satisfying life goal at BL, zero described life goals at FU1 with the personally expressive property. Of the 98 CLP participants with a self satisfying life goal at BL, seven described life goals at FU1 with the personally expressive property (see Table 6).

Table 6: Frequencies of Change in Self Satisfying Life Goals

\begin{tabular}{cccc}
\hline \multicolumn{5}{c}{ Life Goal at FU1 } \\
\hline Condition & Non-Personally Expressive & Personally Expressive & Total \\
\hline Ctrl & 66 & 0 & 66 \\
CLP & 91 & 7 & 98 \\
\hline & 157 & 7 & 164
\end{tabular}

As a result of the report by Eichas (2010) the current study performed finergrained analyses of the relationship between CLP and LG at FU2. In addition, the same analysis was performed to evaluate the relationship between CLP and FPS at FU1 and FU2. The current study utilized limited information tests of conditional independence for these analyses. 
The current study extended the analysis by Eichas (2010), by including LG at FU2 in order to investigate the effects of the CLP on LG at FU2. The current study found that this relationship was not significant for participants with a non-personally expressive life goal at BL $\left(\chi^{2}(1)=.679, p=.410\right.$, Fisher's exact test, $95 \% \mathrm{CI}=.493$ to .315$)$, or for those with a personally expressive life goal at $\mathrm{BL}\left(\chi^{2}(1)=.300, p=.584\right.$, Fisher's exact test, $95 \% \mathrm{CI}=1.00$ to .576 ). In addition, the current study also found that the CLP was not significantly associated with LG at FU2 among participants with a self satisfying life goal at BL $\left(\chi^{2}(1)=.281, p=.596\right.$, Fisher's exact test, $95 \% \mathrm{CI}=.608$ to .395$)$.

As a result of the large proportion (51\%) of participants with a self satisfying future possible self at baseline, the current study performed finer-grained analyses of the relationship between CLP and FPS at FU1. The analysis found that this relationship was not significant for participants with a Non-Actualizing future possible self at BL $\left(\chi^{2}(1)=\right.$ $.003, p=.96$, Fisher's exact test, $95 \% \mathrm{CI}=1.000$ to .561$)$, or for those with an actualizing future possible self at $\mathrm{BL}\left(\chi^{2}(1)=.102, p=.75\right.$, Fisher's exact test, $95 \% \mathrm{CI}=$ .799 to .479$)$. The analysis also found that the CLP was not significantly associated with FPS at FU1 among participants with a self satisfying future possible self at BL $\left(\chi^{2}(1)=\right.$ $2.315, p=.128$., Fisher's exact test, $95 \% \mathrm{CI}=.142$ to .089 ).

The current study also performed finer-grained analyses of the relationship between CLP and FPS at FU2. The analysis found that this relationship was significant for participants with a Non-Actualizing future possible self at BL $\left(\chi^{2}(1)=5.750, p<\right.$ $.001)$, and not significant for those with an actualizing future possible self at BL $\left(\chi^{2}(1)=\right.$ $.194, p=.66$, Fisher's exact test, $95 \% \mathrm{CI}=.800$ to .428 ). The analysis also found that the CLP was significantly associated with FPS at FU1 among participants with a self 
satisfying future possible self at BL $\left(\chi^{2}(1)=4.892, p=.02\right.$., Fisher's exact test, $95 \%$ CI $=.050$ to .023$)$.

Although no significant relationships were detected with FPS at FU1, the results detected with FPS at FU2, primarily reflect that, among participants with a self satisfying future possible self at BL, CLP participants' responses at FU2 were more likely to have the self actualizing property than expected and that comparison control participants' responses at FU2 were less likely to have the self actualizing property than expected. Of the 13 comparison control group participants with a self satisfying future possible self at $\mathrm{BL}$, zero described future possible selves at FU2 with the self actualizing property. Of the 53 CLP participants with a self satisfying future possible self at BL, twelve described future possible selves at FU2 with the self actualizing property (see Table 7). Table 7: Frequencies of Change in Self Satisfying Future Possible Selves

\section{Future Possible Self at FU2}

\begin{tabular}{rccc}
\hline Condition & Non-Self Actualizing & Self Actualizing & Total \\
\hline Ctrl & 13 & 0 & 13 \\
CLP & 41 & 12 & 53 \\
\hline & 54 & 12 & 66
\end{tabular}




\section{DISCUSSION}

This study had three main research aims. The first research aim was to investigate CLP intervention effectiveness in promoting positive change in emotion-focused and cognitively-focused identity exploration processes and level of identity conflict resolution as further evidence for empirical utility of the Self-Transformative Development (STD) model of identity development (Albrecht, 2007). The second research aim was to investigate intervention change in identity processes as mediators of intervention change in subjective sense of self and identity. The third aim was to further evaluate the utility of the RDA framework for investigating differential intervention change in sense of self and identity through examination of narrative expressions of subjective meaning and significance of participant's sense of self and identity as an outreach research methodology.

Research Aim 1: Promoting Emotion-Focused and Cognitively-Focused Identity Exploration Processes

With respect to the first research aim, the results of this study provided support for the hypothesis that participation in the CLP's intervention was differentially associated with statistically significant differences between intervention and control conditions in change in level of identity conflict resolution and feelings of personal expressiveness from pre- to post-test, but not significantly associated with informational identity processing style. The results also indicated statistically significant moderation of intervention effects on level of identity resolution by ethnicity. In addition, the results also found significant directionality of change between level of identity conflict 
resolution, informational identity processing style, and feelings of personal expressiveness.

\section{Feelings of Personal Expressiveness}

Participation in the intervention condition was found to have a statistically significant association with positive change in PE (see Figure 6) relative to the control condition. Gender, age, and ethnicity were not significant moderators of differential change. These findings suggest that alternative high school students in Miami may experience a decrease in feelings of personal expressiveness (Eichas, 2010), and that participation in the CLP intervention is associated with an increase in personal expressiveness. As such, these findings appear to be consistent with those of previous CLP stage II evaluation studies (Eichas, 2008), in suggesting that participation in the CLP may not only protect against declines in feelings of personal expressiveness but actually promotes personal expressiveness.

Identity Conflict Resolution

A statistically significant condition $\mathrm{x}$ ethnicity interaction was found to moderate change in IDCR (see Figure 6). Among Hispanic participants, participation in the intervention condition was associated with a non-significant increase in IDCR relative to participation in the control condition (path $=.150, p=.150)$. Among African-American participants, in contrast, the effect of condition on IDCR (path e $=-.266, p<.020$ ) was significant. That is, African-American intervention group participants decreased .266 units relative to African-American control group participants, $p<.020$. These findings suggest that within some subgroups, namely African-American participants, the CLP 
intervention may be associated with a decrease in the resolution of identity conflict levels of identity resolution.

\section{Mediation of Mediators}

Consistent with previous research (Eichas, 2010), PE was found to increase as IDCR decreased (path $\mathrm{h}=.276, p=.02$ ). The relationship between increasing levels of identity conflict and increasing personal expressiveness of life goal activities may further suggest that decreases in psychosocial conflict resolution facilitate self-discovery by allowing individuals to focus more time and energy on the affective exploration of life goal-related activities and less time and energy on resolving the conflicts themselves (Eichas, 2008). The nature of the identity conflict that is being resolved or left unresolved is of particular interest. As noted, for adolescents who live in disempowering lowincome, urban community contexts and often are exposed to daily violence, crime, and substance abuse (Berman, Kurtines, Silverman, \& Serafini, 1996), identity conflict may be particularly severe. Indeed, one third of CLP participants experience moderate, severe, or very severe upset, distress, and/or worry associated with long-term goals, career choices, friendships, sexual orientation and behavior, religion, values and beliefs, and group loyalties (Hernandez, Montgomery, \& Kurtines, 2006).

Consistent with previous research (Eichas et al. 2010), INFO was found to increase as IDCR decreased (path $i ; \beta=.171, p<.01$ ). Thus, level of identity conflict resolution may be predictive of an individual's orientation toward information-seeking in their cognitive exploration of identity alternatives. Further, this finding suggests that cognitive identity exploration may be influenced by change in identity-related conflict, and the resolution of this conflict (Eichas, 2008), as previously found. Albrecht (2007) 
emphasized the role of the particular developmental challenges faced by the individual as an important influence on the degree of cognitive and affective exploration undertaken at any particular time. It is plausible that the challenge of resolving identity-related conflict may play a role in shaping the balance of cognitive and affective exploration at any particular time (Eichas, 2008).

Directionality of Effects

The current study's findings are indicative of a relationship between selfconstruction and self-discovery processes and levels of psychosocial identity conflict resolution in at-risk adolescents. Previous research has generated empirical evidence suggesting that self-construction processes are amenable to change through cognitivelyfocused intervention strategies and that self-discovery processes are amenable to change through emotion-focused intervention strategies (Schwartz et al, 2005). The results of the present study suggest that CLP intervention may have an effect on both self-construction and self-discovery processes. Thus, in not limiting itself to cognitively-focused strategies or emotion-focused strategies, the CLP's person-centered participatory transformative approach may have the advantage of having a greater impact on both types of identity exploration (Eichas, 2008). In addition, the results also provide empirical evidence that suggests that self-transformative identity development intervention strategies demonstrate effectiveness in promoting both emotion-focused identity exploration and cognitivelyfocused identity exploration in adolescent youth. 


\section{Research Aim 2: Mediation of Positive Outcomes}

The second research aim was to investigate intervention change in identity processes as mediators of intervention change in subjective sense of self and identity. Two of these factors were found to moderate positive intervention outcomes.

Engagement in identity crisis, personally expressiveness, and an informational identity style were conceptualized as mediators of change in both positive outcomes. The results yielded significant relationships of meditational change between PE and FPS and IDCR and LG. Specifically, the results indicated that participation in the CLP was associated with a BL to FU1 decrease in identity conflict resolution among African American participants, relative to the comparison control group, but not among Hispanic participants. Results further indicated that BL to FU1 change in identity conflict resolution was associated with BL to FU1 change in the probability of a personally expressive life goal. Thus, the findings provided support for identity conflict resolution as a moderated mediator of contemporaneous changes in the probability of a personally expressive life goal (CLP $\rightarrow \mathrm{IDCR}_{2} \rightarrow$ Life Goal 2 ; path e, $\left.\mathrm{n}\right)$.

The results also yielded significant indications that participation in the CLP was associated with BL to FU1 increase in personal expressiveness. Results further indicated that BL to FU1 change in personal expressiveness was associated with BL to FU1 change in the probability of an actualizing future possible self at FU1 and FU2. Thus, the findings provided support for personal expressiveness as a mediator of changes in the probability of an actualizing future possible self $\left(\mathrm{CLP} \rightarrow \mathrm{IDCR}_{2} \rightarrow \mathrm{FPS}_{2}\right.$; path $\left.\mathrm{m}\right)$ and $\left(\mathrm{CLP} \rightarrow \mathrm{IDCR}_{2} \rightarrow \mathrm{FPS}_{3}\right.$; path 1$)$. 
The current findings further contribute to closing the gap in our knowledge of the relationship between the CLP's intervention on promoting positive identity development and intervention change in positive outcomes. The results provide preliminary evidence consistent with the hypothesis that PYD interventions are likely to have mediated effects on positive outcomes through the specific targeting of identity processes. The pattern of findings also provide consistency with the idea that the causal effects that are generated for intervention outcomes are likely to follow multifaceted pathways that interact in complex ways with moderator and mediator variables rather than solely flowing directly from intervention to positive outcomes (direct effects).

Research Aim 3: The Utility of RDA

As noted, the findings provided evidence that the intervention had a mediated effect on qualitative change in participants' most important life goals (from a nonpersonally expressive life goal to a personally expressive life goal) and participants' most important future possible self (from a non-actualizing future possible self to an actualizing future possible self) that operated through changes in identity conflict resolution and feelings of personal expressiveness. As previously noted, the use of complementary qualitative free-response measures and quantitative fixed response measures in DIS outreach research effectively expands the scope of intervention outcome investigation beyond the examination of properties identified as theoretically meaningful prior to conducting the research, i.e., as is usually done under cross-sectional and longitudinal quantitative research and "efficacy" research designs using fixed response measures (Eichas, 2010). All of these pathways would have been un-hypothesized (and therefore undetected) without the use of qualitative free response methods because it was 
only through the use of RDA coding procedures that conceptually and theoretically meaningful properties were detected and identified, of which were found to be statistically significantly associated with participation in the CLP intervention.

Although the process of the construction and discovery of self and identity has many quantifiable dimensions, there are both strengths and limitations to a quantitative approach using fixed-response quantitative measures. The development and refinement of a relatively straightforward, standardized, and reliable method that can be used to add a free response qualitative component to the full range of fixed response quantitative measures currently used to assess core developmental concepts and constructs offers an approach to advancing the unification of qualitative and quantitative methods that appears promising. Specifically, the potential that the emergence of ready at hand methods for capturing unique or newly emergent structural organizational properties of free response data for advancing a theoretically and empirically meaningful fusion of quantitative and qualitative methods has the potential for make an important contribution to the unification of two historically split methodological meta-theoretical traditions (Overton, 1998). Specifically, to begin to address the conceptual and empirical limitations of their "mixed" use of qualitative and quantitative methods because of the essential differences rather than the conceptual and empirical advantages of their "unified" use because of their essential complementarity.

The current study also made it possible to integrate theoretically meaningful narrative descriptions of the subjective meaning and significance of the content properties of life course experiences derived via open-ended free response methods and theory driven dimensional variation in the content properties of identity formation processes 
derived via theory driven fixed response methods in the analysis (e.g. self-construction, self-discovery). Specifically, RDA provided a ready-at-hand framework for unifying data analytic strategies across both dimensions of analysis (quantitative, qualitative) and phases of analyses (conceptual, theoretical, and research analyses). Specifically, this study modeled the PEAQ-QE and PSQ-QE within a previous model theoretically and empirically informed by descriptions of the relationship between how self-construction and self-discovery relate in the identity formation literature. Although this relationship has been investigated in the past, the use of a qualitative measure within an investigation of how self-construction relates to self-discovery in the current study facilitated detecting and evaluating response properties that are uniquely meaningful within the population of interest.

Identification of Theoretically Meaningful Properties

The current study utilized RDA's reversible movement (see RDA description above), to modify Kortsch's et al., (2008) structural model that resulted from the need to conceptualize the structural model of participant's future possible self in a manner consistent with the current study's research aims. RDA's reversible movement in the current study was a first attempt, in the investigation of the CLP, to utilize this methodological process. The utilization of this method with a larger more inclusive sample, contributed to the empirical findings of this study by facilitating the detection and identification of properties (both ordinary language and theoretically meaningful) of participants' future possible selves previously not detected in the smaller sample used by Kortsch's et al., (2008). 
The present study also further, contributed to RDA by using SEM to investigate specific hypotheses regarding how change in the properties of life goals and future possible selves occurs. The findings regarding the unique identifying property of the Self Satisfying subcategory in both qualitative extensions further illustrate the contribution made by this approach. Specifically, a central finding of this study was that participation in the CLP was significantly associated with change with change from a Non-Actualizing future possible self to an Actualizing future possible self among participants whose narrative/linguistic expressions were assigned to the Self Satisfying subcategory at baseline.

Identification of Theoretically Meaningful Relationships

An additional contribution of the use of qualitative free response measures in intervention outcome research is an increased likelihood of identifying more complete and empirically supported theory informed models of intervention change during adolescence that include hypotheses regarding the relationship between dimensional (quantitative) change in properties identified as theoretically meaningful by previous research and change in properties that theory-laden coders agree is theoretically meaningful within the specific sample under investigation (Eichas, 2010). For example, previous research (Eichas et al., 2010) has reported intervention decreases in identity conflict resolution, but the meaning of this finding has been unclear. One possible interpretation by Eichas et al., (2010) for this finding is that the intervention under investigation had a deleterious effect on the participants by increasing identity conflict. This interpretation would be consistent with the idea that a positive outcome for an intervention that targets positive identity formation would be the resolution of identity 
crisis and cessation of identity exploration (Eichas et al., 2010). An alternative interpretation is that the intervention had a positive effect on the participants by increasing identity conflict, an interpretation that would be consistent with at least some perspectives within the identity literature on how the identity process begins (e.g., Bosma \& Kunnen, 2001, Eichas et al., 2010).

Consistent with Eichas et al., (2010) the current study found that identity conflict resolution and the probability of a personally expressive life goal were related. Consistent with perspectives within the identity literature that conceptualize identity conflict as the “starting point" for increased identity processing (Bosma \& Kunnen, 2001), these findings suggest that an increase in identity conflict (i.e., decrease in IDCR) predicts a greater probability that participants' most important life goals change from nonpersonally expressive to personally expressive (Eichas, 2010). That is, while there may be benefits of decreased identity conflict, at least in the short-term, there are also likely important long-term benefits of increased identity conflict (or of the contextual conditions that facilitate identity conflict), such as the increased likelihood of conceptualizing, or perhaps re-conceptualizing, long-term life goals in a qualitatively more integrated manner (Eichas, 2010). This interpretation and relationship would not have been possible without the RDA's ability of detecting and evaluating relationships between dimensional (quantitative) changes in properties identified as theoretically meaningful by previous research and change in properties that theory-laden coders agree is theoretically meaningful within the specific sample under investigation.

The current study's finding on future possible selves also provides evidence for an increased likelihood of identifying more complete and empirically supported theory 
informed models of intervention change. Although contrary to the hypothesis, the results yielded no significant relationships between life goals and future possible selves, the results did find significant relationships between personal expressiveness and future possible selves. Specifically, that personal expressiveness and the probability of an Actualizing future possible self are related (i.e., an increase in personal expressiveness was significantly associated with an increased probability of an Actualizing future possible self). As noted above, Non-Actualizing possible selves lack a specific reference to a striving beyond gratification or direct reinforcement and make no reference to a defined purpose in living. As proposed by Albrecht (2007) individuals with this future possible self might be presumed to score low on feelings of personal expressiveness while engaging in activities necessary to achieve that goal. In terms of developing a positive sense of identity, personally expressive individuals may conceptualize their future in terms of fulfillment of known interests, strengths, and potentials thus increasing the potential for continued positive development into the future, whereas less personally expressive individuals may conceptualize their future self in terms of hedonic pleasure or extrinsic reward (Self-Satisfying), potentially limiting future growth. This previously proposed interpretation of the possible relationship between personal expressiveness and future possible self was, at the time, unable to be evaluated. The current study's findings provide insight into this issue that was previously unavailable by Albrecht (2007). It is now possible to interpret the relationship between personal expressiveness and future possible self as originally proposed by Albrecht (2007) due to RDA's ability of detecting and evaluating relationships properties identified as theoretically meaningful by previous research or current research, as is the case in the current study's refinement of the future 
possible self structural organization in Kortsch et al. (2008) and change in properties that theory-laden coders agree is theoretically meaningful within the specific sample under investigation.

\section{Study Limitations}

Missing Data and Participant Attrition

The alternative high schools from which the sample was drawn do not record their own attrition data (Albrecht, 2007), however, Miami-Dade County Public Schools (MDCPS) reports county-wide graduation rates of approximately $59 \%$ and an official dropout rate of 4.5\%. On-time graduation rates are reported at 45.3\% (Toppo, 2006). None of these figures account for students who are not officially withdrawn. Because little specific information is available regarding these students, it is possible that selection effects are potentially biasing results. Future YDP research should begin to address this issue.

Thus, the missing data found in the analyses may be associated with the nature of the population the intervention targets, i.e., a population composed of multi-problem adolescents in alternative high schools, many of whom are coming of age in disempowering contexts (Eichas, 2010). In order to allow the use of missing data in future models, researchers have a better understanding of the role that attrition plays in generating observed missing data patterns, as well as an understanding of the factors that contribute to participant attrition.

Measurement Error

The model analyzed in the present study also did not account for measurement error, in effect assuming no measurement error. Future studies should either use multiple 
indicators of the latent constructs included in the evaluation model or consider adopting the strategy suggested by Joreskog and Sorbom (1996) that involves depicting each measure as a single indicator of the associated underlying construct and constraining the error variances for each measure to values corresponding to a priori determined levels of reliability based on alpha coefficients or previous research (Eichas, 2010).

\section{Statistical Power and Sample Size Considerations}

To determine an appropriate sample size, structural equation modeling requires that in addition to statistical power, issues of the stability of the covariance matrix and the use of asymptotic theory be taken into account (Eichas, 2010). In the case of this study, with a sample of 259 used for the full information analyses, there was an effect on the statistical power available for analyses of the full model, especially with respect to analyses of dichotomous outcomes that require large sample sizes to capture the relationship, if any, between the independent and dependent variables, thereby increasing the likelihood of the occurrence of type II errors, i.e., the inability to detect small effects. The current study did use limited information strategies, however, according to Eichas (2010), these strategies are problematic in that they do not use all available information from the hypothesized model.

\section{Future Research Directions}

As noted, several directions for future research have been mentioned. Perhaps the most two important directions for future are the inclusion of additional theoretically meaningful qualitative indicates of subjective positive outcomes and problem outcomes in the evaluation of the CLP and the utilization of level 2 categories for the dimensionalization of the subjective experience of self and identity. 


\section{Problem Outcomes}

Drawing on the finding in the feasibility study (Eichas et al., 2010) that PYD intervention change is likely to follow complex pathways that interact in multifaceted ways with relevant moderator, mediator, and outcome variables, this study has retained both the outcome and mediation component of this model. However, this study has only extended features of the model to investigate the conditions under which the PYD intervention process generates intervention effects in positive developmental outcomes and did not investigated the conditions in which the PYD intervention process generates intervention $\leftrightarrow$ developmental $(\mathrm{I} \leftrightarrow \mathrm{D})$ cascade effects, i.e., spillover intervention effects across both positive and problem developmental outcomes (Eichas, 2010). For this study, only positive developmental outcome were investigated in the current study. Although, these findings make an initial contribution to closing the gap in our knowledge of the relationship between intervention change in positive outcomes, no relationship among the interaction of multiple positive developmental outcomes and problem developmental outcomes were investigated. As described by Garcia (2005), a review of the literature appears to indicate that youth development programs can promote positive domains of self-development and reduce negative outcomes, concurrently. Future research investigating the effects of the CLP should include multiple positive and problem outcomes within an outcome, mediation, cascade model to contribute to the evolution of more empirically supported theory informed models of both short and long-term developmental change. 


\section{Dimensionality of Theoretically Meaningful Properties}

The inclusion of a dichotomous outcome variable (a non-personally expressive versus a personally expressive life goal and a non-actualizing versus an actualizing future possible self) introduced a number of complications into the analysis of the evaluation model and required the use of a continuous latent response formulation (with probit thresholds and probit path coefficients) for categorical outcomes as implemented in Mplus (Eichas, 2010). Moreover, the dichotomous nature of this variable, that is, the assignment of the narrative/linguistic expressions of meaning and significance to either the Non-personally Expressive subcategory or the Personally Expressive subcategory and either the Non-Actualizing or the Actualizing subcategory, likely reflects a crude discretized measurement of a measurable continuous "personally expressive" or "actualizing" dimension (Eichas, 2010). That is, the unique identifying properties of the Non-Personally Expressive and Personally Expressive level 1 categories as well as the Non-Actualizing and Actualizing level 1 categories, vary in magnitude as seen by the level 2 categories.

The measurement of these categories used in this study, did not use a dimensionalization (i.e., level 2 categories) of the property, i.e., an assessment of the magnitude of the property (level 2 categories). Instead, the measurement simply documented the presence or absence of the property. Future RDA research on the subjective experience of self and identity should seek to dimensionalize (i.e., utilize level 2 categories) within an SEM research approach in order to capture, detect, and isolate the specific content and structural organizational properties that changed and increasing the 
probability of identifying (i.e., rendering explicit and intelligible) the meaning and significance of the changes.

\section{Conclusions}

A main contribution of this study was to further provide empirical evidence that self-transformative identity development intervention strategies demonstrate efficacy in promoting both emotion-focused and cognitive-focused identity exploration in adolescent youth. Albrecht (2007) proposed a Self-Transformative Model of Identity Development in which the adolescent's sense of self is hypothesized to be the direct result of both affective exploration for insight (self-discovery) and cognitive exploration of alternatives (self-construction), as well as contextual factors that may moderate identity processes. This study replicated previous findings that the CLP intervention resulted in increases in reported feelings of "fit" between intervention participants and their life goals-related activities and also found that the CLP intervention resulted in increased reported orientation toward seeking out and utilizing of self-relevant information when making identity-related decisions.

A second contribution of this study was to further demonstrate the integration of quantitative dimensional change and qualitative structural organizational change within a Relational Data Analysis framework using structural equation modeling techniques.

Although previous research has been conducted using an RDA/SEM research analyses by hypothesizing a path model and testing its fit to the data (Eichas, 2010), the current study was the first attempt at using multiple qualitative assessments of subjective sense of self and identity. This approach allowed the simultaneous modeling of multiple pathways of intervention change, including direct, mediated, and moderated effects. 
Findings suggested (1) that an increase in identity conflict was associated with a decreased probability of a personally expressive life goal; (2) that an increase in feelings of personal expressiveness generated by life goal pursuit was associated with an increased probability of an actualizing future possible self; and (3) that participation in the CLP was associated with change from a Non-Actualizing future possible self to an Actualizing future possible self among participants with a self satisfying future possible self at baseline evaluation.

The pattern of these findings likely reflects the complex and contingent nature of the systematic, successive, and adaptive developmental processes involved in constructing and re-constructing a positive sense of self and identity during initial stages of formation (Eichas, 2010). The pattern of these findings further highlights the need for methods of capturing the process of change at the individual level that have the capability of identifying and rendering explicit and intelligible the content, structure, and organization of the categories and properties of the subjective meaning and significance of participants' experiences of self and identity (Rinaldi et al., under review). One of the key aims of the CLP's program of research is to contribute to the evolution of new theory though the development and refinement of data analytic strategies such as RDA with the capability of capturing in the "raw" and in "real time" the leading edge of the meaning and significance of intervention, developmental, and historical change. Specifically, the current study sought to do so through the unified use of well-established qualitative research methods and procedures (e.g., open coding, theoretical sampling/saturation, etc.) and quantitative research methods and procedures. (Rinaldi, et al., under review). Moreover, because of the nature of the adolescent population, the CLP seeks to render 
RDA, a practical, ready-at-hand framework that developmental intervention scientist can use to address complex issues of documenting life course change that results from developmental interventions (e.g., positive youth development interventions) in real life “applied" settings as well as clinic and laboratory settings (see Kurtines, et al. 2008).

Relational Data Analysis has included the development and refinement of a core of qualitative measures intended for use in coding and classifying unstructured free response interview data that complements our core of structured self-report quantitative measures, including multiple indices of core psychosocial developmental concept and constructs related to the development of a positive sense of self and secure and consolidated sense of identity.

The analysis and results of the current study was an essential part of this process. The development and use of qualitative extensions enables the construction and evaluation of an array of developmentally appropriate unstructured response measures capable of capturing and evaluating change in the subjective meaning and significance of the life course experiences and intervention change of participants in positive developmental interventions.

As Rinaldi, et al., (under review) have noted, with respect to new directions for developmental science, there is an interest in contributing to in the analysis and interpretation of intervention, developmental, and contextual-historical change. With regards to change at the intervention and developmental level, RDA as a data analytic strategy and the CLP's work on the development of qualitative measures and methods capable of capturing and analyzing qualitative intervention and developmental change intersect with the broader interest of understanding contextual-historical change as 
reflected in changes in the linkages in subjective meaning and significance of life course experiences and observed human behavior in real world human ecologies, as these are interpreted by both the researcher and as interpreted by participants themselves. This study represents an attempt to contribute to the array of tools available in developmental intervention research and to identify potential directions for future use and further refinement of these tools. 


\section{REFERENCES}

Adams, G. R., \& Marshall, S. K. (1996). A developmental social psychology of identity: Understanding the person-in-context. Journal of Adolescence, 19, 429-442.

Agresti, A. (2007). An introduction to categorical data analysis ( $2^{\text {nd }}$ Edition). Hoboken, NJ: John Wiley.

Albrecht, R. E. (2005). An investigation of the effects of a school-based intervention on feelings of personal expressiveness in multi-problem youth. Unpublished Master's thesis. Florida International University, Miami.

Albrecht, R. E. (2007). A model of self-transformative identity development in troubled adolescent youth. Unpublished doctoral dissertation. Florida International University, Miami.

Archer, S. (Ed.) (1994). Interventions for Adolescent Identity Development. Thousand Oaks: Sage.

Arnett, J. J. (2000). Emerging adulthood: A theory of development from the late teens through the twenties. American Psychologist, 55(5), 469-480.

Arnett, J. J. (2004). Emerging adulthood: The winding road from the late teens through the twenties. New York: Oxford University Press.

Baumeister, R. F., Shapiro, J. J., \& Tice, D. M. (1985). Two kinds of identity crisis. Journal of Personality, 53, 407-424.

Benson, P. L., Scales, P. C., Hamilton, S. F., Sesma, A. Jr. (2006). Positive youth development: theory, research, and application. In W. W. Damon \& R. M. Lerner (Eds.), Handbook of child psychology, Volume 1, Theoretical models of human development. New York: John Wiley.

Berman, S. L., Kurtines, W. M., Silverman, W. K, \& Serafini, L. T. (1996). The impact of exposure to crime and violence on urban youth. American Journal of Orthopsychiatry, 66, 329-336.

Berman, A. M., Schwartz, S. J., Kurtines, W. M., \& Berman, S. L. (2001). The process of exploration in identity formation: The role of style and competence. Journal of Adolescence, 24, 513-528.

Berzonsky, M. D. (1989). Identity Style: Conceptualization and measurement. Journal of Adolescent Research, 4, 267-281. 
Berzonsky, M. D. (1990). Self-construction over the life-span: A process perspective on identity formation. In Neimeyer, G. J. and Neimeyer, R. A. (eds.), Advances in Personal Construct Psychology (Vol 1, pp. 156-186). Greenwich, CT: JAI Press.

Berzonsky, M.D. (1992b). Identity Style Inventory (ISI3). Unpublished Manuscript, State University of New York, Cortland.

Berzonsky, M. D. (1993) Identity style, gender, and social-cognitive reasoning. Journal of Adolescent Research, 8, 289-296.

Berzonsky M.D., Kuk L.S. (2000) Identity status, identity processing style, and the transition to university. Journal of Adolescent Research 15(1): 81-98.

Berzonsky, M. D. \& Neimeyer, G. J. (1994). Ego identity status and identity Processing orientation: The moderating role of commitment. Journal of Research in Personality, 28, 425-435.

Berzonsky, M. D. \& Sullivan, C. (1992). Social-cognitive aspects of identity style: Need for cognition, experiential openness, and introspection. Journal of Adolescent Research, 7, 140-155.

Bollen, K. \& Long, S. (1993). Testing structural equation models. Newbury Park: Sage.

Bosma, H. A. \& Kunnen, E. S. (2001). Determinants and mechanisms in ego identity development: A review and synthesis. Developmental Review, 21, 39-66.

Brandtstädter, J., \& Lerner, R. M. (1999). Action and self-development: Theory and research through the life span. Thousand Oaks, CA: Sage.

Breakwell, G. M. (1988). Strategies adopted when identity is threatened. Revue Internationale de Psychologie Sociale, 1(2), 189-203.

Byrne, B. M. (2001). Structural equation modeling with AMOS: Basic concepts, applications, and programming. Mahwah, NJ: Laurence Erlbaum Associates, Inc.

Catalano, R. F., Berglund, M. L., Ryan, J. A. M., Lonczak, H. S., \& Hawkins, J. D. (1999). Positive youth development in the United States: Research findings on evaluations of positive youth development programs. Washington, D.C.: U.S. Department of Health and Human Services.

Coatsworth, J. D., Sharp, E. H., Palen, L., Darling, N., Cumsille, P., \& Marta, E. (2005). Exploring adolescent self-defining leisure activities and identity experiences across three countries. International Journal of Behavioral Development, 29, 361370.

Côté, J. E. (1994). Adolescent storm and stress. Hillsdale, NJ: Lawrence Erlbaum. 
Csikszentmihalyi, M. (1975). Beyond Boredom and Anxiety. San Francisco: Jossey-Bass.

Csikszentmihalyi, M. (1990a). Flow: The Psychology of Optimal Experience. New York: Basic Books.

Csikszentmihalyi, M. (1990b). The domain of creativity. Theories of Creativity. Runco, M. (Ed.), Sage Publications, 190-212.

Csikszentmihalyi, M. (1998). The development of the person: An experiential perspective on the ontogenesis of psychological complexity. In Damon, W. \& Lerner, R.M. (Eds.), Handbook of child psychology, Vol 1: Theoretical models of human development. New York, NY: Wiley.

Damon, W. (2004). What is positive youth development? Annals of the American Academy of Political \& Social Science. Special Positive Development: Realizing the Potential of Youth, 591, 13-24.

Damon, W., Menon, J., \& Bronk, K. C. (2003). The development of purpose during adolescence. Applied Developmental Sciences, 7(3), 119-128.

Deci, E. (1992). The relation of interest to the motivation of behavior: A selfdetermination theory perspective. In Renninger, K., Hidi, S., and Krapp, A. (eds), The Role of Interest in Learning and Development, Erlbaum, Hillsdale, NJ, pp. 43-70.

Duchnowski, A. J. Kutash, K. \& Friedman, R. M. (2002). Community-based interventions in a system of care and outcomes framework. In B. J. Burns, \& K. Hoagwood (Eds). Community treatment for youth: Evidence-based interventions for severe emotional and behavioral disorders. New York: Oxford University Press, pp.16-37.

Dunkel, C. (2000) Possible selves as a mechanism for identity exploration. Journal of Adolescence, 23, 519-529.

Dunkel, C. \& Kerpelman, J. (2006) Temporal comparisons, identity, and motivation: The relation between past, present, and possible future selves. Possible Selves: Theory, Research, and Applications. Hauppage, NY: Nova Science Publishers.

Eichas, K. (2008). Promoting Self-Construction and Self-Discovery Processes: An MLC Stage II Evaluation of the Changing Lives Program Intervention. Unpublished Master's thesis. Florida International University, Miami.

Eichas, K. (2010). An Investigation of Multiple Pathways of Developmental Intervention Change. Unpublished doctoral dissertation. Florida International University, Miami. 
Eichas, K., Albrecht, R. E., Garcia, A. J., Ritchie, R. A., Varela, A., Garcia, A., Rinaldi, R., Montgomery, M. J., Silverman, W. K., Jaccard, J., \& Kurtines, W. M. (2010). Mediators of positive youth development intervention change: Promoting change in positive and problem outcomes? Child and Youth Care Forum.

Elder, G. H. (1998). The life course and human development. In R. M. Lerner (Ed.), Handbook of child psychology, Vol. 1: Theoretical models of human development. New York: John Wiley.

Enright, R. D., Ganiere, D. M., Buss R. R., Lapsley, D. K., \& Olson, L. M. (1983). Promoting identity development in adolescents. Journal of Early Adolescence, 3, 247-255.

Erikson, E. H. (1959). Identity and the life cycle. New York: Norton.

Erikson, E. H. (1963). Childhood and society. New York: Norton.

Erikson, E. H. (1968). Identity: Youth and crisis. New York: Norton.

Erikson, E. H. (1985). The life cycle completed. New York: Norton.

Erikson, E. H., \& Erikson, K. T. (1957). The confirmation of the delinquent. In S. Schlein (Ed.), A way of looking at things: Selected papers from 1930 to 1980 Erik H. Erikson. N.Y: Norton.

Freer-Wreder, L. A., Cass-Lorente, C., Kurtines, W. M., Briones, E., Bussell, J. R., \& Berman, S. L. (2002). Promoting identity development in marginalized youth. Journal of Adolescent Research, 17, 168-187.

Ferrer-Wreder, L., Montgomery, M. J., \& Lorente, C. C. (2003). Identity promotion, adolescence. In T. Gullotta \& M. Bloom (Series Ed.) \& G. R. Adams (Vol. Ed.), The encyclopedia of primary prevention and health promotion: Adolescent Volume (600-607). New York: Kluwer Academic/Plenum.

Ferrer-Wreder, L., Palchuk, A., Poyrazli, S., Small, M. L., \& Domitrovich, C. E. (2008). Identity and adolescent adjustment. Identity: An International Journal of Theory and Research, 8(2), 95-105.

Finney, S. J. \& DiStefano, C. (2006). Non-normal and categorical data in structural equation modeling. In Hancock, G. R. \& Mueller, R. O. (Eds.), Structural Equation Modeling: A Second Course (pp. 269-314). Greenwich, Connecticut: Information Age Publishing.

Forthun, L. F., Montgomery, M. J., \& Bell, N. J. (2006). Identity formation in a relational context: A person-centered analysis of troubled youth. [Refereed]. Identity, 6(2), 141-167. 
Freire, P. (1970/1983). Pedagogy of the oppressed. New York: Herder \& Herder.

Garcia, A. J. (2005). New directions in research on positive youth development interventions. Unpublished qualifying paper manuscript. Florida International University, Miami.

Greenberger, E., and Sorensen, A. B. (1974). Toward a concept of psychosocial maturity. Journal of Youth and Adolescence, 3, 329-358.

Grotevant, H. (1987). Toward a process model of identity formation. Journal of Adolescent Research, 2, 203-222.

Hernandez, L., Montgomery, M. J., \& Kurtines, W. M. (2006). Identity distress and adjustment problems in at-risk adolescents. Identity: An International Journal of Theory and Research, 6(1), 27-33.

Holmbeck, G. N. (2002). A developmental perspective on adolescent health and illness: An introduction to the special issues. Journal of Pediatric Psychology, 27, 409416.

Jaccard, J. \& Turrisi, R. (2003). Interaction effects in multiple regression. Thousand Oaks, CA: Sage.

Jensen, P., Hoagwood, K., \& Trickett, E. (1999). Ivory towers or earthen trenches? Community collaborations to foster "real world" research. Applied Developmental Science, 3(4), 206-212.

Kelly, G. A. (1955). The psychology of personal constructs. New York: Norton.

Kerpelman, J. L., Pittman, J. F., \& Lamke, L. K. (1997a). Toward a microprocess perspective on adolescent identity development: An identity control theory approach. Journal of Adolescent Research, 12, 325-346.

Kortsch, G. (2003). The possible selves method in evaluating youth development intervention: The use of integrated qualitative/quantitative data analytic strategies (IQ-DAS). Unpublished Master's thesis. Florida International University, Miami.

Kortsch, G. \& Kurtines, W. K. (2005). The possible selves questionnaire-qualitative extension (PSQ-QE): Relational data analysis. New Directions in Promoting Positive Youth Development. Unpublished manuscript.

Kortsch, G., Kurtines, W. M., \& Montgomery, M. J. (2008). A multi-stage longitudinal comparative (MLC) design stage II evaluation of the Changing Lives Program (CLP): The Possible Selves Questionnaire-Qualitative Extensions (PSQ-QE). Journal of Adolescent Research, 23(3), 342-358.

Kroger, J. (1997). Gender and identity: The intersection of structure, content, and context. Sex Roles, 36(11/12), 747-770. 
Kurtines, W. M., \& Silverman, W. K. (1999). Emerging views of the role of theory. Journal of Clinical Child Psychology, 28, 558-562.

Kurtines, W.M., Eichas K., Briones, E., Ritchie., R.A., Montgomery, M.J., \& Arango, L. (2008). Relational Data Analysis (RDA) Workshop Manual. (I-YDF Technical Report No. 2008-07). Miami, FL: Florida International University, Youth Development Project.

Kurtines, W. M., Ferrer-Wreder, L., Berman, S. L., Lorente, C. C., Silverman, W. K., \& Montgomery, M. J. (2008). Promoting positive youth development: New directions in developmental theory, methods, and research. Journal of Adolescent Research, 23(3), 233-244.

Kurtines, W. M., Ferrer-Wreder, L., Berman, S. L., Lorente, C. C., Briones, E., Montgomery, M. J., Albrecht, R., Garcia, A. J., \& Arrufat, O. (2008). Promoting positive youth development: The Miami Youth Development Project (YDP). Journal of Adolescent Research, 23(3), 256-267.

Kurtines, W. M., Montgomery, M. J., Arango, L. L., \& Kortsch, G. (2004). Does intervention change anything?: New Directions in promoting positive youth development. European Journal of Developmental Psychology, 1(4), 383-397.

Kurtines, W. M., Montgomery, M. J., Arango, L. L., Kortsch, G., Albrecht, R., Garcia, A., Ritchie, R., \& Eichas, K. (2008). Promoting positive youth development: Relational data analysis (RDA). Journal of Adolescent Research, 23(3), 291-309.

Kurtines, W. M., Montgomery, M. J., Eichas, K, Ritchie, R., Garcia, A., Albrecht, R., Berman, S., Ferrer-Wreder, L., \& Lorente, C. C. (2008). Promoting positive development in troubled youth: A Developmental Intervention Science outreach research approach. Identity: An International Journal of Theory and Research, 8, 125-138.

Larson, R. W. (2000). Toward a psychology of positive youth development. American Psychologist, 55(1), 170-183.

LeCroy, C. (2004). Evaluation of an empowerment program for early adolescent girls. Adolescence. Retrieved March 14, 2006, from www.findarticles.com.

Lerner, R. M. (2002). Concepts and theories of human development ( $3^{\text {rd }}$ ed.). Mahwah, NJ: Lawrence Erlbaum.

Lerner, R. M. (2005). Promoting Positive Youth Development: Theoretical and Empirical Bases. White paper: Workshop on the Science of Adolescent Health \& Development, NRC/Institute of Medicine. Washington, D.C.: National Academies of Science. 
Lerner, R. M., Fisher, C. B., \& Weinberg, R. A. (2000). Toward a science for and of the people: Promoting civil society through the application of Developmental Science. Child Development, 71(1), 11-20.

Lerner, R. M., Lerner, J. V., Almerigi, J. B., Theokas, C., Phelps, E., Gestsdottir, S., Naudeau, S., Jelicic, H., Alberts, A., Ma, L., Smith, L. M., Bobek, D. L., Richman-Raphael, D., Simpson, I., Christiansen, E. D., \& von Eye, A. (2005). Positive youth development, participation in community youth development programs, and community contributions of fifth-grade adolescents: Findings from the first wave of the 4-H study of positive youth development. Journal of Early Adolescents, 25(1), 17-71.

Lewis-Arango, L. L., Kurtines, W. M., Montgomery, M. J., \& Ritchie, R. (2008). A multi-stage longitudinal comparative design stage II evaluation of the Changing Lives Program: The Life Course Interview (RDA-LCI). Journal of Adolescent Research, 23(3), 310-341.

Marcia, J. E. (1966). Development and validation of ego-identity status. Journal of Personality and Social Psychology, 3(5), 551-558.

Marcia, J. E. (1980). Identity in adolescence. In J. Adelson (Ed.), Handbook of adolescent psychology (pp. 159-187). New York: Wiley.

Marcia, J. E. (1988). Common processes underlying ego identity, cognitive/moral development, and individuation. In D. K. Lapsley \& F. C. Power (Eds.), Self, ego, and identity: Integrative approaches (pp. 211-266). New York: Springer-Verlag.

Markstrom-Adams, C., Ascione, F., Braegger, D., \& Adams, G. (1993). The effect of two forms of perspective taking on ego identity formation in late adolescence. Journal of Adolescence, 16, 217-224.

Markus, H. \& Nurius, P. (1986). Possible selves. American Psychologist, 41(9), 954969.

Maslow, A. (1968). The farther reaches of human nature. New York: Penguin.

Masten, A. S., \& Coatsworth, D. J. (1998). The development of competence in favorable and unfavorable environments: Lessons from research on successful children. American Psychologist, 53(2), 205-220.

Montgomery, M. J. (2005). Psychosocial intimacy and identity: From early adolescence to emerging adulthood. Journal of Adolescent Research, 20(3), 346-374. 
Montgomery, M. J. Ferrer-Wreder, L., Kurtines, W. M., \& Cass Lorente, C. (2001). Identity interventions: Where are we now? Where are we going? In M. J. Montgomery (Chair), Intervening to promote identity development: How do we foster and evaluate positive change? Presented at the Society for Research on Identity Formation. London, Ontario, CA.

Montgomery, M. J., Hernandez, L., Ferrer-Wreder, L. (2008). Identity development and intervention studies: The right time for a marriage? Identity: An International Journal of Theory and Research, 8(2), 173-182.

Montgomery, M. J., Kurtines, W. M., Ferrer-Wreder, L., Berman, S. L., Lorente, C. C., Briones, E., Silverman, W., Ritchie, R., \& Eichas, K. (2008). A Developmental Intervention Science (DIS) outreach research approach to promoting youth development: Theoretical, methodological, and meta-theoretical challenges. Journal of Adolescent Research, 23(3), 268-290.

Muthen, L. K. \& Muthen, B. O. (1998-2007). Mplus User's Guide (5 ${ }^{\text {th }}$ ed.). Los Angeles, CA: Muthen \& Muthen.

Nurmi, J., Berzonsky, M. D., Tammi, K., \& Kinney, A. (1997). Identity Processing orientation, cognitive and behavioural strategies and well-being. International Journal of Behavioral Development, 21(3), 555-570.

Oyserman, D. (1987). Possible selves and behavior: The case of juvenile delinquency. Unpublished doctoral dissertation, University of Michigan, Ann Arbor.

Oyserman, D. \& Fryberg, S. (2006). The possible selves of diverse adolescents: Content and function across gender, race, and national origin. In Dunkel, C., Kerpelman, J. (Eds.) Possible selves: Theory, research, and applications (pp. 17-39). Hauppauge, NY: Nova Science Publishers.

Oyserman, D., \& Markus, H. (1990a). Possible Selves and Delinquency. Journal of Personality and Social Psychology. 59(1), 112-125.

Oyserman, D., \& Markus, H. (1990b). Possible Selves in Balance: Implications for Delinquency. Journal of Social Issues, 46(2), 141-157.

Overton, W. (1998). Developmental psychology: Philosophy, concepts, and methodology. In, R. M. Lerner (Ed.), W. Damon (Series Ed.), Handbook of child psychology: Vol. 1. Theoretical models of human development (5th ed., pp. 107187). New York: Wiley.

Overton, W. F. (2006). Developmental psychology: Philosophy, concepts, methodology. In W. Damon \& R. M. Lerner (Eds.) \& R. M. Lerner (Vol. Ed.), Handbook of child psychology. Vol. 1: Theoretical models of human development (6th ed., pp. 18-88). Hoboken, NJ: Wiley. 
Palen, L. \& Coatsworth, J. D. (2007). Activity-based identity experiences and their relations to problem behavior and psychological well-being in adolescence. Journal of Adolescence, 30, 721-737.

Peterson, N. A. and Reid, R. J. (2003). Paths to psychological empowerment in an urban community: Sense of community and citizen participation in substance abuse prevention activities. Journal Of Community Psychology, 31(1), 25-38.

Pittman, K. J. (2000). What youth need: Services, supports, and opportunities, the ingredients for youth. Paper presented at the White House Conference on Teenagers, Washington, DC, May 2, 2000.

Pumain, D. (2006). Hierarchy in Natural and Social Sciences. New York, NY: SpringerVerlag.

Rausch, J. R., Maxwell, S. E., \& Kelly, K. (2003) Analytical methods for questions pertaining to randomized pretest, posttest, follow-up design. Journal of Clinical Child and Adolescent Psychology, 32(2), 467-86.

Rinaldi, R. L., Eichas, K., Meca, A., Albrecht, R. E., Ritchie, R. A., Garcia, A., \& Kurtines, W. M. (under review). The development and evaluation of an RDA qualitative extension for the Personally Expressive Activities Questionnaire (PEAQ-QE). Identity: An International Journal of Theory and Research.

Rosenthal, D.A., Gurney, R. M., \& Moore, S. M. (1981). From trust to intimacy: A new inventory for examining Erikson's stages of psychosocial development. Journal of Youth and Adolescence, 10, 525-537.

Roth, J., Brooks-Gunn, J., Murray, L., \& Foster, W. (1998). Promoting healthy adolescents: Synthesis of youth development program evaluations. Journal of Research on Adolescence, 8, 423-459.

Rounsaville, B. J., Carroll, K. M., \& Onken, L.S.. (2001). A stage model of behavioral therapies research: Getting started and moving on from stage I. Clinical Psychology: Science and Practice, 48, 133-142.

Schwartz, S. J. (2001). The evolution of Eriksonian and Neo-Eriksonian identity theory and research: A review and integration. Identity: An International Journal of Theory and Research, 1(1), 7-58.

Schwartz, S. J. (2002). In search of mechanisms of change in identity development: Integrating the constructivist and discovery perspectives in identity. Identity: An International Journal of Theory and Research, 2(4), 317-339.

Schwartz, S. J. (2006). Predicting identity consolidation from self-construction, eudaimonistic self-discovery, and agentic personality. Journal of Adolescence, 29, 277-293. 
Schwartz, S. J., Cote, J. E., \& Arnett, J. J. (2006). Identity and agency in emerging adulthood: Two developmental routes in the individualization process. Youth and Society, 37(2), 201-229.

Schwartz, S. J., Kurtines, W. M., \& Montgomery, M. J. (2005). A comparison of two strategies for facilitating identity formation processes in emerging adults: An exploratory study. Journal of Adolescent Research 20, 309-345.

Schwartz, S. J., Mullis, R. L., Waterman, A. S., \& Dunham, R. M. (2000). Ego identity status, identity style, and personal expressiveness: An empirical investigation of three convergent constructs. Journal of Adolescent Research, 15(4), 504-521.

Schwartz, Seth, J. Pantin, Hilda, Coatsworth, J. Douglas \& Szapocznik, Jose. (2007). Addressing the Challenges and Opportunities for Today's Youth: Toward an Integrative Model and its Implications for Research and Intervention. The Journal of Primary Prevention, 28, 117-144.

Schwartz, S. J., Zamboanga, B. L., Weisskirch, R. S., \& Rodriguez, L. (2009). The relationships of personal and ethnic identity exploration to indices of adaptive and maladaptive psychosocial functioning. International Journal of Behavioral Development, 33(2), 131-144.

Seligman, M. \& Csikszentmihalyi, M. (2000). Positive psychology: An introduction. American Psychologist, 55(1), 5-14.

Seligman, M., Steen, T., Park, N., \& Peterson, C. (2005) Positive psychology progress: Empirical validation inventions. American Psychologist. 60(5), 410-421.

Sharp, E. H., Coatsworth, J. D., Darling, N., Cumsille, P., \& Ranieri, S. (2007). Gender differences in self-defining activities and identity experiences of adolescents and emerging adults. Journal of Adolescence, 30, 251-269.

Silverman, W. K., Kurtines, W. M., Jaccard, J., \& Pina, A. A. (2009). Directionality of change in youth anxiety CBT involving parents: An initial examination. Journal of Consulting and Clinical Psychology, 77(3), 474-485.

Soenens, B., Berzonsky, M. D., Vansteenkiste, M., Beyers, W., \& Goossens, L. (2005). Identity styles and causality orientations: In search of the motivational underpinnings of the identity exploration process. European Journal of Personality, 19, 427-442.

Spencer, M.B. \& Markstrom-Adams, C.. (1990) Identity among racial and ethnic minority children in America. Child Development, 61, 290-310.

Strauss, A., \& Corbin, J. (1998). Basics of qualitative research: Techniques and procedures for developing grounded theory. Thousand Oaks, CA: Sage. 
Sue, D. W. \& Sue, D. (2003). Counseling the Culturally Diverse: Theory and Practice. New York: Wiley \& Sons.

Vleioras, G., \& Bosma, H. A. (2005). Are identity styles important for psychological well-being? Journal of Adolescence, 28(3), 397-409.

Waterman, A. S. (1984). Discovery or creation? Journal of Early Adolescence, 4(4), 329341.

Waterman, A. S. (1990). Personal expressiveness: Philosophical and psychological foundations. Journal of Mind and Behavior, 11, 47-74.

Waterman, A. S. (1993). Finding something to do or someone to be: A eudaimonist perspective on identity formation. In L. Kroger (ed.), Discussions on Ego Identity. (p. 147-167). Hillsdale, NJ: Lawrence Erlbaum Associates, Inc.

Waterman, A. S. (1995). Eudaimonic theory: Self-realization and the collective good. In W. M. Kurtines \& J. L. Gewirtz (Eds.), Moral development: An introduction. (p. 255-278). Boston: Allyn \& Bacon.

Waterman, A. S. (1999). Identity, the identity statuses, and identity status development: A contemporary statement. Developmental Review, 19, 591-621.

Waterman, A. (2004). Finding someone to be: Studies on the role of intrinsic motivation in identity formation. Identity: An International Journal of Theory and Research, 4(3), 209-228.

Waterman, A. (2005). When effort is enjoyed: Two studies of intrinsic motivation for personally salient activities. Motivation and Emotion, 29(3), 165-188.

Weisz, J. R. \& Hawley, J. (2002). Developmental factors in the treatment on adolescents. Journal of Consulting \& Clinical Psychology, 70(1), Feb 2002, 21-43.

Wittgenstein, L. 1953. Philosophical investigations. (Anscombe, G.E.M., trans.). Oxford: Basil Blackwell.

Yu, C. \& Muthen, B. (2002). Evaluation of model fit indices for latent variable models with categorical and continuous outcomes. Paper presented at the annual meeting of the American Educational Research Association, New Orleans, LA. 
VITA

\section{ROBERTO L. RINALDI}

$\begin{array}{ll}\text { April 16, } 1975 & \text { Born, Rio Piedras, Puerto Rico } \\ 2000-2004 & \begin{array}{l}\text { B.A., Psychology } \\ \text { Florida International University } \\ \text { Miami, FL }\end{array} \\ & \begin{array}{l}\text { M.S., Psychology } \\ \text { Florida International University } \\ \text { Miami, Florida }\end{array} \\ 2006-2008 & \begin{array}{l}\text { Teaching Assistant } \\ \text { Florida International University } \\ \text { Miami, Florida }\end{array} \\ & \begin{array}{l}\text { Doctoral Candidate, Psychology } \\ \text { Florida International University } \\ \text { Miami, Florida }\end{array}\end{array}$

\section{PUBLICATIONS AND PRESENTATIONS}

Rinaldi, R.L., Meca, A., Ritchie, R.A., Eichas, K., \& Kurtines, W.M. (Under Review). Deciding between Fixed or Free Response Data... Why Not Both? A Relational Data Analysis Approach.

Rinaldi, R.L., Meca, A., Ritchie, R.A., Eichas, K., \& Kurtines, W.M. (Under Review). The Development and Psychometric Evaluation of an RDA Qualitative Extension for the Personally Expressive Activities Questionnaire (PEAQ-QE).

Eichas, K., Albrecht, R. E., Garcia, A.J., Ritchie, R.A., Varela, A., Garcia, A., Rinaldi, R.L., Wang, R., Montgomery, M. J., Silverman, W. K., Jaccard, J., \& Kurtines, W.M. (2010). Mediators of positive youth development intervention change: Promoting positive and problem outcomes? Child and Youth Care Forum.

Eichas, K., Rinaldi, R.L., Ritchie, R., Garcia, A., Varela, A., Madrazo, V., Maximin, B., Ekasian, K., Meca, A., O’Dowd, B., Quintana, S., and Kurtines, W.M. (2009). Evaluating positive youth development: An integration of quantitative and qualitative methods. Poster presented at the $6^{\text {th }}$ biennial conference meeting of the Society for the Study of Human Development, Ann Arbor, Michigan. 
Rinaldi, R.L., Meca, A., Eichas, K., Kasian, E., Harari, G., Ritchie, R.A., \& Kurtines, W.M. (2010). A Longitudinal Investigation of the Effects of Participation in the Changing Lives Program: An Integrative Quantitative Qualitative Evaluation Model. Poster presented at the annual meeting of the Society for Research on Identity Formation, Philadelphia, PA.

Meca, A., Rinaldi, R.L., Eichas, K., Ritchie, R.A., Olarte, S., Kasian, E., \& Kurtines, W.M. (2010). A Longitudinal Investigation of the Effects of Participation in the Changing Lives Program on Control and Responsibility over Life Change Goals. Poster presented at the annual meeting of the Society for Research on Identity Formation, Philadelphia, PA.

Meca, A., Eichas, K., Rinaldi, R.L., \& Kurtines, W.M. (2010). Positive Youth Development: Promoting control and responsibility for life challenges. Poster presented at the annual meeting of the Society for Research on Identity Formation, Philadelphia, PA.

Eichas, K., Rinaldi, RL.., Ritchie, R.A., Garcia, A., Varela, A., Madrazo, V., Maximin, B., Ekasian, K., Meca, A., O’Dowd, B., Quintana, S., \& Kurtines, W.M. (2009). Evaluating Positive Youth Development: An Integration of Quantitative and Qualitative Methods. Poster presented at the 6th biennial conference meeting of the Society for the Study of Human Development, Ann Arbor, Michigan.

Meca, A., Eichas, K., Rinaldi, R.L., Ritchie, R., Garcia, A., Madrazo, V., Ekasian, K, O'Dowd, B., Quintana, S., \& Kurtines, W.M. (2009). Positive youth development: Promoting Control and Responsibility for Life Challenges. Poster presented at the 6th biennial conference meeting of the Society for the Study of Human Development, Ann Arbor, Michigan.

Rinaldi, R.L, Eichas, K., Varela, A., Ritchie, R., Garcia, A., Wang, R., Maximin, B., Su, J., Madrazo, V., \& Kasian, E. (2009, March). The Development and Evaluation of a Relational Data Analysis Coding Template (RDA-CT) for the Personally Expressive Activities Questionnaire-Qualitative Extention (PEAQ-QE). Presented at the annual meeting of the Society for Research on Identity Formation, Pacific Grove, CA.

Garcia, A., Varela, A., Eichas, K., Ritchie, R.A., Harris, R., Rinaldi, R.L., \& Kurtines, W. (2008, March). Investigating Group Processes in a Positive Youth Development Program for Multi-problem Youth. Poster presented at the annual meeting of the Society for Research on Identity Formation, Chicago, IL.

Eichas, K., Albrecht, R., Varela, A., Ritchie, R.A., Garcia, A., Wang, R., Chen, P., Garcia, A., Bird, B., \& Rinaldi, R.L., (2007, March). The Effect of a Positive Youth Development Intervention on Identity Styles, Processes, and Outcomes with Culturally Diverse Troubled Adolescents. Poster session presented at the annual meeting of the Society for the Study of Identity Formation, Washington, DC. 